(11) Nordic Council of Ministers

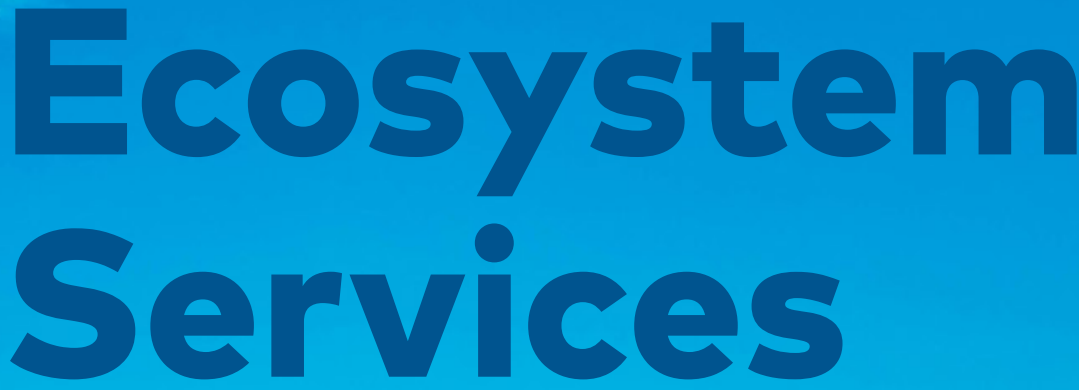

In the Coastal Zone of the Nordic Countries

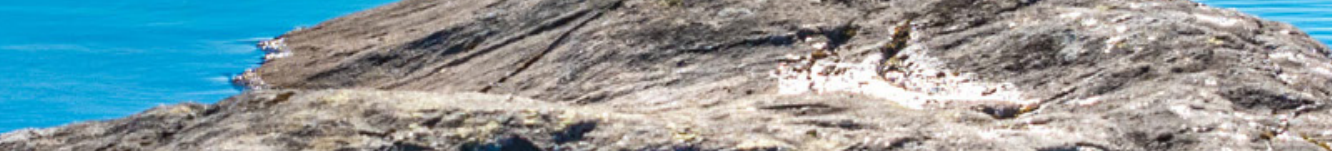

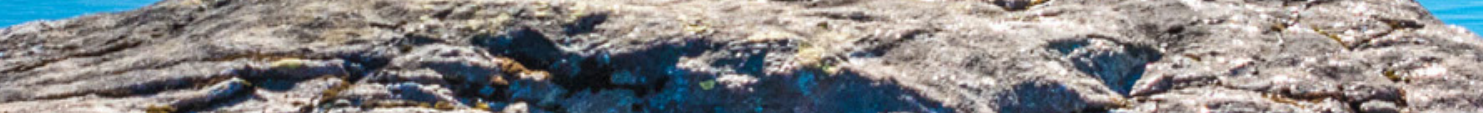

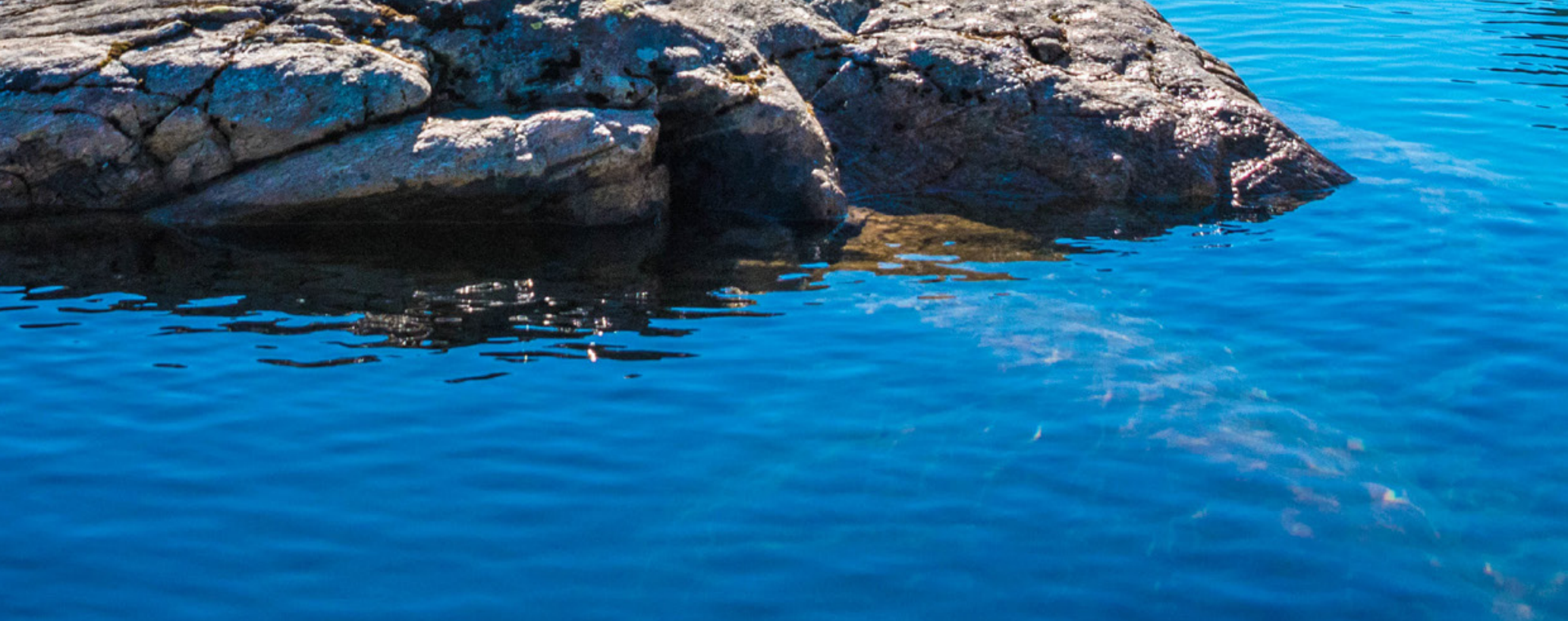





\section{Ecosystem Services}

In the Coastal Zone of the Nordic Countries

Hege Gundersen, Tanya Bryan, Wenting Chen, Frithjof E. Moy, Antonia N. Sandman, Göran Sundblad, Susi Schneider, Jesper H. Andersen, Sindre Langaas and Mats G. Walday

TemaNord 2016:552 


\section{Ecosystem Services}

In the Coastal Zone of the Nordic Countries

Hege Gundersen, Tanya Bryan, Wenting Chen, Frithjof E. Moy, Antonia N. Sandman, Göran Sundblad,

Susi Schneider, Jesper H. Andersen, Sindre Langaas and Mats G. Walday

ISBN 978-92-893-4747-1 (PRINT)

ISBN 978-92-893-4748-8 (PDF)

ISBN 978-92-893-4749-5 (EPUB)

http://dx.doi.org/10.6027/TN2016-552

TemaNord 2016:552

ISSN $0908-6692$

Standard: PDF/UA-1

ISO 14289-1

(c) Nordic Council of Ministers 2017

Layout: NMR

Cover photo: Scanpix

Print: Rosendahls-Schultz Grafisk

Printed in Denmark

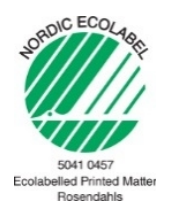

Although the Nordic Council of Ministers funded this publication, the contents do not necessarily reflect its views, policies or recommendations.

\section{Nordic co-operation}

Nordic co-operation is one of the world's most extensive forms of regional collaboration, involving Denmark, Finland, Iceland, Norway, Sweden, the Faroe Islands, Greenland, and Åland.

Nordic co-operation has firm traditions in politics, the economy, and culture. It plays an important role in European and international collaboration, and aims at creating a strong Nordic community in a strong Europe.

Nordic co-operation seeks to safeguard Nordic and regional interests and principles in the global community. Shared Nordic values help the region solidify its position as one of the world's most innovative and competitive. 


\section{Contents}

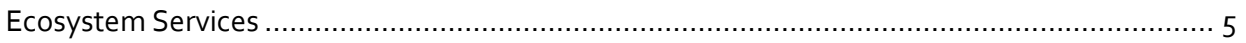

In the Coastal Zone of the Nordic Countries ........................................................... 5

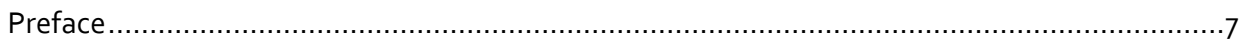

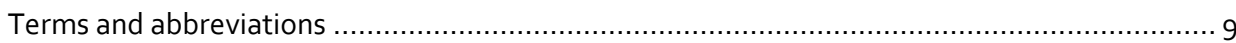

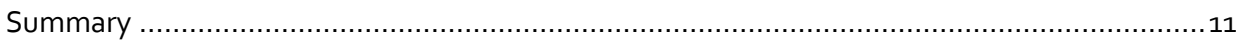

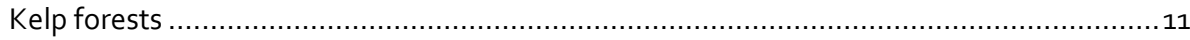

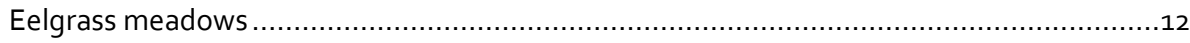

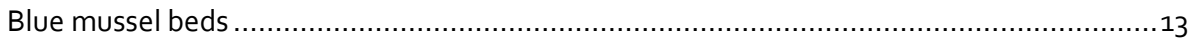

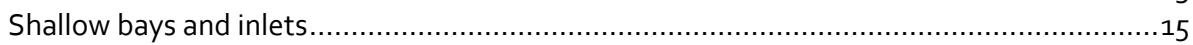

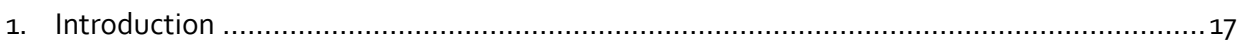

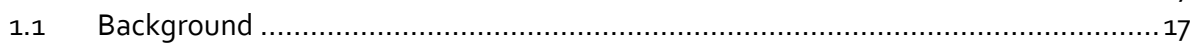

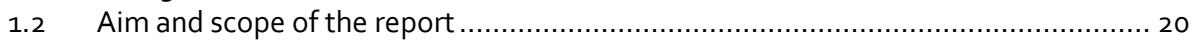

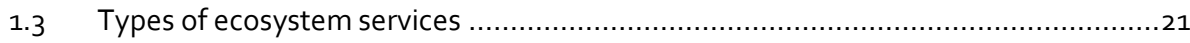

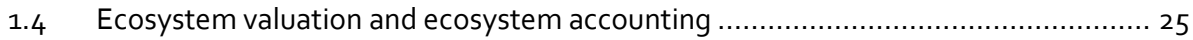

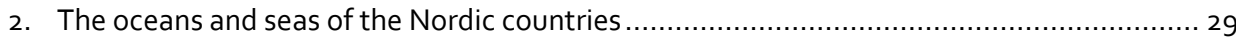

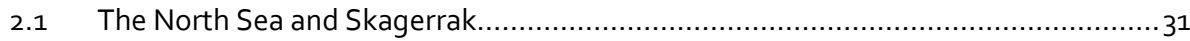

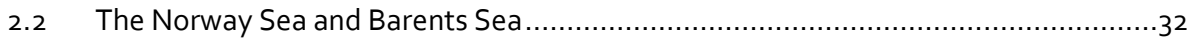

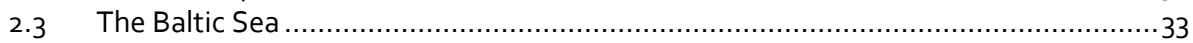

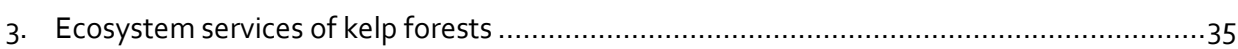

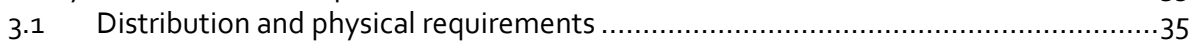

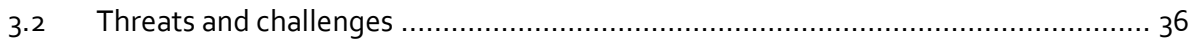

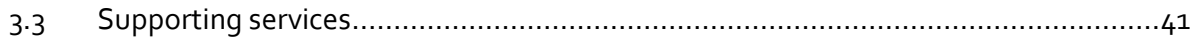

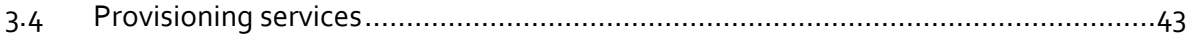

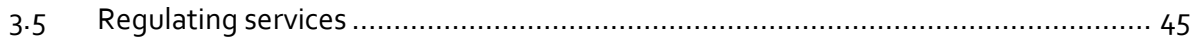

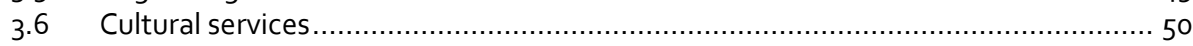

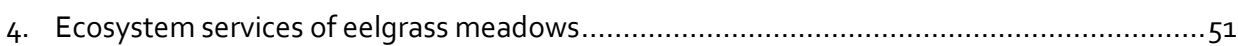

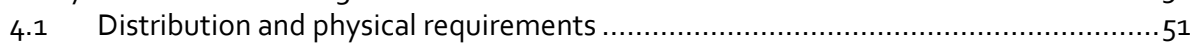

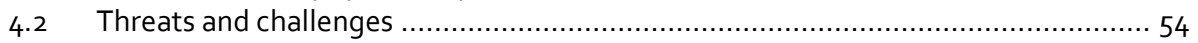

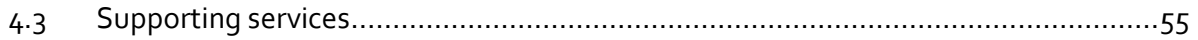

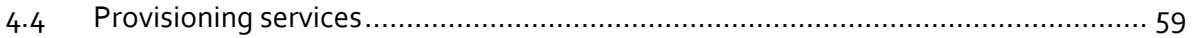

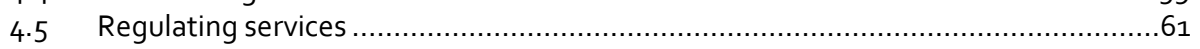

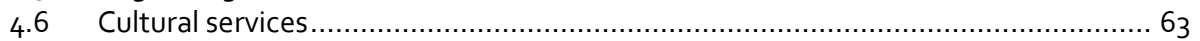




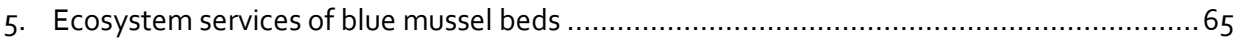

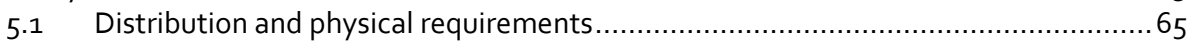

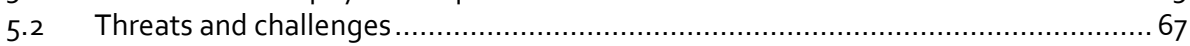

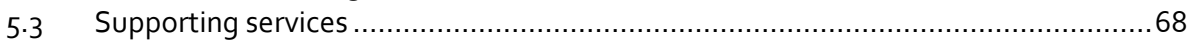

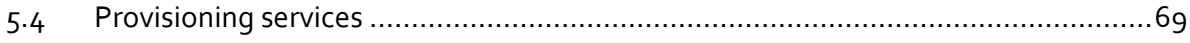

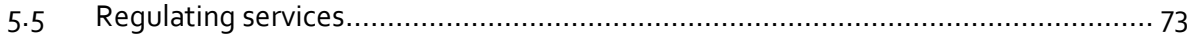

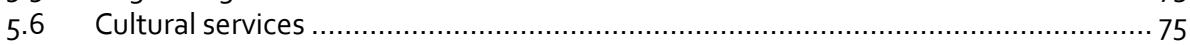

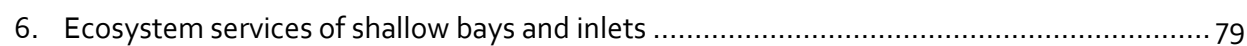

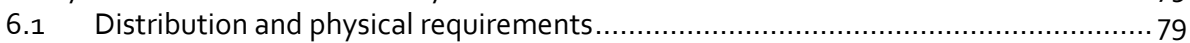

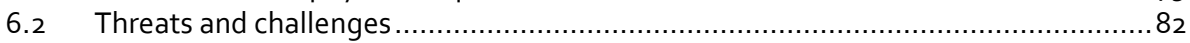

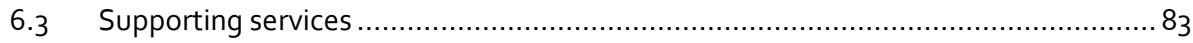

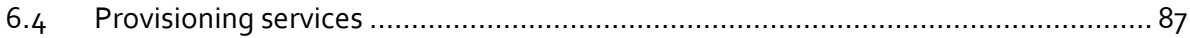

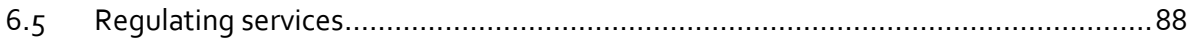

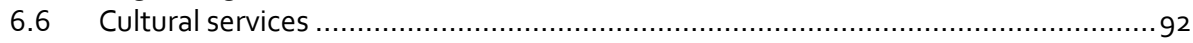

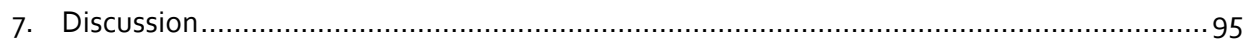

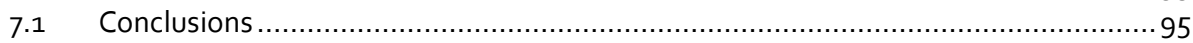

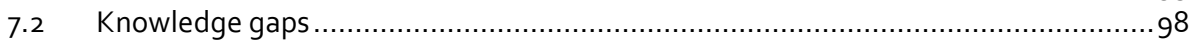

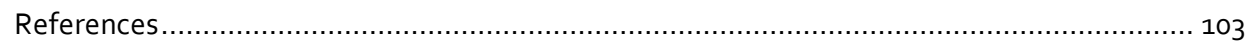

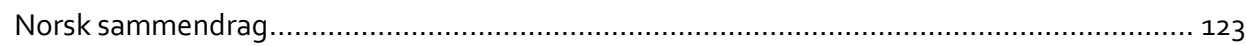

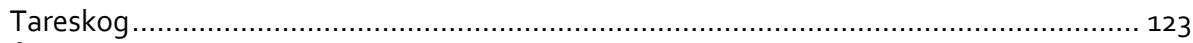

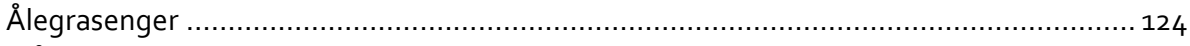

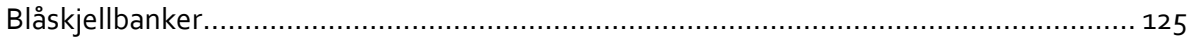

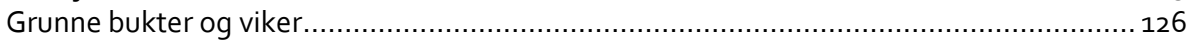




\section{Ecosystem Services}

In the Coastal Zone of the Nordic Countries

- Hege Gundersen (NIVA)

- Tanya Bryan (GRID-Arendal)

- Wenting Chen (NIVA)

- Frithjof E. Moy (IMR)

- Antonia N. Sandman (AquaBiota)

- Göran Sundblad (AquaBiota)

- Susi Schneider (NIVA)

- Jesper H. Andersen (NIVA)

- Sindre Langaas (NIVA)

- Mats G. Walday (NIVA) 



\section{Preface}

This report gives an overview of the values related to important ecosystems along the Nordic coasts. Four key systems were selected to be examined for their services. These were kelp forests, eelgrass meadows, blue mussel beds, and shallow bays and inlets. The report is based on the common knowledge and network of researchers across the Nordic countries and is conducted under the leadership of the Norwegian Institute for Water Research (NIVA) in collaboration with the Institute of Marine Research (IMR), GRID-Arendal, NIVA Denmark Water Research, and the Swedish AquaBiota Water Research.

The project is funded by the Nordic Council of Ministers (NCM) and is a collaboration between The Environment and Economy Group (MEG), Marine Group (HAV) and Terrestrial Ecosystem Group (TEG). We hope this overview will support the further work in our countries to solve common challenges and to ensure an integrated marine management of the Nordic countries.

October 2016

Fredrik Granath

Chairman of the Working Group on Environment and Economy under the Nordic Council of Ministers 



\title{
Terms and abbreviations
}

\author{
Tabel 1: List of terms and abbreviations used in the report \\ Baseline The line consisting of segments between the outermost islands and reefs along the coast \\ at low tide

\begin{tabular}{|c|c|}
\hline Biotope & $\begin{array}{l}\text { An area of uniform environmental conditions providing a living place for a specific assemblage } \\
\text { of plants and animals }\end{array}$ \\
\hline CBD & Convention on Biological Diversity (UN) \\
\hline Coastal zone & All marine areas within one nautical mile outside the baseline \\
\hline Cultural services & $\begin{array}{l}\text { A category of Ecosystem Services, such as recreational, aesthetic, and spiritual benefits (MEA } \\
\text { 2005) }\end{array}$ \\
\hline Ecosystem & $\begin{array}{l}\text { A dynamic complex of plant, animal, and microorganism communities and the non-living envi- } \\
\text { ronment interacting as a functional unit (UNEP 2006) }\end{array}$ \\
\hline Ecosystem Services & $\begin{array}{l}\text { The direct and indirect contributions from the ecosystems to human welfare (TEEB 2010). } \\
\text { The benefits that people obtain from ecosystems (UNEP 2006) }\end{array}$ \\
\hline EU & European Union \\
\hline FAO & Food and Agriculture Organization of the United Nations (UN) \\
\hline FGFRI & Finnish Game and Fisheries Research Institute \\
\hline FTEs & Full-time Equivalents \\
\hline Habitat & $\begin{array}{l}\text { An ecological or environmental area that is inhabited by a particular species of animal, plant, or } \\
\text { other type of organism }\end{array}$ \\
\hline HAV & The Marine Group (working group of NCM) \\
\hline HELCOM & Baltic Marine Environment Protection Commission - Helsinki Commission \\
\hline HVMFS & (Swe: Havs- och vattenmyndighetens författningssamling) \\
\hline IMR & Institute for Marine Research \\
\hline IPBES & The Intergovernmental Platform on Biodiversity and Ecosystem Services \\
\hline MEA & The Millennium Ecosystem Assessment \\
\hline MEG & NCM Working Group on Environment and Economy \\
\hline MR-M & Environment \\
\hline
\end{tabular}




\begin{tabular}{|c|c|}
\hline Baseline & $\begin{array}{l}\text { The line consisting of segments between the outermost islands and reefs along the coast } \\
\text { at low tide }\end{array}$ \\
\hline Natura 2000 & $\begin{array}{l}\text { A network of nature protection areas in the European Union. The network includes both terres- } \\
\text { trial and marine sites }\end{array}$ \\
\hline NCM & The Nordic Council of Ministers \\
\hline NIVA & Norwegian Institute for Water Research \\
\hline NOK & Norwegian Krone (currency) \\
\hline Provisioning services & A category of Ecosystem Services, such as food, water, timber, and fiber (MEA 2005) \\
\hline Regulating services & $\begin{array}{l}\text { A category of Ecosystem Services, such as climate, floods, disease, wastes, and water quality } \\
\text { (MEA 2005) }\end{array}$ \\
\hline SAV & Submerged aquatic vegetation \\
\hline SDG & Sustainable Development Goals (UN) \\
\hline SDM & Spatial Distribution Modeling \\
\hline SEK & Swedish Krona (currency) \\
\hline Supporting services & $\begin{array}{l}\text { A category of Ecosystem Services, such as soil formation, photosynthesis, and nutrient cycling } \\
\text { (MEA 2005) }\end{array}$ \\
\hline SWAM & The Swedish Agency for Marine and Water Management \\
\hline TEEB & The Economics of Ecosystems and Biodiversity \\
\hline TEG & NCM Working Group on Terrestrial Ecosystem \\
\hline UN & The United Nations \\
\hline UNEP & The United Nations Environmental Programme \\
\hline WFD & Water Framework Directive \\
\hline
\end{tabular}




\section{Summary}

People are dependent on the ocean and coasts and their resources for their survival and well-being. Coastal ecosystems of the Nordic countries, such as kelp forests, blue mussel beds, eelgrass meadows and shallow bays and inlets, provide a number of supporting, provisioning, regulating and cultural ecosystem services to both the local communities as well as the wider population who benefit from them.

These are high biodiversity ecosystems with numerous species of flora and fauna. They act as important nursery habitats for several species of fish, shellfish and plants, including commercial species. They are also an important part in a number of system processes including water purification, coastal erosion protection and carbon fixation, to mention a few. Further, the coastal zone is important as a recreational area for swimming and fishing and there is a large potential for new applications such as biofuel production and increased production of alginate. As a result, there are many interests and benefits related to these areas.

Four key ecosystems have been selected to be examined in this report. These are kelp forests, eelgrass meadows, blue mussel beds and shallow bays and inlets. For kelp forest and mussels, the economic potential of cultivation is also considered.

The study has focused on examining these coastal values through selected examples, and recommend possible applications for the management of the Nordic coastal areas and their resources. The study also identifies key knowledge gaps and suggests where further work should be emphasized.

\section{Kelp forests}

The three dimensional structure of the kelp forest provides habitat, nursery ground and food for a myriad of mobile pelagic and benthic organisms. Kelp plants are photosynthetic organisms and therefore hugely important as primary producers, and regarded among the most productive systems on earth. The production of particulate organic material throughout the year enhances secondary production also in other surrounding communities. The structure of the forest implies high resilience to disturbances and biological control against potential pests and invasive species. 
Kelp has a long tradition of being used as fertilizer, and there is a growing interest for human foods based on algae and seaweed, and for hundreds of different products made from kelp alginate. There is also an increasing demand for non-fossil energy which has made kelp interesting as biofuel. Norway is said to be capable of cultivating 20 million tons of kelp with an annual added value of 40 billion NOK. Since kelp forests are assumed to be crucial habitats for many economic important fish species, the value creation from fishery and other sea food is high. Fish are believed to depend on this habitat for spawning, hatching, nursing and grazing.

Kelp forests are remarkably resilient to natural disturbances such as wave impacts, storm surges, and other extreme oceanographic events and this service is essential for the safeguarding of ecosystem functions. Being primary producers, kelp use solar energy to convert inorganic material to organic matter through photosynthesis and therefore affect the biochemical cycles and regulate the global climate by using $\mathrm{CO}_{2}$. The kelp plants act as reserves or sinks for $\mathrm{CO}_{2}$ as long as they are alive and through the disposal of dead organic plant material into the sediments. However, the proportion of dead kelp material stored for the future is still an unanswered question. Eutrophication mitigation is mediated by kelp forests and reduces the threats of algal blooms, hypoxia, etc., thus contributing to the improvement of water quality, which is, in terms of transparency, believed to infer great benefits for the production of food and to all aspects of ecosystem diversity and function. Many studies are also supporting bioremediation and integrated aquaculture practices that utilize seaweeds as biofilters in multitrophic farming operations. Coastal defense, such as erosion prevention, represents a critical ecosystem service provided by the kelp forest and will be increasingly important along many coastlines as the consequences of anthropogenic climate change intensifies.

Certain ecosystem services related to tourism can be directly associated with kelp forest, such as scuba diving, whereby people actually enjoy watching a healthy kelp forest with its associated biodiversity. But there is also a strong indirect connection via for instance the role of kelp in eutrophication mitigation, since swimming and other activities will be experienced more positively in clean water. Also, recreational fishing in marine waters is a big industry and is related to kelp through the importance of kelp forests as fish habitats.

\section{Eelgrass meadows}

Eelgrass meadows provide habitat for a wide range of species due to the three dimensional structure it creates on shallow soft bottoms. They provide suitable substratum for a rich epifauna and flora which also in turn support diverse fish communities finding 
shelter and food. This ecosystem is considered the most productive of shallow, sedimentary environments and has a high production, building up both above- and belowground biomass during growth season. By high primary production, nutrient cycling, and by providing a three dimensional structure, eelgrass in many ways provide biological control. Growth of many marine bacterial species is inhibited by water-soluble extracts of eelgrass leaves, and by that eelgrass is altering the activity of microorganisms.

Today, eelgrass harvesting is of no value, but eelgrass has for centuries been used as building material for houses, as cattle feed and soil amendment. No medicinal use is known for eelgrass, but it may be a good resource for screening natural antibiotics due to its slow decay rates. No commercial or subsistence fishery is conducted in eelgrassmeadows today, but eelgrass is still essential for commercial fisheries through its role as key habitats for juvenile cod and other commercial species.

Seagrass and other eelgrass meadows are natural hot spots for carbon sequestration and have a high ability to produce, trap, and store organic compounds, making them important carbon sinks. Due to nutrient cycling and storage, eelgrass minimize the efflux of ammonia and phosphate to the water column, clean the water and mitigate eutrophication, and possibly reduce growth of opportunistic macroalgae and phytoplankton. Eelgrass may play an important role in biogeochemical cycling of heavy metals. Uptake of nutrients by eelgrass and other submerged aquatic vegetation can help to prevent nuisance algal blooms and can improve water clarity. The eelgrass leaf canopy and the network of rhizomes and roots fix and stabilize the sediment and reduce resuspension of sediment by currents and waves.

Ecosystem services provided by eelgrass meadows, like high biodiversity and shelter and feeding ground for many species, implies that the eelgrass meadows are popular fishing sites for recreational fishing. Eelgrass meadows play a role in tourism by cleaning the water, through eutrophication mitigation and coastal defense, and by boosting the biodiversity on sandy beaches and create good sites for bathing and recreational fishing.

\section{Blue mussel beds}

The blue mussel is one of our most common marine species and an important habitat builder. Blue mussels increase biodiversity by providing substrate for algae and refuge for small animals. Constituting $70 \%$ of the coastal biomass in the Baltic, blue mussels contribute greatly to ecosystem structure and function. By filtering phytoplankton, including toxic algae, filter feeders like blue mussels can inhibit or even prevent harmful blooms and also its influence on biological control can be attributed to their filtering abilities. 
Traditionally, blue mussels have been more important as bait than for direct human consumption. However, the mussels are a good source of iron, selenium and vitamin B12. They have small but healthy fats, with a large proportion of omega-3 fatty acids. Investigations are in progress to ascertain whether mussels can be used to filter out nutrients at sewage works. Further, blue mussels are also being explored for possible benefits through marine bioprospecting; researchers have developed a glue which can stop bleeding wounds in less than 60 seconds. The commercial blue mussel fishing industry is not as big as its aquaculture, but fishermen in the Limfjord in Denmark have for several decades harvested blue mussels for food production, and up to 100000 tons are scraped up from the sea floor each year.

Being an important habitat builder for many other species of algae and fauna, blue mussel beds have relatively high biodiversity, and are thus quite resilient to disturbances. The role of blue mussels in carbon storage is assumed to be connected to the amount of carbon stored in blue mussel banks. The amount of released carbon from the decomposed mussel that are actually sequestrated for the future, however, is believed to be minimal. As phytoplankton feeders, mussels play a key role in the ecosystem, particularly in light of ongoing eutrophication from human activities. Mussels can help to counteract eutrophication by being harvested and used as food, animal feed and fertilizer. Perhaps the most important service of blue mussels, in addition to reducing eutrophication, is its ability to take up, and thereby remove, organic pollutants and toxic substances. Through its filter feeding habits, blue mussels can reduce the amount of phytoplankton and cyanobacteria in the water column and thus contribute to water purification, filtering and removing of hazardous substances. Mussels can store relatively large amounts of toxins without themselves being affected. Being long-lived, this storage helps preventing the toxic substance from ending up in far more sensitive organisms. Mussel beds can influence tidal flow and wave action within estuaries, modify patterns of sediment deposition, consolidation and stabilization and are thus potentially useful for coastal protection.

The pleasure and recreative value of blue mussel picking, and the enjoyment of gathering your own food, are an important cultural ecosystem service in many coastal communities. Blue mussel beds can also be an attractive view for divers and snorkelers, and help maintaining water quality fit for swimming and beaching. 


\section{Shallow bays and inlets}

A multitude of ecosystem services are provided by the flora and fauna of shallow, wave sheltered bays and inlets in the northern Baltic Sea. Shallow bays and inlets are characterized by rich vegetation communities, including submerged rooted plants and charophytes (early relatives to modern land plants often given high conservation values), as well as algae on the occasional hard substrate, and grasses along the shoreline. These systems often contain diverse and structurally complex underwater forests that host a range of other organisms. The most important ecosystem services include their supporting role for biodiversity, habitat provision and maintaining food webs. These ecosystems serve as essential habitat for several species of fish, including perch, pike and cyprinids such as roach, by providing habitat and food during the most sensitive earliest life-stages. The service of top down control exerted by large predatory fish can through trophic cascades prevent eutrophication symptoms of the system. The primary production of plants and benthic macro- and microalgae in these systems is high, contributing substantially to the total primary production of the Bothnian Bay.

Charophytes can effectively remove organic chemicals and metals from the water. They mitigate cyanobacterial blooms in surface waters, reduce the viability of certain pathogen microalgae, as well as reduce the development of benthic biofilms. Both commercial and subsistence fisheries are dependent on recruitment of the target species, and perch, pike, roach, rudd, tench, breams, and other cyprinids benefit from the generally warmer temperatures of shallow bays and inlets.

Several studies have measured carbon uptake and storage for particular species and areas of wave sheltered bays and inlets in the Baltic Sea, which taken together indicate their potential importance for carbon sequestration. Phosphorus can be removed via assimilation by submerged aquatic plants and in wetlands and via many other mechanisms. Sedimentation in vegetated patches can reduce the risk of resuspension, increase water visibility, as well as bind nutrients in the sediments, thereby reducing eutrophication. Although not well documented, it is assumed that many of the submerged rooted plants of the bays and inlets will have sediment stabilizing effects, since all structures dampening wave and current energy favor sediment retention and coastal protection.

Fish species recruited in shallow, wave sheltered bays and inlets are highly valued in the Baltic countries, and the contribution of these habitats to the amount of expenditures of recreational fishing is potentially large. Due to their sheltered character, bays and inlets are popular for boating, swimming, kayaking and other activities which are dependent on healthy ecosystems providing regulating services such as water filtering and eutrophication mitigation. 



\section{Introduction}

\section{$1.1 \quad$ Background}

Marine and coastal biotopes are among the most productive ecosystems on earth and provide a range of social and economic benefits to humans. As much as one third of the world's population lives in coastal areas, which covers only $4 \%$ of the Earth's total land area. In 2013, 135 million tons of shellfish, seafood and aquatic plants were harvested from the ocean for food and industrial application (FAO 2015), comprising $16 \%$ of the global population's animal protein intake (FAO 2014). Worldwide, nearly 200 million full-time equivalent jobs are found in marine fisheries alone, accounting for about one in every fifteen people employed on the planet (Teh and Sumaila 2013). Furthermore, coastal tourism is one of the fastest growing sectors of global tourism and provides direct and indirect employment for many people and generates local incomes.

The Millennium Ecosystem Assessment (MEA) evaluated in 2005 the services provided by ecosystems, and how changes in these services will impact upon human wellbeing (MEA 2005). The United Nations Environmental Programme (UNEP 2006) gives a synthesis of the results concerning the marine and coastal ecosystems. The two reports provide an analysis of the ecosystem services at global and sub-global (local or regional) scales in terms of current conditions and trends, plausible future scenarios, and possible responses for sustainable resource use.

Another important initiative is "The Economics of Ecosystems and Biodiversity" (TEEB), which was founded in 2007 by leaders of the $G 8$ countries. TEEB aims to get a better understanding of "the true economic value of the benefits we receive from nature" (TEEB 2010). Several countries in Europe, such as Germany, the Netherlands and Poland have initiated national TEEB studies, and Nordic countries (Finland, Sweden, Norway, Denmark and Iceland) have published a synthesis on the socio-economic role and significance of biodiversity and ecosystem services (TEEB Nordic, Kettunen et al. 2012) in addition to official reports in Norway (NOU 2013:10), Sweden (SOU 2013:68), and Finland (Jäppinen and Heliölä 2015).

Within the Norwegian TEEB report, the Commission was asked to describe the consequences for society of the degradation of ecosystem services, to identify how rele- 
vant knowledge can best be communicated to decision-makers, and to make recommendations about how greater consideration can be given to ecosystem services in private and public decision making. The findings of this report indicated that:

- Our huge consumption of ecosystem services is largely due to the fact that the services appear to be free or cheap to utilize.

- The fact that natural capital is scarce and the loss of nature comes at a cost is often not taken into consideration when decisions about production and consumption are made.

- The Nordic countries should attempt to better demonstrate these values in decision-making processes.

- These values must be better communicated to both the general public as well as decision-makers at all government levels and be included in policy instruments, regulations and incentives.

These conclusions indicate that an ecosystem services approach is a helpful addition to current environmental and resource management practices as it helps to demonstrate how protecting nature is important to our well-being. The TEEB Nordic report looks at the region more generally. While they have a section on marine and freshwater fisheries, the report also acknowledges that there is a large knowledge gap around marine ecosystem services, beyond fisheries.

On a global scale, all of the Nordic countries, but in particular Norway, have committed to working to achieve a number of international targets, including meeting Aichi targets and the UN Sustainable Development Goals (SDG), which can benefit from using an ecosystem service approach. Aichi Target 2 states that "[b]y 2020, at the latest, biodiversity values have been integrated into national and local development and poverty reduction strategies and planning processes and are being incorporated into national accounting, as appropriate, and reporting systems", while SDG 14 calls for the conservation and sustainable use of the oceans, seas and marine resources for sustainable development and provides a comprehensive framework for moving towards sustainable ocean use. By including ecosystem services in these global policy frameworks, these countries have the opportunity to provide leadership and guidance on how to strengthen local and national level policy and planning frameworks through the holistic integration of ecosystem services into these processes.

The intensive use of the oceans has led to considerable pressure on marine resources and marine environment, resulting in an urgent need for sustainable coastal management which must be based on knowledge of the ecosystem and the conse- 
quences of different uses (Meld. St. 37, 2012-2013, HELCOM 2007). There is also an understanding within the Nordic countries that marine areas should be managed through ecosystem-based and multi-sectoral policies, with integrated management plans as important tools. For Norway, see Meld. St. 8 (2005-2006), Meld. St. 10 (2010-2011), Meld. St. 37 (2012-2013), von Quillfeldt et al. 2009 and HELCOM 2007, for Sweden, see e.g. SFS 2010:1341, SFS 2012:373, HVMFS 2012:18. The objective of the management plans is to facilitate the sustainable use of resources and ecosystem services in the waters while maintaining the structure, functioning, productivity and biodiversity. The management plans are thus a tool for promoting economic development and food security within a sustainable framework and ensure good environmental status.

The different ecosystems of the Nordic coasts together contribute to a long range of important services for the benefit of humans. They are highly productive ecosystems that purify the water (c.f. Kautsky 1981, Dame and Prins 1998, Kufel and Kufel 2002, Kovtun-Kante et al. 2014, Rodrigo et al. 2014), protect against erosion and storm surges (c.f. Brix 1997, Madsen et al. 2001, Horppila and Nurminen 2003, Rönnbäck et al. 2007, Costanza et al. 2014), fuel marine food webs through the capture, storage and export of carbon (Dayton 1985, Krumhansl and Scheibling 2012), as well as being important nursery grounds for many species, including commercial fish species (Norderhaug et al. 2005). Some of the ecosystems are also proved to be major contributors to carbon storage and sequestration (Nellemann et al. 2009). Traditionally, the resources associated with these ecosystems have been used for direct exploitation (e.g. blue mussels, seaweeds and macroalgae) as food and animal feed. More recently, new applications such as the production of alginate and biofuel are becoming increasingly profitable. This report gives an overview of ecosystem services from coastal areas of the Nordic countries, with examples from kelp forests, seagrass meadows, blue mussel beds and shallow bays and inlets.

Some recent reports have been reviewed to compile the results of this report. The most essential ones to help define marine ecosystem services have been the MEA (2005), UNEP (2006), in addition to the management plans for the different sea areas, already mentioned. Especially, some recent reports summarizing the ecosystem services in the oceans and seas of the Nordic countries have been very informative. These are treating the marine ecosystems of the North Sea and Skagerrak (Ottersen et al. 2010, Magnussen et al. 2102), the Swedish seas (Naturvårdsverket 2008, Bryhn et al. 2015, Naturvårdsverket 2015, Hasler et al. 2016). Many of these reports also describe the non-coastal zone, i.e. sea areas outside the baseline. When it comes to evaluating the ecosystems in monetary values, the BalticSTERN (2013) have been particularly useful, in addition to e.g. Gren et al. (2000) and Naturvårdsverket (2015). 


\subsection{Aim and scope of the report}

Ecosystem services are one of the main priorities of the Nordic Environmental Action Programme for 2013-2018. The work on ecosystem services is embedded in the Convention on Biological Diversity, as one of the strategic objectives for the work forward in 2020.

This report is the result of a project financed by the working groups on Environment and Economy (MEG), Coastal Environments (HAV) and Terrestrial Ecosystem (TEG) of the Nordic Council of Ministers (NCM). Collaborators have been the Norwegian Institute for Water Research (NIVA), the Institute of Marine Research (IMR), GRID-Arendal and AquaBiota Water Research.

The report aims to give an overview of the available information on the benefits and values of ecosystem services in the coastal zone of the Nordic countries, through illustrations and selected examples. Also, the possible uses and relevance for the management of these areas, resources, important knowledge gaps, and recommendations for further work are emphasized.

The assessment of ecosystems in the coastal zone and the services they provide is a very broad subject. The task has therefore been restricted to a few selected shallowwater ecosystems, all of which have great importance for the condition and management of key ecological functions in the Nordic countries. The four selected ecosystems are 1) kelp forests, 2) eelgrass meadows, 3) blue mussel beds, and 4) shallow bays and inlets, which together cover large parts of the Nordic countries' coastal areas.

Geographically, the assessment includes the following Nordic countries: Denmark, Finland, Norway, Sweden, Aland, Estonia, Latvia, and Lithuania. The team expertise has in particular been strong on the coastal ecosystems surrounding Norway, Sweden, Finland and Denmark (including the north-western Baltic Sea, Bottenvika, Kattegat, Skagerrak, North Sea, Norwegian Sea and Barents Sea) - and the valuation of these. For an assessment of the other areas (e.g. the south-eastern Baltic, the Faroe Islands and Iceland), we have used available literature and relevant contacts and networks.

The coastal zone has been defined as all marine areas within one nautical mile outside the baseline, which consists of line segments between the outermost islands and reefs along the coast at low tide. Thus, ecosystem services related to fisheries (except those related to nursing grounds for fish and recreational fishing), petroleum industry, and shipping are kept out of this evaluation.

This report attempts to cover all services provided by the selected ecosystems of the coastal zone of the Nordic countries. However, greater emphasis has been placed on recreational (coastal) fishing, carbon capture and storage, and the ecosystems' role in buffering against ocean acidification and eutrophication. For blue mussels and kelp 
forests, we have also looked at the commercial and ecological values from their cultivation - both at present and the future, unexploited potential.

Trends, future scenarios, and management issues, are regarded as beyond the scope of the project, and covered only in a limited extent in the report. But these aspects are often covered in more detail within the management plans for specific areas, such as Skagerrak and the North Sea (Meld. St. 37, 2012-2013, Ottersen et al. 2010), the Norwegian Sea (Meld. St. 37, 2008-2009), the Barents Sea (Meld. St. 8, 2005-2006, Meld. St. 10, 2010-2011, Meld. St. 20, 2014-2015), the Baltic Sea (HELCOM 2007), and the Baltic Sea and Skagerrak (HVMFS 2012:18).

The report is organized with an introduction (Chapter 1 ) and a description of each of the main oceans and seas of the Nordic countries (Chapter 2). Then come four separate chapters for the selected ecosystems (Chapter 3-6), each including sub-chapters for each ecosystem service type. Finally, the last chapter gives a conclusion and points at some existing knowledge gaps (Chapter 7).

\subsection{Types of ecosystem services}

Our welfare and quality of life depends on a variety of environmental goods and services - ecosystem services (Figure 1). These consist partly of a number of visible and well-known goods and services such as fish and shellfish, recreation and tourism, but also lesser-known services such as maintaining the stability of ecosystems, genetic resources and atmospheric regulation. Most of these goods and services are public goods that are not currently traded on the market, and therefore they have no traditional market value. This means that, currently, the cost of destroying such services does not appear on any accounting forms. As a result, these services are undervalued and put at risk to be impoverished.

Ecosystem services are defined as the direct and indirect contribution from ecosystems to human welfare (TEEB 2010). Ecosystem services are also referred to as natural goods, i.e. goods that humans are dependent on (e.g. NOU 2013). The different ways humans benefit from ecosystems have been divided into four main groups of ecosystem services according to The Millennium Ecosystem Assessment (MEA 2005): 1) supporting, such as soil formation, photosynthesis, and nutrient cycling, 2) provisioning, such as food, water, timber, and fiber; 3 ) regulating, that affect climate, floods, disease, wastes, and water quality; and 4) cultural services, that provide recreational, aesthetic, and spiritual benefits. The conceptual framework of ecosystem services and their constituents of well-being are reproduced in Figure 1. 
Figure 1: The conceptual framework of ecosystem services and their linkages to the constituents of well-being, as presented by the Millennium Ecosystem Assessment (MEA 2005)

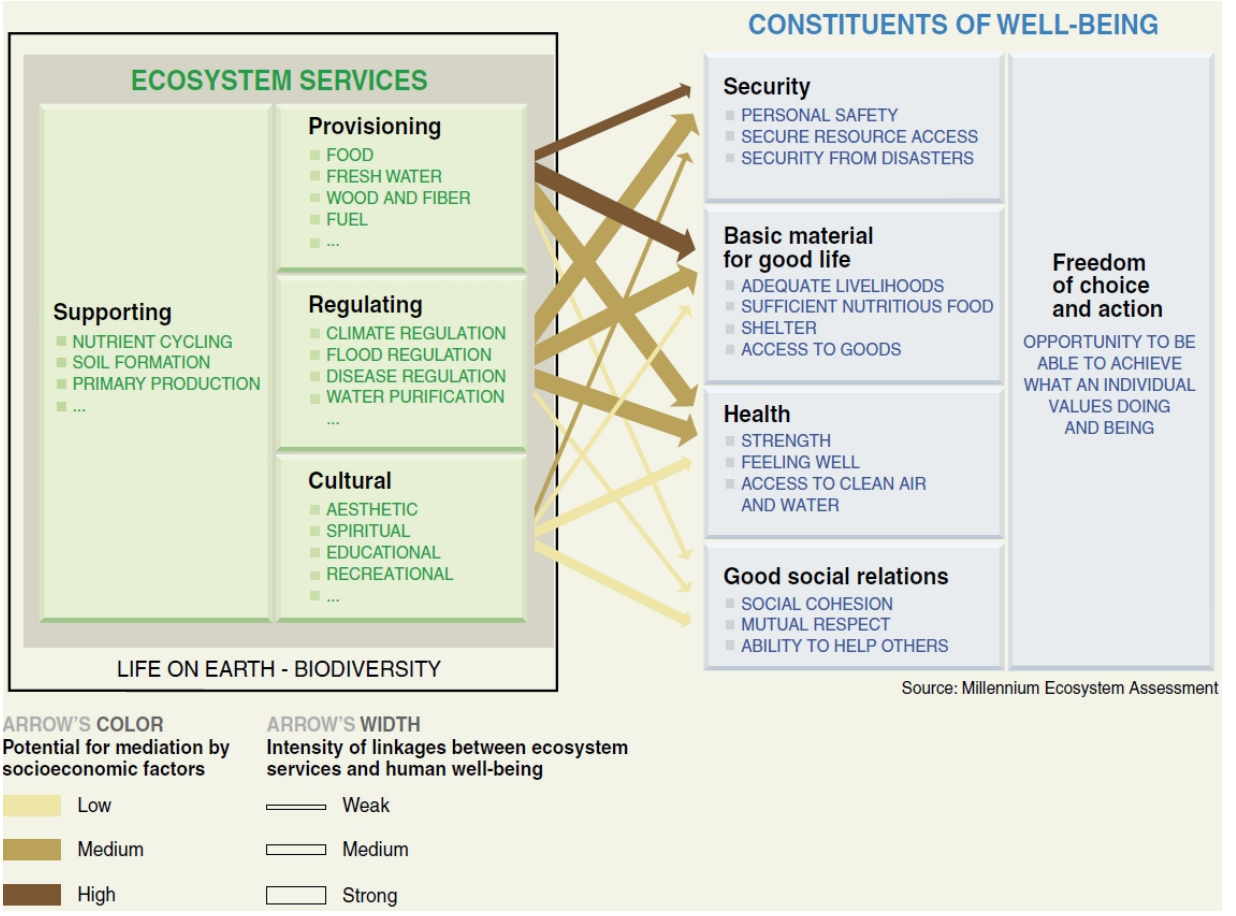

Source: MEA 2005, Figure A.

\subsubsection{Supporting ecosystem services}

Supporting ecosystem services are fundamental to virtually all other ecosystem services, and the safeguarding of these ecosystem services is crucial for future human welfare. The supporting ecosystem services include services such as maintenance of geochemical cycles, primary production and maintenance of biodiversity, habitats and resilience.

These supporting benefits are perhaps the most important of all features and services in the ocean. They constitute the very basis of e.g. continuous fishery and recreation, which we usually associate with services from the ocean. In ecosystem accounting, these services are valued and appreciated indirectly through looking at what is the change in value of producing or cultural services if the basic supportive services somehow are disturbed. Such values represent primarily the value of the supportive services in that they are the foundation for other services. 
Important supporting ecosystem services typically include habitat provision, nutrient cycling, primary productivity, and photosynthesis. Coastal ecosystems such as seagrass beds are important nursery areas for the young stages of fishes and invertebrates that support coastal communities and commercial and recreational fisheries. Maintaining the basic biostructures, i.e. the supportive services, such as maintaining biodiversity may also be said to have a value in itself and in an economists' terms will be part of what is called non-use values.

In addition to having a value in itself, biodiversity is a fundamental aspect that underpins all ecosystem processes and should be valued in its own right (Cardinale et al. 2012, Mace et al. 2012, Naeem et al. 2012). Biodiversity also has an important role in the provision of ecosystem services and can be summarized as the supporting roles of biodiversity including the underpinning of ecosystems through structural, compositional, and functional diversity; regulatory roles through the influence of biodiversity on the production, stability, and resilience of ecosystems; cultural roles from the nonmaterial benefits people derive from the aesthetic, spiritual, and recreational elements of biodiversity; and provisioning roles from the direct and indirect supply of food, fresh water, fiber, etc. (from MEA 2005).

Biodiversity is usually referred to as the composition of the number of species and individuals of each species in a given area. However, biological diversity also refers to the variety of life on other levels, such as functional groups and variation at the genetic level and may represent all kinds of variety, quantity, quality or distribution; with functional diversity signifying the variability among ecological functional processes within an ecosystem. This aspect of biodiversity is particularly important for maintenance of the food web and resilience. Variation at the genetic level could mean any material of plant, animal, microbial, or other origin may contain functional units of heredity.

The Intergovernmental Platform on Biodiversity and Ecosystem Services (IPBES), established in 2012, is dedicated to assessing the state of the planet's biodiversity, its ecosystems and the essential services they provide to society. It provides a mechanism recognized by both scientific and policy communities to synthesize, review, assess and critically evaluate relevant information and knowledge. In Norway and the Baltic countries, biodiversity is acknowledged through the recent white paper and action plan on biodiversity (Meld. St. 14, 2015-2016) and the HELCOM Baltic Sea Action Plan (HELCOM 2007). 


\subsubsection{Provisioning ecosystem services}

Provisioning ecosystem services represent the best known and most visible benefits and services, such as food, fuel wood, energy resources, natural products, and ornamental resources. Other producing goods and services are so-called future use values (option value). These include genetic resources and resources for pharmaceutical, chemical and biotechnology industries. In the Nordic coastal zone, provisioning services typically include sea food such as fish, mussels and crustaceans, and industrial raw material e.g. alginate extracted from kelp. Ocean energy supplies, such as wave and tidal energy, also represent major potential values.

\subsubsection{Regulating ecosystem services}

The regulatory services include services such as climatic and atmospheric regulation, reduction of eutrophication, regulation of harmful substances, biological control and retention of sediments. Climate change and associated changes in temperature can affect almost any other ecosystem services. Therefore, the ocean's ability to regulate climate, through its' ability to bind the greenhouse gas $\mathrm{CO}_{2}$, is a very important feature. Regulating services also include shoreline stabilization, flood prevention, storm protection, climate regulation, nutrient regulation, detoxification of polluted waters, and waste disposal.

Within the Nordic countries, shallow bays and inlets (also called coastal lagoons) typically improve water quality by capturing and filtering sediments and organic wastes in transit from inland regions to the ocean, whereas blue mussels and other bivalves are important for the sea's ability to take up pollutants. Also, eelgrass and macroalgae, such as kelp, play an important role in both fixation of atmospheric carbon and its deposition in deep water and absorbing the nutrients in the seawater.

\subsubsection{Cultural ecosystem services}

The traditions and cultures of many coastal societies are closely connected to the marine ecosystems on which they depend. Tourism is one example of an ecosystem service with use value. Globally, coastal tourism is a fast-growing industry, and plays an important role in the local economy for coastal communities.

Coastal and marine areas provide opportunities for activities such as boating, kayaking, diving, swimming, whale watching and recreational fishery. These activities also improve overall mental and physical health for the locals and tourists. Recreational values are high across all the Nordic countries, from the Barents Sea in the north to the 
Skagerrak and Baltic in the south. Whale watching, fjord cruising and coastal seabird watching have contributed large income to both local and national economy.

The Norwegian Management Plan for the North Sea and Skagerrak states that access to the sea and experiences related to boating and cottage life, swimming and fishing are important for a large part of the population and the basis for the tourism industry. Good experiences on the coast also have a close relationship with a clean, rich and productive marine environment (Meld. St. 37, 2012-2013). The white papers also provide numbers and estimates related to tourism and recreation in Norway (Meld. St. 37, 2012-2013, Meld. St. 37, 2008-2009). In Sweden, the national environmental objectives number 7 (Zero eutrophication), 10 (A Balanced Marine Environment, Flourishing Coastal Areas and Archipelagos) and 16 (A Rich Diversity of Plant and Animal Life) states that "Nutrient levels in soil and water must not be such that they adversely affect [...] the possibility of varied use of land and water"; "[The coasts of] the North Sea and the Baltic Sea [...] must be characterized by a high degree of biological diversity and a wealth of recreational, natural and cultural assets."; "Biological diversity must be preserved and used sustainably for the benefit of present and future generations. [...] People must have access to a good natural and cultural environment rich in biological diversity, as a basis for health".

Ecosystem services with non-use values are for instance cultural goods and services, such as aesthetic and spiritual values, cultural heritage and identity, which are also extremely important to local communities along the Nordic coastal zone. These benefits have proven to make up a significant part of people's willingness to pay for environmental goods and services.

\subsection{Ecosystem valuation and ecosystem accounting}

The ecosystem services approach has received considerable attention in international negotiations where the aim is to get agreements so that the earth is preserved in such a state that enables it to produce what people need in the future. This turns the perspective from appreciating biodiversity for its own sake, to incorporating human needs. The underlying idea is that biodiversity is preserved when assuring that nature's production capacity is maintained. 


\subsubsection{Ecosystem valuation}

The Economics of Ecosystems and Biodiversity (TEEB) was founded in 2007 by leaders of the $\mathrm{G} 8$ countries aiming to get a better understanding of the true economic value of the benefits we receive from nature (TEEB 2010). The 2010 report describes how ecosystem services have great importance for economy and well-fare. It also shows that if we do not react quickly, the current reduction of biodiversity and the related loss of ecosystem services will continue, and in some cases, accelerate.

Ecosystem values can be estimated and expressed in both monetary and non-monetary terms (UNEP-WCMC 2011). Economic valuation can be a useful method to measure the contribution of ecosystem services to our quality of life and welfare, and to improve our understanding of what you win and lose by using the ecosystems differently. Even with the limitations that exist, this type of valuation is important to show some of the major economic values associated with such goods and services - and the heavy losses that occur when ecosystems deteriorate (TEEB 2010).

However, not all values associated with, for instance biodiversity, can be valued in monetary terms (TEEB 2010). For example, nature has an intrinsic value that is independent of the use or enjoyment people have of it. Among all the different ecosystem services, we are only able to appreciate a few of them in monetary terms. There is a fast growing literature on marine ecosystem valuation. For example, UNEP-WCMC (2011) describes the valuation methods and application suitable for marine and coastal ecosystem services. Beaudoin and Pendleton (2012) highlight areas of ocean and coastal management for which a better understanding of the economic value of marine ecosystem services could improve the critical marine resources management and thus improve ocean governance. In line with requirements from EU marine initiatives and directives (MSFD), Koundouri et al. (2016) describe a tool for assessing the impacts on ecosystem and ecosystem services of offshore investments to support the requirements for sustainable management of the oceans and blue growth. The tool incorporates the technical and legal requirements, the environmental impact assessment for ecosystem change, the market and non-market valuation of change in marine ecosystem services change and the social welfare change. Other relevant valuation studies including both use-value and non-use value related to marine ecosystem service valuation can be found in Chen et al. (2014).

\subsubsection{Ecosystem accounting}

Ecosystem accounting is a coherent and integrated approach to the assessment of the environment through the measurement of ecosystems, and measurement of the flows of services from ecosystems into economic and other human activity (UN SEEA 2014). 
The approach goes beyond ecosystem analysis by linking the ecosystems to economic and other human activity. Ecosystem accounting as presented in the UN SEEA (2014) includes the contribution of ecosystems to standard measures of economic activity, such as gross domestic product (GDP) and national income as well as the assessment of ecosystem services that are commonly unpriced and not considered in national-level economic reporting and analysis (UN SEEA 2014). Ecosystem accounting assesses both expected ecosystem service flows and changes in ecosystem assets. Ecosystem assets are assessed in both physical and monetary terms.

Mazza et al. (2013) evaluated the strengths and weaknesses of some of the most prominent international approaches to natural capital accounting in the light of the policy goals, conditions and institutions in the Nordic countries. The report reviews approaches that were developed for incorporation of biodiversity and ecosystems in national accounts. 



\section{The oceans and seas of the Nordic countries}

The oceans and seas of the Nordic countries are all part of the North-eastern Atlantic Ocean, and consist of the Barents Sea, Norwegian Sea, North Sea, Skagerrak (including Kattegat), Baltic Sea (including Bothnian Bay and Baltic Proper), Iceland Sea, Greenland Sea, and the Arctic Ocean (Figure 2). The four focal ecosystems of this study are naturally not equally distributed among the Nordic countries, with kelp forests generally much more common in the more exposed and saline areas of the Norwegian Sea, North Sea and Skagerrak, whereas shallow bays and inlets are more frequently seen in the Baltic Sea. Blue mussels and sea grasses are found in all regions, given their environmental requirements (more detailed descriptions of the distributions are given in the each of the ecosystem chapters). 
Figure 2: Map of the Nordic countries and their surrounding oceans and countries

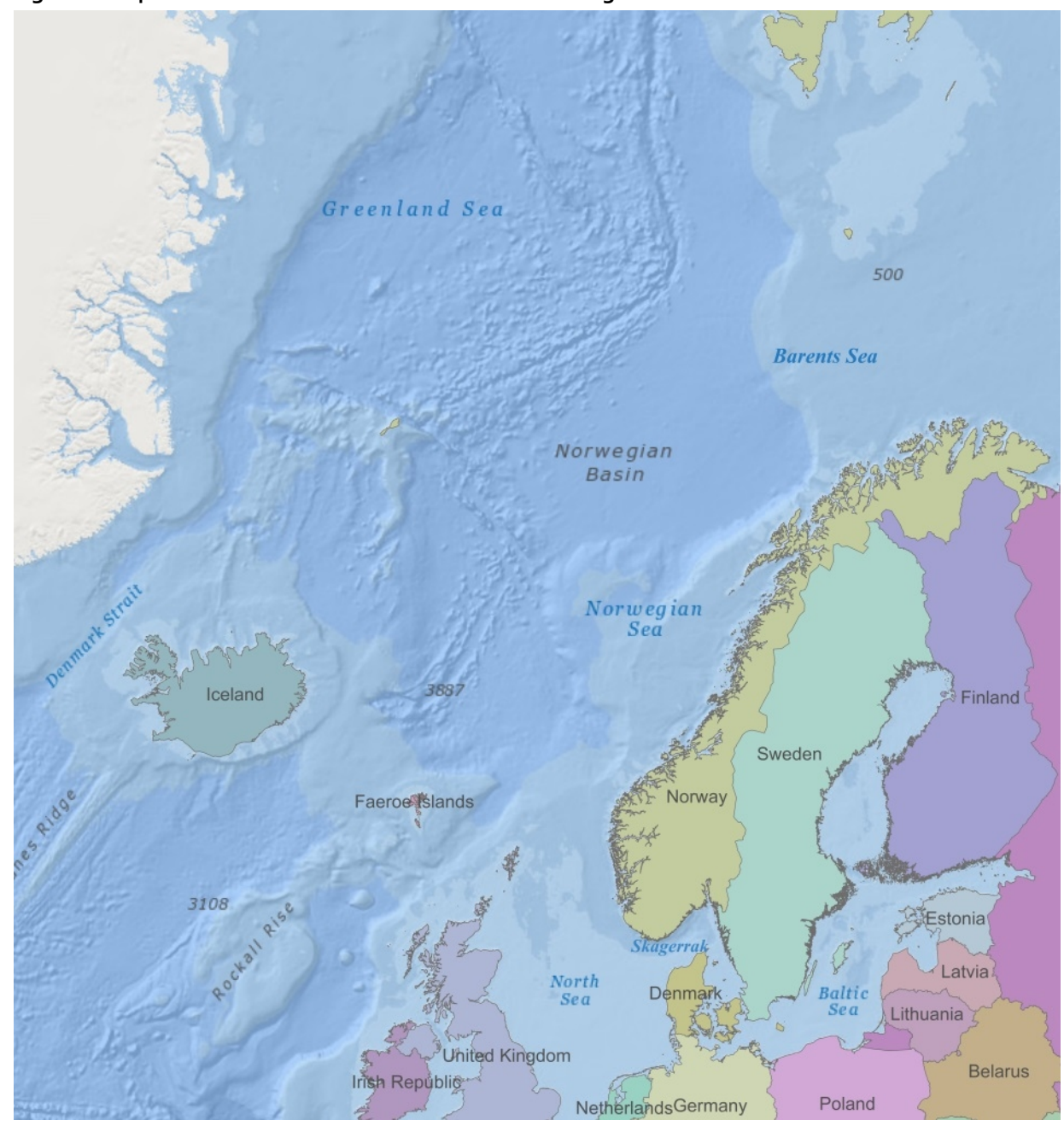

Source: ESRI. 
The coastal areas, which extend up to one nautical mile outside the baseline, house rich ecosystems, both at the bottom and in the water column above - the pelagic. Inputs of nutrients from land, the shallow areas that receive light from the sun, and the stirring of water layers in different seasons are conditions that make the coast highly productive compared to the deeper waters further out. The bloom of phytoplankton in the spring provides large quantities of food for small unicellular and multicellular organisms, including ciliates and copepods. These in turn are eaten by predators such as zooplankton, fish and jellyfish, but also by polychaetas, clams and other animals that live on the sea floor. Kelp and seaweed grow on hard substrate, forming marine forests that dominate the part of the seabed that receives sunlight. These forests provide food, breeding- and feeding places for a myriad of other species of algae, large and small crustaceans, snails and fish. Mollusks, crustaceans and polychaetas hide in the vegetation and are food for fish both inside and outside the kelp forest. Many fish species live their entire lives on the coast, while others come to the coast to eat or spawn. The great access to food forms the basis for life of rich populations of seabirds, seals and whales along the coast, and these populations are completely dependent on the coastal ecosystem in order to survive.

\subsection{The North Sea and Skagerrak}

The North Sea and Skagerrak region is one of Scandinavia's most intensively exploited seas and is among the world's busiest sailing areas. The use of the seas creates great values for the Norwegian and Swedish societies. The North Sea is particularly productive and supports extensive fishing, from small coastal fishing vessels to huge trawls, and at the same time Skagerrak is particularly important for small scale fisheries.

Many different activities with several conflicting interests create challenges for the management. The main industrial activities in these waters are currently fisheries, shipping and petroleum industry as well as tourism. The majority of the Norwegian oil and gas production takes place in the North Sea. Other industries include possible future offshore energy, marine bioprospecting and mineral exploration on the seabed (Meld. St. 37, 2012-2013, HVMFS 2012:19).

Sea and coast has great importance for recreation, outdoor activities, and tourism in Scandinavia. The coastline is very attractive and widely used by Scandinavians and their tourists (Naturvårdsverket 2008). Coastal and marine environment is important for sport in that it provides adventure value, as it is a place to exercise activities, providing health effects, thus making it an important basis for local and national economic activity through 
the tourism industry. The total value added from the tourism industry in the counties bordering the management area was NOK 25 billion in 2007 and SEK 18 billion in 2004 for Norway and Sweden, respectively (Meld. St. 37, 2012-2013, Falklind and Gustafsson 2006). In Norway, the core business in the seafood industry, i.e. fishing, hunting, farming, fish processing and wholesale level, resulted in a total contribution to gross domestic product of NOK 28 billion in 2010, a production value of 91.2 billion, employing 24,300 full-time equivalents (FTEs) (Meld. St. 37, 2012-2013).

Marine organisms are believed to have properties that can be exploited to create the basis for various products and processes in a number of business areas. Marine bioprospecting is related to biodiversity (Naturvårdsverket 2008), and the North Sea and Skagerrak are considered to have good opportunities to compete internationally within this field. Other ecosystem services are for example marine degradation of harmful substances and organisms, maintaining the stability of the ecosystem and climate regulation.

The fishery in the management plan area in the North Sea is exercised by Scandinavian and foreign fishing vessels, including EU vessels fishing on the allocated quotas in the Nordic countries' economic zones as negotiated through the bilateral agreements. In 2015, the proportion of Swedish catches in Skagerrak and Kattegat in relation to total Swedish catches was $15 \%$, contributing to $46 \%$ of the total value of 805 million SEK (SWAM 2016). The proportion of catch value in the North Sea and Skagerrak in relation to other Norwegian waters is on average $25 \%$. For catches the figure is $23 \%$.

\subsection{The Norway Sea and Barents Sea}

The Norwegian Sea has rich biodiversity and high biological production and there is a significant fishery throughout the year. In the Norwegian Sea, there are also significant petroleum deposits. The coastal areas are important transport routes. Also, the waters are important for tourism based on nature experiences and tourist fishing. Based on an overall assessment, environmental conditions in the Norwegian Sea are good (Meld. St. 37, 2008-2009). There are still significant challenges in the management of the Norwegian Sea, especially related to the effects of climate change and ocean acidification, overexploitation of certain fish stocks, the risk of acute pollution, decline in seabird populations and the need for conservation of coral areas. More on the importance of the Norway Sea to industries and society can be read in the Norwegian Management Plans (Meld. St. 37, 2008-2009, Meld. St. 8, 2005-2006, Meld. St. 20, 2014-2015). 


\subsection{The Baltic Sea}

The Baltic Sea is one of the world's largest semi-enclosed bodies of brackish water. The catchment area is densely populated with intensive agriculture and industry. From an evolutionary perspective, the Baltic Sea is young, approximately 12,000 years and characterized by relatively low species diversity. There is a gradient in species diversity and composition, following the south to north salinity gradient, with 20-40 times higher biomass of both flora and fauna in the Baltic proper compared to the Bothnian Bay (Jansson and Kautsky 1977, Kautsky 1988).

The Baltic Sea provides many valuable services including transport, energy, food, mineral resources, recreational facilities and cultural heritage. Recreation, outdoor activities and tourism in Scandinavian countries are greatly dependent on sea and coastal areas. Cruise tourism in the countries around the Baltic Sea give annual revenues of around EUR 443 million. Sales of leisure boats in Sweden were approximately EUR 265 million in 2006 (COWI 2007). In Finland, 28\% of the population between the ages of 16 and 80 years took part in recreational fishing (FGFRI 2014). In Sweden, the corresponding figure was $17 \%$, with a related total expenditure of around EUR $670 \mathrm{M}$ (SWaM 2012).

The environmental status of the Baltic Sea is generally impaired. Eutrophication is a major concern in most areas of the Baltic Sea. A downside example is from the Swedish island Öland, where algal blooms in 2005 caused losses in the tourism industry estimated at around EUR 27 million (Naturvårdsverket 2009). Despite significant reductions of the nutrient inputs over the past, the only coastal areas not affected are confined to the Gulf of Bothnia (HELCOM 2010). Apart from eutrophication, pollution, introduction of non-indigenous species and global sea warming can change the Baltic Sea ecosystem, potentially altering the distribution, biomass and abundance of species (Elmgren 1989, Gren et al. 2000, Rodhe and Winsor 2002, HELCOM 2003). 



\section{Ecosystem services of kelp forests}

\subsection{Distribution and physical requirements}

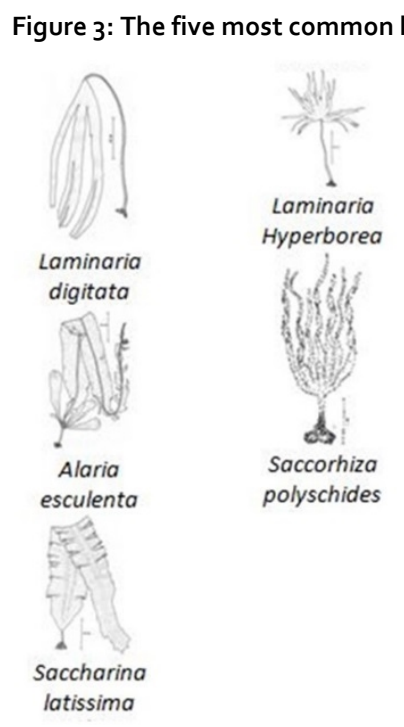

Source: Illustration Per Arvid Åsen

Essentially there are five different species of kelp in the Nordic waters (Figure 3). These are Laminaria hyperborea, Laminaria digitata, Saccharina latissima, Alaria esculenta, and Saccorhiza polyschides. The species $L$. hyperborea and S. latissima are most important in terms of key habitat, spatial extent, biomass, and harvesting revenue, and are thus treated more thoroughly in this report than the three other kelp species.

Kelp forests occur worldwide throughout temperate and polar coastal oceans (Figure 4). In the Nordic region kelp is found all along the Norwegian coast, as far west as Iceland and Greenland (except Saccorhiza polyschides) and east to the Swedish west coast (except Alaria esculenta and Saccorhiza polyschides). Based on studies on the distribution and regrowth of kelp forests (e.g. Norderhaug and Christie 2009), we have good knowledge about the habitat requirements of kelp. Generally we find kelp forests on shallow (down to about $25 \mathrm{~m}$ ) hard bottom areas. L. hyperborea is found in relatively 
wave-exposed areas (Bekkby et al. 2009); whereas S. latissima lives more sheltered (Bekkby and Moy 2011).

The distribution of kelp forests in the coastal zones of the Barents Sea, Norwegian Sea, North Sea and Skagerrak have been mapped through the Norwegian Programme for mapping of marine nature types (Bekkby et al. 2013). Gundersen et al. predicted in 2011 the standing and potential distribution and biomass of $L$. hyperborea and S. latissima for the whole coast of Norway. The standing distribution was $8,000 \mathrm{~km}^{2}$, whereas an additional area of $9,000 \mathrm{~km}^{2}$ were expected to regrow within some decades due to the effects of climatic changes on sea urchins recruitment (Box 1). Similar kelp mapping programs on the Swedish side of Skagerrak do not exist, but some inventories and modelling studies show that there are extensive and well-grown kelp forests in some offshore banks between the coasts of Denmark and Sweden in this area (Naturvårdsverket 2010, 2012).

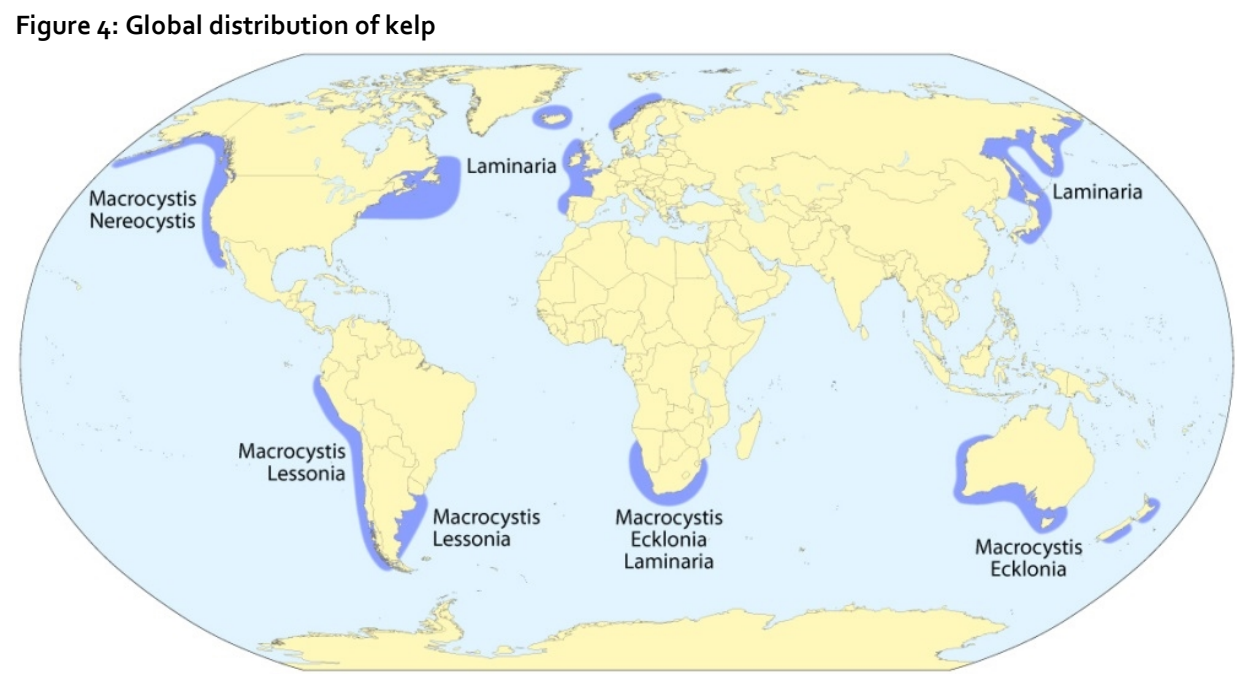

Source: Maximilian Dörrbecker.

\subsection{Threats and challenges}

Smale et al. (2016) state that NE Atlantic kelp forest ecosystems are currently threatened by a range of anthropogenic stressors that operate across multiple spatial scales (Smale et al. 2013, Mineur et al. 2015), including overfishing (Tegner and Dayton 2000, Ling et al. 2009, Moksnes et al. 2008, Korpinen et al. 2007, Östman et al. 2016), increased temperature (Wernberg et al. 2011, 2013), storminess (Byrnes et al. 2011, Smale 
and Vance 2015), the spread of invasive species (Saunders and Metaxas 2008, Korpinen et al. 2007), elevated nutrient and sediment inputs (Gorgula and Connell 2004, Moy and Christie 2012), and turbidity (Pehlke and Bartsch 2008, Desmond et al. 2015). Anthropogenic stressors can cause shifts from structurally diverse kelp forests to unstructured depauperate habitats characterized by mats of turf-forming algae and sea urchins (Ling et al. 2009, Moy and Christie 2012, Wernberg et al. 2013).

Of all different stressors, the largest and most important threat to kelp forests in the Nordic countries has been the green sea urchin Strongylocentrotus droebachiensis which has turned large areas of kelp forests into barren grounds from the county of Møre and Romsdal and as far northeast as the Russian border within the last 45 years (Box 1). Also in Iceland the sea urchins have deforested extensive areas of kelp forests (Hjorleifsson et al. 1995). This phenomenon has been reported as an almost continuous overgrazed belt on inner and moderate wave exposed coasts. However, kelp forests are still dominating in the outer and more wave-exposed part of the coast of Norway (e.g. Norderhaug and Christie 2009).

Further, due to increased nutrient concentrations, reduced water transparency (Moy et al. 2008), and most likely also increased temperatures (Syvertsen et al. 2009, Korpinen et al. 2007), S. latissima and other macroalgae in the Bothnian Bay and the Skagerrak-Kattegat region have in some areas been lost or strongly reduced (Dahlgren and Kautsky 2002, Moy et al. 2008) (Box 2, Figure 5). The macroalgae are instead replaced by less productive and supportive habitats, such as filamentous algae, which often end up covering beaches (Malm et al. 2004), with reduced benefits and increased costs for recreational businesses (Hasselström et al. in prep.). 
Box 1: Sea urchins turn viable kelp forests into desert-like barren grounds in the Norwegian Sea and Barents Sea

Since the early 1970 's, more than $50 \%$ of kelp forests in the sheltered and moderately exposed areas from $\sim 63$ to $71^{\circ} \mathrm{N}$ have been grazed by green sea urchins, Strongylocentrotus droebachiensis, which have transformed the areas along the Norwegian coast into marine deserts, or so-called barren grounds (Sivertsen 1997) (Figure 5). The reason for this development is not fully understood, but might relate to both stochastic and cyclic events (Norderhaug and Christie 2009). However, the last decade we have observed a gradually northwards recovery of kelp (Norderhaug and Christie 2009, Rinde et al. 2014), partly explained by the negative effects from warming on sea urchin recruitment (Fagerli et al. 2013) and to some degree from increased predation by northward expanding Cancer pagurus and Carcinus maenas crabs (Fagerli et al. 2014, Christie et al. in prep.).

Figure 5: The kelp forests of the northern coasts of Norway have been kept back by green sea urchins for decades, but are now slowly recovering in a northward direction

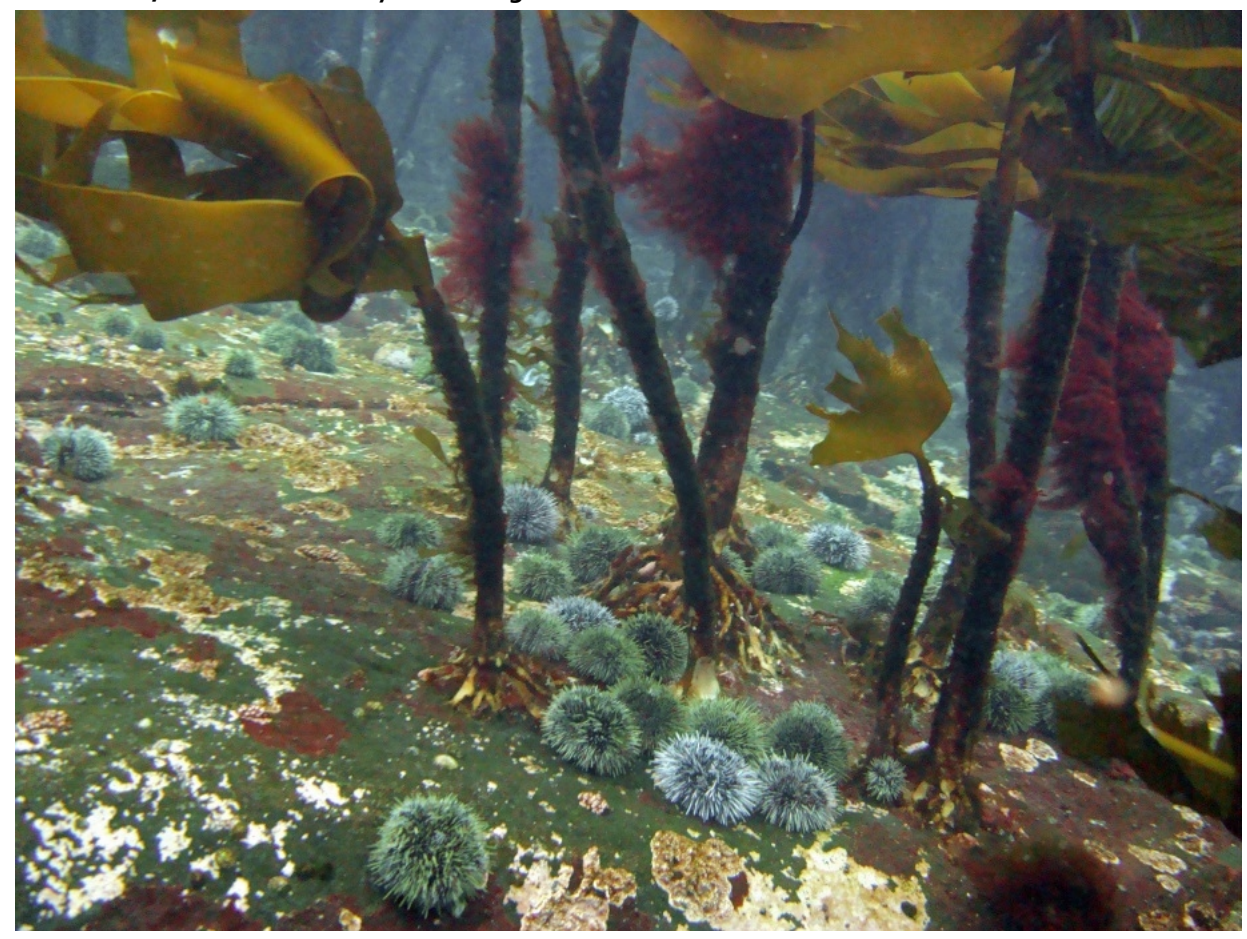

Source: Hartvig Christie, NIVA. 


\section{Box 2: Eutrophication, climate change and overfishing threatens the kelp forest in Skagerrak}

An important threat to S. latissima and other macroalgae in the Skagerrak and North Sea region is the competition and overgrowth of filamentous algae on less exposed hard bottom localities during summer. Moy et al. (2008) found that S. latissima had disappeared at about $80 \%$ and $40 \%$ of surveyed stations at the Skagerrak and west coast, respectively. Worst affected are areas with good conditions for filamentous algae, which are in protected areas with good light conditions (Bekkby and Moy 2011). Based on today's knowledge, the loss of S. latissima is most likely related to eutrophication and climate change (Syvertsen et al. 2009). Increasing temperature and inputs of nutrients and particulate matter, together with overfishing of for instance the cod Gadus morhua are probable reasons why sugar kelp has disappeared and not yet returned (Moy et al. 2008, Syvertsen et al. 2009). A decline in large predators can lead to domino effects in the food chain that increases the effects of eutrophication (Moksnes et al. 2008, Korpinen et al. 2007, Östman et al. 2016).

Figure 6: Saccharina latissima kelp in the Skagerrak and North Sea becomes overgrown by filamentous algae in late summer, probably due to a combination of high temperatures, rich loads of nutrients and overfishing

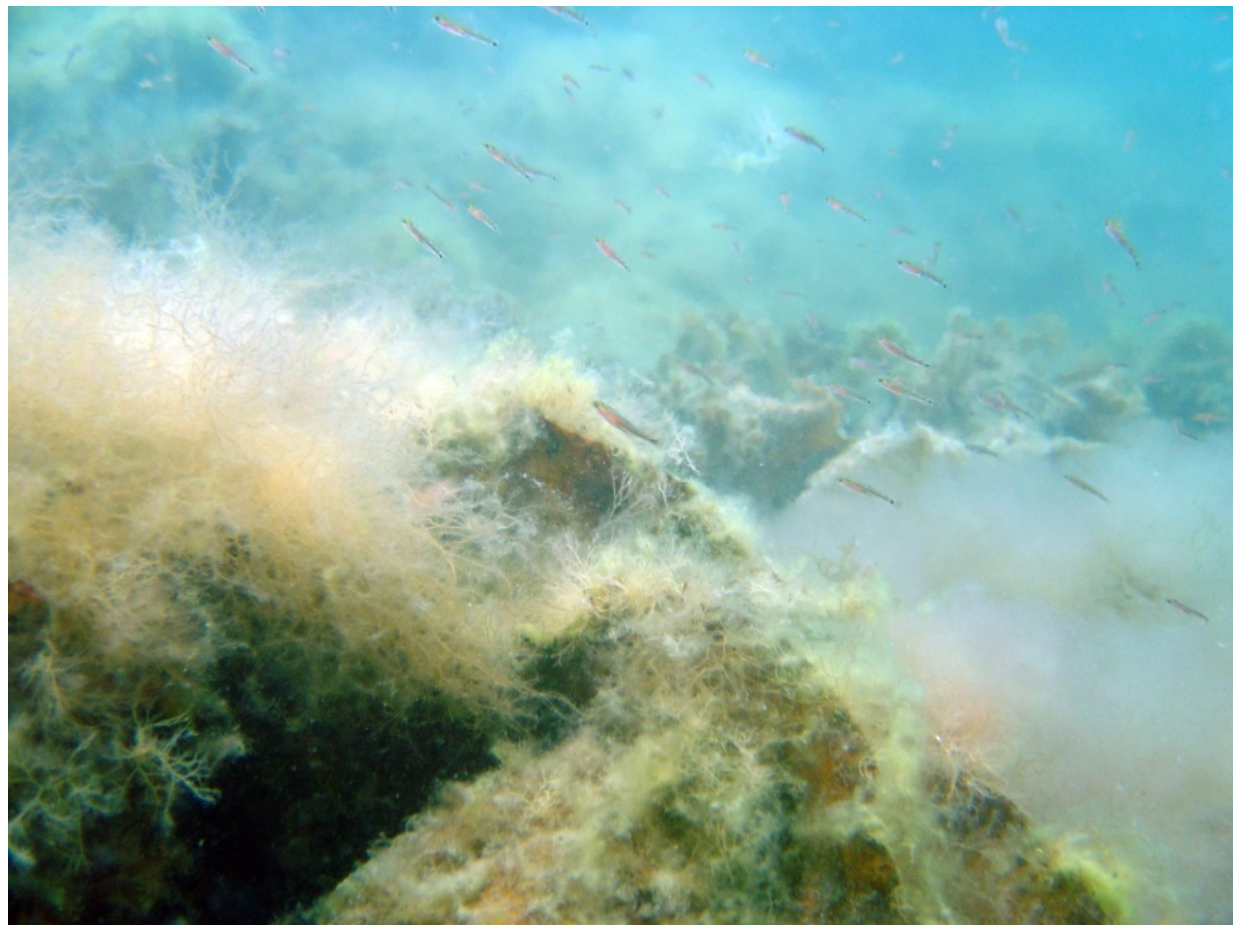

Source: Hartvig Christie. 
Figure 7: Map showing the five ecoregions of Norway and western coast of Sweden and the kelp situation in each of them today. The red zone in the north depicts the area where sea urchins have turned the kelp forest into desert-like barren grounds, the green zone in mid-Norway shows where vital kelp forest exist at present and the orange zone in the south is where macroalgae beds are threatened by eutrophication and warming and kelp forest are replaced by mats of turf-forming filamentous algae

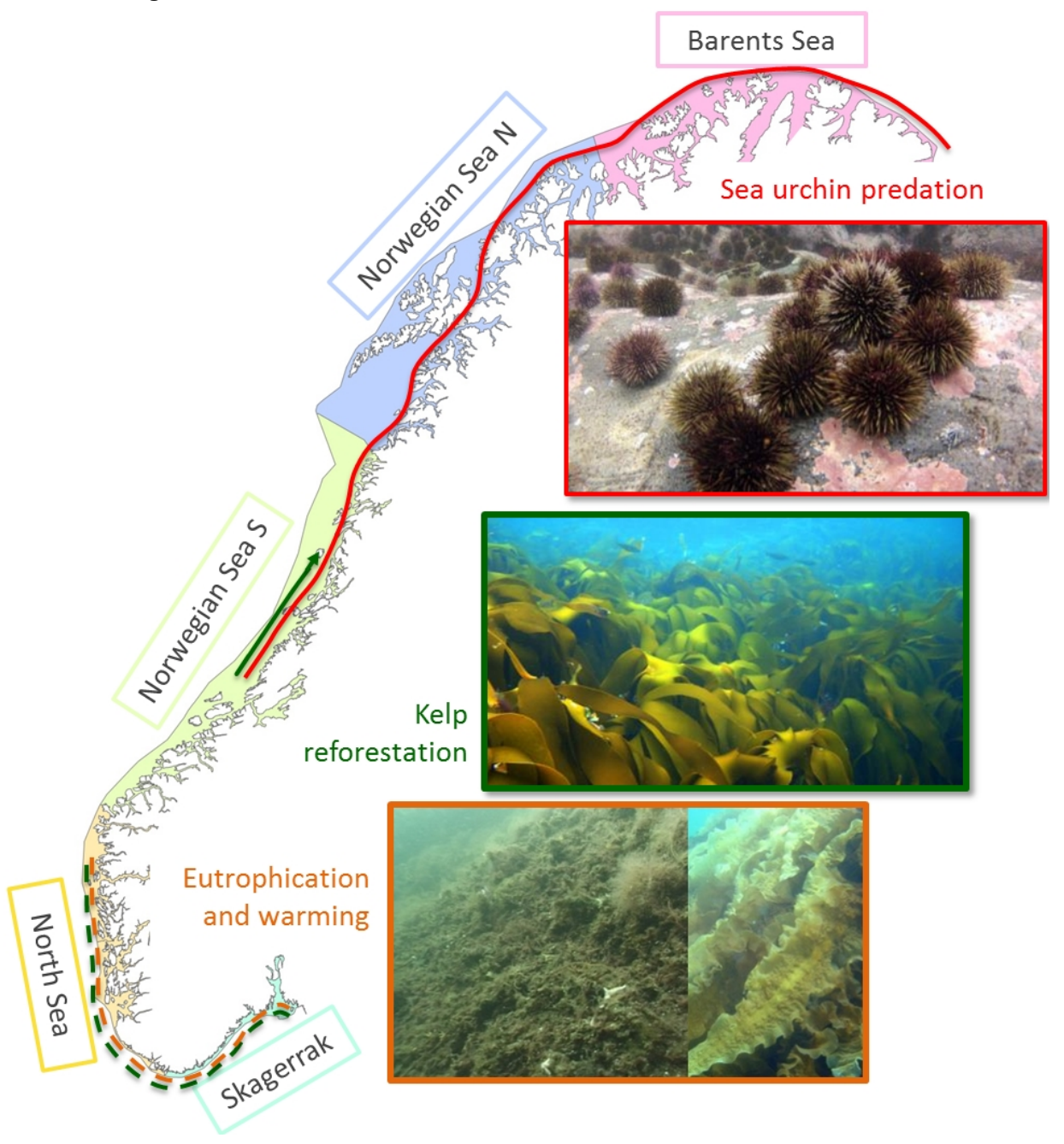




\subsection{Supporting services}

\subsubsection{Habitat and biodiversity}

Already on his trip to the Strait of Magellan in 1834, Charles Darwin was astonished about the diversity of the great kelp forests of South America. Darwin writes in "The voyage of the Beagle": I can only compare these great aquatic forests of the southern hemisphere with the terrestrial ones in the intertropical regions. Yet if in any country a forest was destroyed, I do not believe nearly so many species of animals would perish as would here, from the destruction of the kelp. Amidst the leaves of this plant numerous species of fish live, which nowhere else could find food or shelter; with their destruction the many cormorants and other fishing birds, the otters, seals, and porpoises, would soon perish also; and lastly, the Fuegian savage, the miserable lord of this miserable land, would redouble his cannibal feast, decrease in numbers, and perhaps cease to exist.

The three dimensional structure of the kelp forest provides habitat, nursery ground and food for myriad mobile pelagic and benthic organisms (Christie et al. 2003, Steneck et al. 2002).

Typically, the stipe (the kelp stem) is grown with algae, mostly red algae, but also brown- and green algae (Figure 8). It has been found that more than 50 different epiphytic algae exist in one single kelp stipe. In addition to epiphytic algae, there are also large numbers of epiphytic fauna on the stipe. The most important groups are tunicates, sponges and bryozoans, which can also cover large parts of the lamina (the kelp leaf). Recent studies have found a surprisingly rich fauna of mobile invertebrates. Such animal societies can consist of 2-300 different species and having densities of more than 100000 individuals of snails, crustaceans, clams, polychaetas and other invertebrates per square meter (Christie et al. 2009).

Within and above the kelp forest we find during summertime large densities of different stationary fish species, such as labridae (eng: wrasse; no: leppefisk; swe: läppfiskar) and gobies (no: kutling; swe: smörbult). The two-spotted goby, for instance, being no more than $10 \mathrm{~cm}$ long, is considered as Norway's most numerous fish during summertime and important in the transfer of energy from seaweed and up to larger fish. Other large fish stocks utilize coastal ecosystems as nurseries and feeding grounds and kelp forests are among the most important habitats for both commercial species (e.g. cod, pollock, pike, and perch) and red list species (e.g. the coastal cod, Steneck et al. 2002, Ottersen et al. 2010). These fish are in turn further predated by higher trophic species, such as coastal seals and several species of seabirds (Lorentsen et al. 2010). 
Figure 8: The kelp forest is an extremely diverse system due to its three dimensional structure with many different niches and refuges for small and large plants and animals

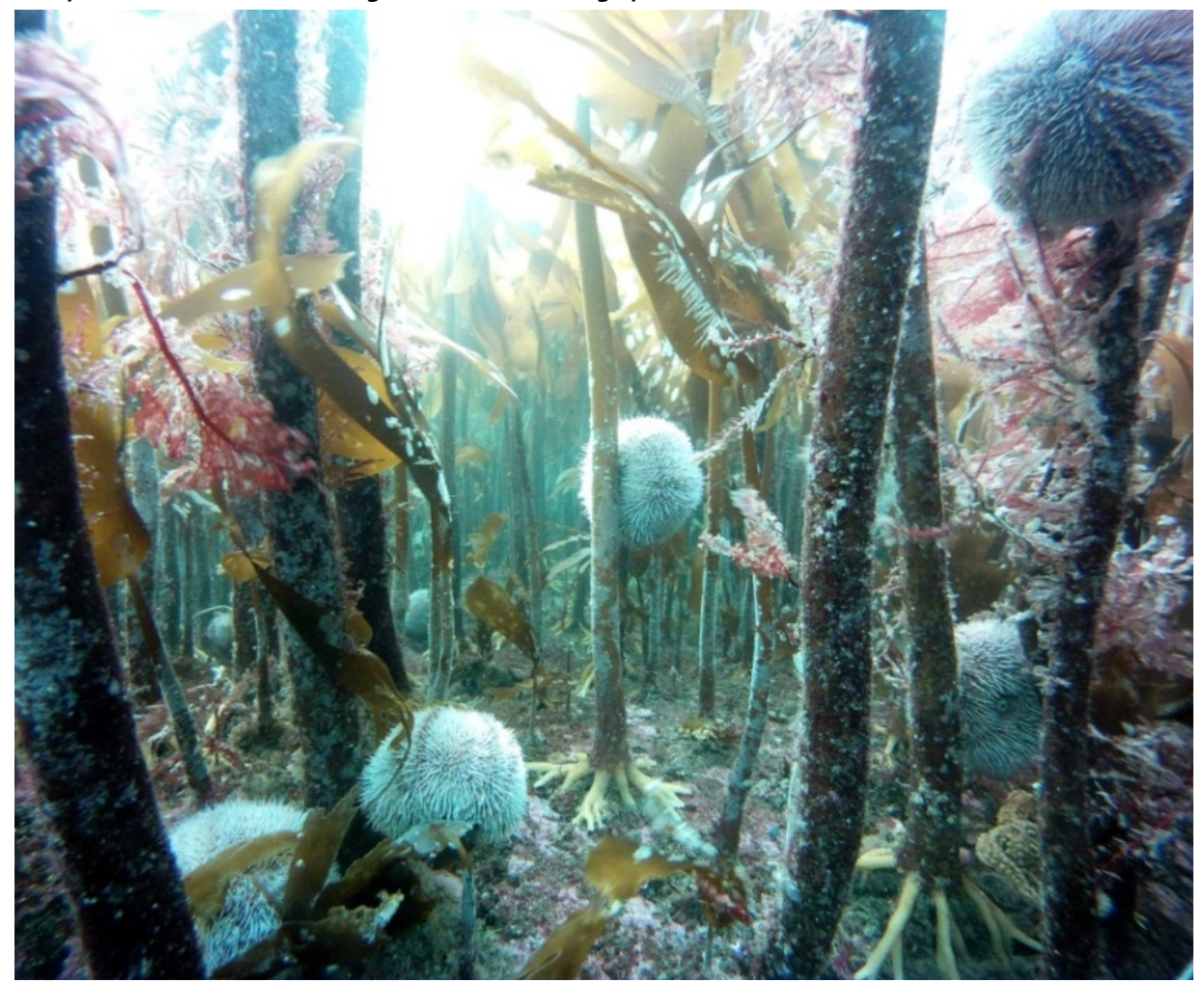

Source: Institute for Marine Research.

\subsubsection{Primary production, food webs and nutrient cycling}

Kelps, which are photosynthetic organisms, are hugely important as primary producers and kelp forests are regarded among the most productive systems on earth (e.g. Dayton 1985, Steneck et al. 2002, Smale et al. 2013). Published values from the Nordic waters show a yearly primary production between 1,200 and 5,000 g carbon per square meter of kelp forest, which corresponds to between 12 and $50 \mathrm{~kg}$ produced plant material (biomass) per $\mathrm{m}^{2}$ per year (Ottersen et al. 2010, Kain 1971, Sjøtun et al. 2006, Gundersen et al. 2011).

Since macroalgae grow fast and have very high production there is a steady production of particulate organic material (POM) throughout the year. The flow of detritus between habitats is thus an important form of connectivity that affects regional productivity and the spatial organization of marine ecosystems (Krumhansl and 
Scheibling 2012). Detritus settles within kelp beds or forests and is exported to neighboring or distant habitats, including sandy beaches, rocky intertidal shores, rocky and sedimentary subtidal areas, and the deep sea. Exported kelp detritus can provide a significant resource subsidy, and enhance secondary production in these communities ranging from tens of meters to hundreds of kilometers from the source of production (Krumhansl and Scheibling 2012).

Of yearly POM from kelp plants, about $10 \%$ are consumed by higher trophic species, like crustaceans and other fauna (Norderhaug and Christie 2011), while the majority of the dead kelp plant material accumulates within or outside the forest being subject to decomposition by microorganisms and bacteria in other food webs. An uncertain amount of the plant material is also thought to be buried in the ocean sediments (see chapter on carbon sequestration and Gundersen et al. 2011).

Although phytoplankton contributes to a greater total volume, the kelp system is regarded among the most productive on the planet, with an annual primary production over ten times more per unit area than for phytoplankton. In Norway, it is primarily the two species $L$. hyperborea and S. latissima that contribute most to the production, whereas fucus and eelgrass also can be significant in the Baltic Sea.

\subsubsection{Biological control}

Through its three-dimensional structure, the kelp forest houses a myriad of species with overlapping functions at all trophic levels. These qualities imply high resilience to disturbances and biological control against potential pests and invasive species. For instance, the kelp forest accommodates facilities for many of the predators of juvenile sea urchins, and thus reducing the possible destructive overgrazing of the kelp forest itself.

Further, the kelp plant contains anti-grazing substances (polyphenols) which means that few species feed directly on the kelp plants. Alginates from kelp have been used in agriculture to encapsulate biocontrol agents and rhizobia as inoculants for legumes (DeLucca 1990).

\subsection{Provisioning services}

\subsubsection{Resource utilization and bioprospecting}

Historically, in the Nordic seas and in other parts of the world, large algae have been used in food production. Also today there is a growing market and interest for human foods based on algae and seaweed (Chapman et al. 2015). Traditionally, kelp and other 
macroalgae have also been collected and used as "kelp ash" in the manufacture of glass and soap and for pottery glazing, as well as for fertilizers (Smale et al. 2013).

Since the early 2oth Century, kelp has mainly been harvested for alginate extraction. The alginate are useful for its abilities in bulking, gelling, and stabilizing processes and are used in a wide range of industries, such as for the production of textiles, food, paper, cosmetics, and pharmaceuticals. Alginate derived from kelp is found in as diverse products as ice cream, shampoo, toothpaste, paint, yoghurt and pet food.

In Norway, about 200,000 tons of L. hyperborea are harvested each year (Vea and Ask 2011), primarily for alginate production, with a first-hand value of NOK 30-35 million and a further increase in value up to 1.5 bill after processing. However, since the further manufacturing of alginate products is not performed in Norway, this value creation is not benefiting the Norwegian society today.

An increasing demand for non-fossil based energy has made kelp interesting as a potential source of biofuels. Kelp can grow very quickly (up to $50 \mathrm{~cm}$ per day), are rich in polysaccharides, do not compete with land-based crops for space, and do not require additional fertilizer or water (Smale et al. 2013, Wargacki et al. 2012). However, a recent analysis of the carbon footprint of the production of ethanol and methane from seaweeds indicated that production of biofuels from other sources (e.g. corn, wheat and sugar cane) is more efficient (Fry et al. 2012). Clearly, the magnitude of kelp production for biofuels would need to be substantial to have any bearing on the energy marked.

Due to its high diversity of organisms, kelp forests have a significant potential when it comes to bioprospecting. There are good reasons to believe that marine organisms, such as bacteria, fungi, viruses, plants, shellfish and fish, possess features and characteristics which can be utilized for different products and processes. The Nordic countries are considered to have excellent opportunities to compete internationally within this field.

The potential for culturing kelps for biofuels, feed for aquaculture and livestock, alginate processing, etc. have led to an increasing interest in large-scale harvesting and cultivation of kelp. According to Olafsen (2012), Norway is capable of cultivating 20 million tons of kelp, which will give a yearly added value of 40 billion NOK.

\subsubsection{Commercial and subsistence fishery}

Since kelp forest are assumed to be crucial habitats for many economic important fish species, the value creation from fishery and other sea food in countries like Norway and Iceland is indisputable (Meld. St. 37, 2012-2013, HELCOM 2007). The supply of fish depends on both the available habitat for spawning, hatching, nursing, and grazing, but also on the existence of habitats available for animals and plants that the fish feed on. 
Based on the well-known food chains from kelp, via fauna and several trophic levels of fish, these areas should theoretically give rise to a substantial annual production of fish, and in fact an estimated 1-2 million tons of cod are assumed to be dependent on the Norwegian kelp forest, according to models by the Institute of Marine Research (Moy and Steen 2014). Also, commercial fisheries are ranked as the second largest marine economic activity in the Baltic Sea Region (HELCOM 2014, Hasler et al. 2016). The three most important species is cod, Baltic herring (Clupea harengus) and sprat (Sprattus sprattus), which constitute $95 \%$ of the landings, but in addition about 20 other species are caught more locally (Hasler et al. 2016). Values that include both provisioning (food) and cultural (recreational fishing) ecosystem services have been estimated for the cod stock (Eggert and Olsson 2009, Carlsson et al. 2010), Baltic salmon (Kulmala et al. 2012), and fisheries and fish stocks in general (Lewis et al. 2013, Kosenius and Ollikainen 2015).

However, the number of people in the fishery sector continues to decrease, particularly in the small-scale fishery, and also the average age of a commercial fisherman is continuously increasing (Naturvårdsverket 2008). Despite a relatively small scale, the processing industry creates jobs in sparsely populated areas while maintaining cultural heritages in coastal communities and is therefore of local importance. For an overview of marine food production and its added values for the Baltic countries, see Naturvårdsverket (2008), and for Norway, see Meld. St. 37 (2012-2013), Meld. St. 8 (20052006) and Meld. St. 10 (2010-2011).

\subsection{Regulating services}

\subsubsection{Maintenance of resilience}

A commonly used definition of ecological resilience is the extent to which ecosystems can absorb recurrent natural and human perturbations and continue to regenerate without slowly degrading or unexpectedly shifting to alternate states (Holling 1973). This service is essential for maintained ecosystem function (Naturvårdsverket 2008). Kelp forests are remarkably resilient to natural disturbances such as wave impacts, storm surges, and other extreme oceanographic events (Dayton 2003, Steneck et al. 2002) and this service is essential for the safeguarding of ecosystem functions. The resilience of the kelp ecosystem depends among others on the biodiversity which contributes to increase the robustness, stability and the ability of the ecosystem to recover. If a species is disturbed, another can take over its function in response to the disturbance. If an ecosystem's resilience is weakened, for instance by over-fishing or eutroph- 
ication, a trophic cascade might happen, where the ecosystem transitions from one dynamic equilibrium level to another - a so-called regime shift (Folke et al. 2004, Ling et al. 2009, Östman et al. 2016). According to Naturvårdsverket (2008), the ecosystem service of resilience can be considered as an insurance against catastrophic or irreversible changes and accompanying loss of ecosystem services.

\subsubsection{Carbon storage and sequestration}

Primary producers use solar energy to convert inorganic material to organic matter through photosynthesis. Among many other important functions, the kelp therefore affects the biochemical cycles and regulates the global climate by using carbon dioxide $\left(\mathrm{CO}_{2}\right)$. The kelp plants act as reserves for $\mathrm{CO}_{2}$ as long as they are alive, whereas the carbon is released back to the system when the plant dies and are decomposed by microorganisms and bacteria. Because of the large areas along the Norwegian coast, the binding and release of carbon from the kelp forest will have great importance to the total carbon and greenhouse gas balance. Carbon can be stored in kelp forests due to increased areal extent and biomass, for instance through the ongoing regrowth of kelp observed in the north of Norway (Box 1), but also through the disposal of dead organic plant material in the sediments. The proportion of the dead kelp material that are buried on the sea floor and stored for the future is still an unanswered question. However, Gundersen et al. (2011) estimated a conservative and a moderate scenario for sedimentation of kelp material with as much as 0.9 and 2.3 million tons deposited each year, respectively, assuming today's production and taking into account different threat factors and probable changes (Box 3 ). 


\section{Box 3: An investigation of $\mathrm{CO}_{2}$ uptake in marine ecosystems}

In their study, Gundersen et al. (2011) estimated the existing and potential future distribution of kelp and other ecosystems by evaluating different threat factors. The total existing area for $L$. hyperborea and S. latissima along the Norwegian coast was estimated to $8,000 \mathrm{~km} 2$ ( 80 mill tons). The total area loss due to sea urchins ( $\operatorname{Box} 1$ ) and fouling by filamentous algae (Box 2) was estimated as $2,000 \mathrm{~km}^{2}$ (20 mill tons) and $7,800 \mathrm{~km}^{2}$ ( 78 mill tons), respectively, and interpreted as a potential increase in area if the threat factors would disappear. If all kelp forest fully recovers, the biomass will increase from 80 to 178 mill tons. This means increased yearly production of 98 mill tons (123\%) per year. Today's standing biomass will bind up to 29 mill tons $\mathrm{CO}_{2}$. But if all kelp forest recovers during the next 20-40 years that will bind up to 65 mill tons $\mathrm{CO}_{2}$, i.e. a gain of 36 mill tons bound $\mathrm{CO}_{2}$. This will be a one-time happening when the sea floor regrows with kelp forest.

Also, a conservative ( $3 \%$ sequestrated - light green line in the figure below) and a moderate ( $8 \%$ sequestrated - dark green line in the figure below) scenario for potential gain from sedimentation of kelp material showed that 0.9 and 2.3 mill tons will be deposited every year, respectively, assuming today's production. These numbers will increase by 1.1 and 2.9 mill tons $\mathrm{CO}_{2}$ per year, respectively, if the kelp forests grows back. An intact kelp forest would have, through the last 40 years, stored about 150 mill tons $\mathrm{CO}_{2}$ more in the oceans (due to increased amounts of standing kelp forest and $8 \%$ accumulation of yearly production).

Figure 9: Estimated sequestration of $\mathrm{CO}_{2}$ from Norwegian kelp forests, given two different regrowth scenarios, a moderate $(8 \%)$ and a conservative $(3 \%)$ one

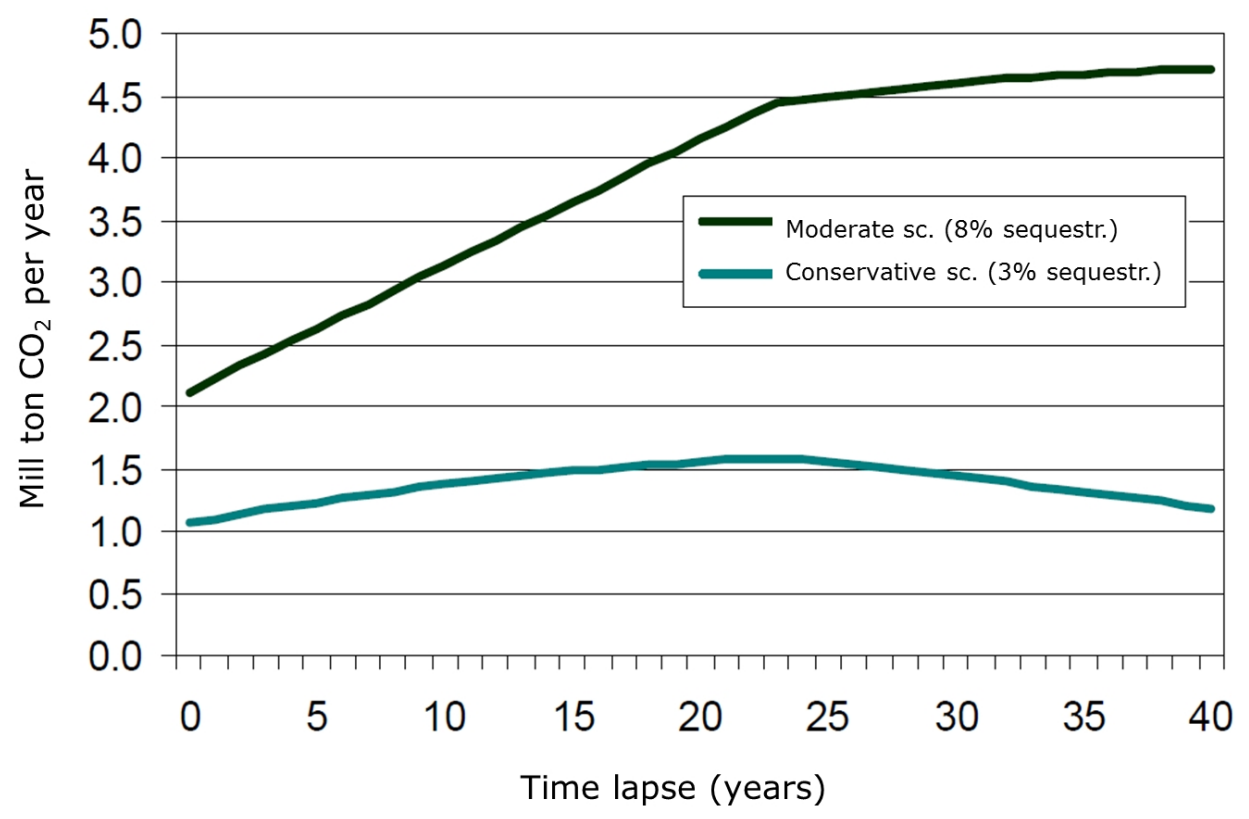

Source: Gundersen et al. (2011). 


\subsubsection{Eutrophication mitigation}

Another important maintenance and regulation service of the kelp forest is nutrient removal. Primary production by macroalgae is based on nutrients available in the water column, with nitrogen and phosphorus being the main elements required for active growth of photosynthetic organisms. But although primary production is a prerequisite for all production in the sea, nutrient input levels and consequential production can be too high, at least for societal and economic aspects of ecosystem services.

Eutrophication is caused by excessive nutrient loads from waterborne sources and from atmospheric deposition (HELCOM 2013, PLC5) mostly caused by human actions, such as agriculture, waste water, industry, and aquaculture. Above certain thresholds the eutrophication will have detrimental effects to the ecosystem and cause increased frequency and magnitudes of algal blooms, increase of filamentous algal mats, reduced water transparency, hypoxic sea floors, habitat loss, and impaired recruitment success of commercial fish (Naturvårdsverket 2008).

Eutrophication mitigation mediated by kelp forests reduces this threat and contributes to the improvement of other services, such as cultural services and provisioning services. A number of studies have looked at nutrient assimilation in the coastal zone as a recognized ecosystem function and service (Hasler et al. 2016). Primary and secondary symptoms of eutrophication have been demonstrated to influence the flow of cultural ecosystem services, such as the recreational use of coastal areas (Ahtiainen et al. 2014, Hyytiäinen et al. 2014). Further, eutrophication becomes obviously detrimental in areas important for tourism, recreation and residential development. But also anoxic bottoms contribute to the degradation of many supporting services (Naturvårdsverket 2008).

Hasler et al. (2016) refer that the major part of the citizens around the Baltic Sea are concerned about the consequences of eutrophication and that they are willing to make considerable economic sacrifices for a healthier sea (Ahtiainen et al. 2014). These findings are supported by Hasselström et al. (2008) who concluded that blue green algae blooms caused by eutrophication were considered to be the most important nuisance reducing aesthetic and recreational values in beaches and coastal areas across the Baltic Sea area (Hasler et al. 2016).

\subsubsection{Water purification, filtering and removing of hazardous substances}

Water purification and filtering are yet other maintenance and regulation services provided by kelp forests. Improved water quality (in terms of transparency) is believed to infer enormous benefits for the production of food and to all aspects of ecosystem diversity and function (Naturvårdsverket 2008). 
Many studies are also supporting integrated aquaculture practices that utilize seaweeds as biofilters within multitrophic farming operations (Neori et al. 2004, Troell et al. 2009). For instance, cultivation of kelps adjacent to salmon farms can generate significant yields of algal biomass while simultaneously removing waste nitrogen (Sanderson et al. 2012). However, the impacts of large-scale kelp cultivation in non-enriched systems are poorly known and may be detrimental (Smale et al. 2013).

Bioremediation of polluted areas and effluents is becoming an important area of interest as novel environmentally sound solutions to pollution are being investigated and processes using tolerant macroalgal species that accumulate metals at high rates may offer an effective, inexpensive and environmentally friendly alternative (Yu et al. 1999, Baumann et al. 2009). Macroalgae is also frequently used as indicator organisms in environmental monitoring, particularly in relation to heavy metals.

\subsubsection{Coastal defense}

Coastal defense, such as erosion prevention, represents a critical ecosystem service provided by the kelp forest and will be increasingly important along many coastlines as the consequences of anthropogenic climate change, such as sea-level rise and increased magnitude and frequency of storms (IPCC 2013), intensify.

Kelp forests, such as the L. hyperborea, are found in highly exposed areas and have been found to reduce wave heights and contribute to wave breaking (Løvås and Tørum 2001), which again may provide protection to coastal societies and man-made constructions. Often kelp forests and seagrass meadows are closely located, with kelp forest in the outer, more exposed areas, and soft bottoms, with seagrass, in more sheltered bays inshore. Consequently, kelp forests may contribute to reducing the amount of hazardous waves on seagrass meadows, thus indirectly reducing the risk of soil erosion at soft sandy bottoms.

In a global perspective, more people use sandy beaches than any other type of seashore (Klein et al. 2004). The beneficiaries of sediment retention and disturbance mitigation are households and industries dependent on the presence of extensive beaches and a stable substrate maintaining and allowing for coastal development (Naturvårdsverket 2008). Also in the Baltic Sea and Skagerrak region, sandy beaches are prime sites for human recreation and tourism activity (Naturvårdsverket 2008). 


\subsection{Cultural services}

\subsubsection{Recreational fishing}

Compared to commercial fishermen who make a profit of around EUR 0.1 per $\mathrm{kg}$ fish caught; the net value of sports fisheries is four times as high per $\mathrm{kg}$ fish, calculated on the basis of willingness to pay (Toivonen et al. 2000, 2004). With an estimated one million sport fishermen in Sweden (including freshwater fishing), the total willingness to pay for sport fisheries in 2006 was around EUR 265 million (Toivonen et al. 2000, 2004).

\subsubsection{Tourism}

Certain ecosystem services related to tourism can be directly associated with kelp forest, such as snorkeling, scuba diving, free diving, and kayaking, which involve people actually enjoying watching a healthy kelp forest with a diversity of inhabitants (Hasler et al. 2016, Beaumont et al. 2008). However, there is also a strong indirect connection between kelp and marine recreation activities such as swimming, windsurfing, water skiing, picnicking, bathing, sunbathing, boating, wildlife watching, angling, and visiting touristic or cultural sites, via for instance kelps' role in eutrophication mitigation, since these activities will be experienced more positively in clean water (SwAM 2012, Hasler et al. 2016).

In the Baltic region, coastal tourism and recreation are currently (and still growing) the largest marine economic activity (Hasler et al. 2016). Also, coastal tourism is the most significant maritime employment sector in almost all EU Member States that have a coastline (ECOTEC 2006).

The socioeconomic importance of kelp forests is especially high in coastal societies. The vast kelp forests along the west coasts of Norway support abundant wildlife, such as sea birds, seals, and otters, and the value of this biodiversity to local economies through "green" tourism is significant. Sea angling, scuba diving, and bird- and whale watching are among such tourist based enterprises.

Commonly, marine and maritime cultural heritage are mostly connected to artworks and relicts such as paintings, photographs, documents, buildings, ships and shipwrecks, but their direct relations to kelp forest are not many. However, it is worth mentioning the Vega Archipelago which is a UNESCO World Heritage Site just south of the Arctic Circle in Norway. It is the name of a dozen islands where fishermen and farmers have been living since the stone age and where particularly the activity around gathering of down from eider ducks (Somateria mollissima, which are closely associated and depending on kelp forest) has been a major part of their livelihood (Skarpaas et al. 2014). 


\section{Ecosystem services of eelgrass meadows}

\subsection{Distribution and physical requirements}

Worldwide there are about 60 different species of seagrasses (Green and Short 2003) and eelgrass, Zostera marina, is the most abundant and important seagrass ecosystem in the Nordic countries. Eelgrass is widely distributed on the northern hemisphere and along the European coasts from the Mediterranean to the northern arctic waters of Norway, and from the coast of Iceland to the Baltic Sea (Figure 10). The biology of the eelgrass is shown in Box 4 .

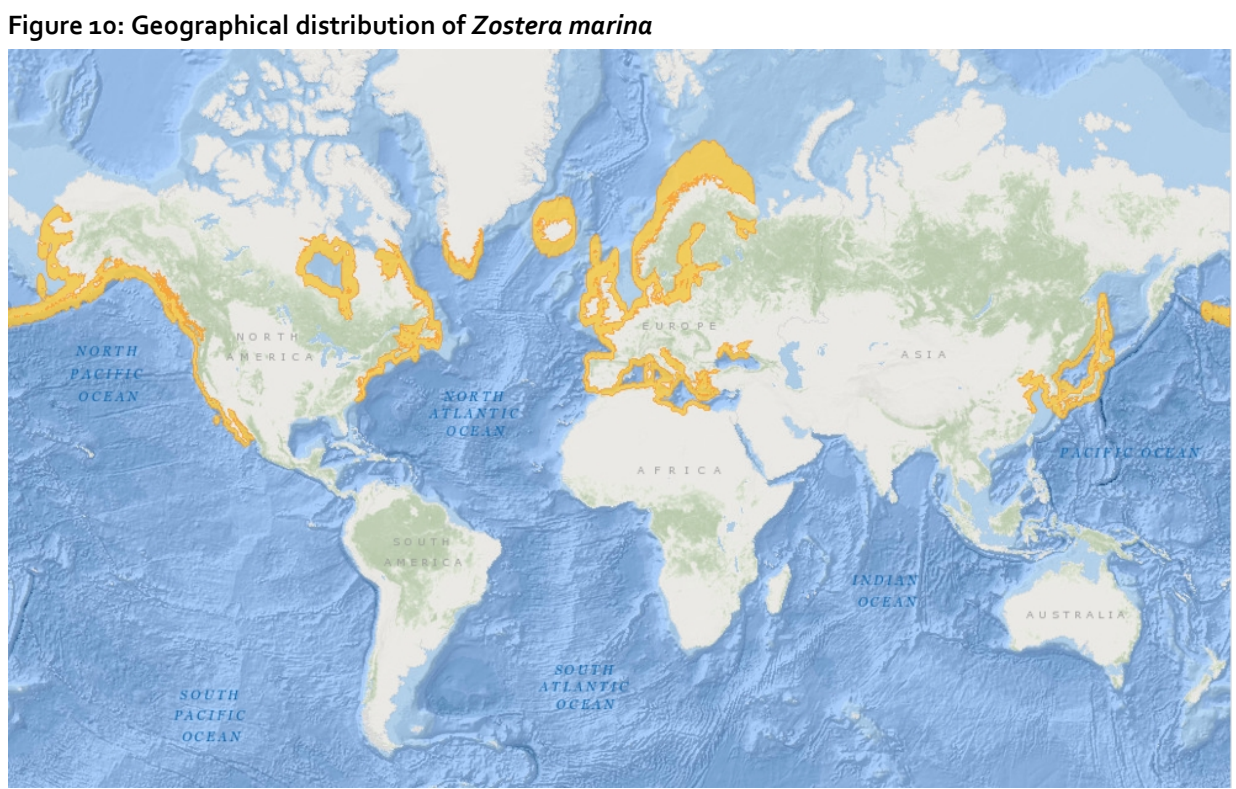

Source: IUCN (www.iucnredlist.org).

Eelgrass is the most studied seagrass species and this has driven an increased awareness of important ecosystem services provided by the eelgrass biotope. Scientific knowledge of the eelgrass biotope is based on many scientific publications; for instance 
Boström et al. (2003, 2014), Fredriksen et al. (2003, 2004, 2005, 2010), Green and Short (2003), and Hily et al. (2003). Especially Boström et al. (2014), which is based on workshops and expert meetings arranged by the Nordic Seagrass Network (a researcher network funded by NordForsk, project no. 926o), provides up to date knowledge on distribution, structure and function of eelgrass in the Nordic countries.

Eelgrass, along with other seagrasses, commonly grows in shallow bays and is therefore specially threatened by human activities like constructions in the coastal zone and pollution. Worldwide seagrass abundance has declined over the past decades (Orth et al. 2006, Waycott et al. 2009).

\section{Box 4: Eelgrass Zostera marina}

Eelgrass is a flowering plant with $20-150 \mathrm{~cm}$ long and 2-10 $\mathrm{mm}$ wide green leaves growing 3 to 7 leaves together in each shoot. Eelgrass may grow scattered or in dense meadows from the intertidal to approximately $10 \mathrm{~m}$ depth, depending on light conditions. The root system (rhizomes) is long, but grows shallow in the sediment. Flowers are small and greenish and male and female flowers are found on the same individual on long thin flowering shoots (Dawes 1998). 
Figure 11: Eelgrass meadow with flowering shoots

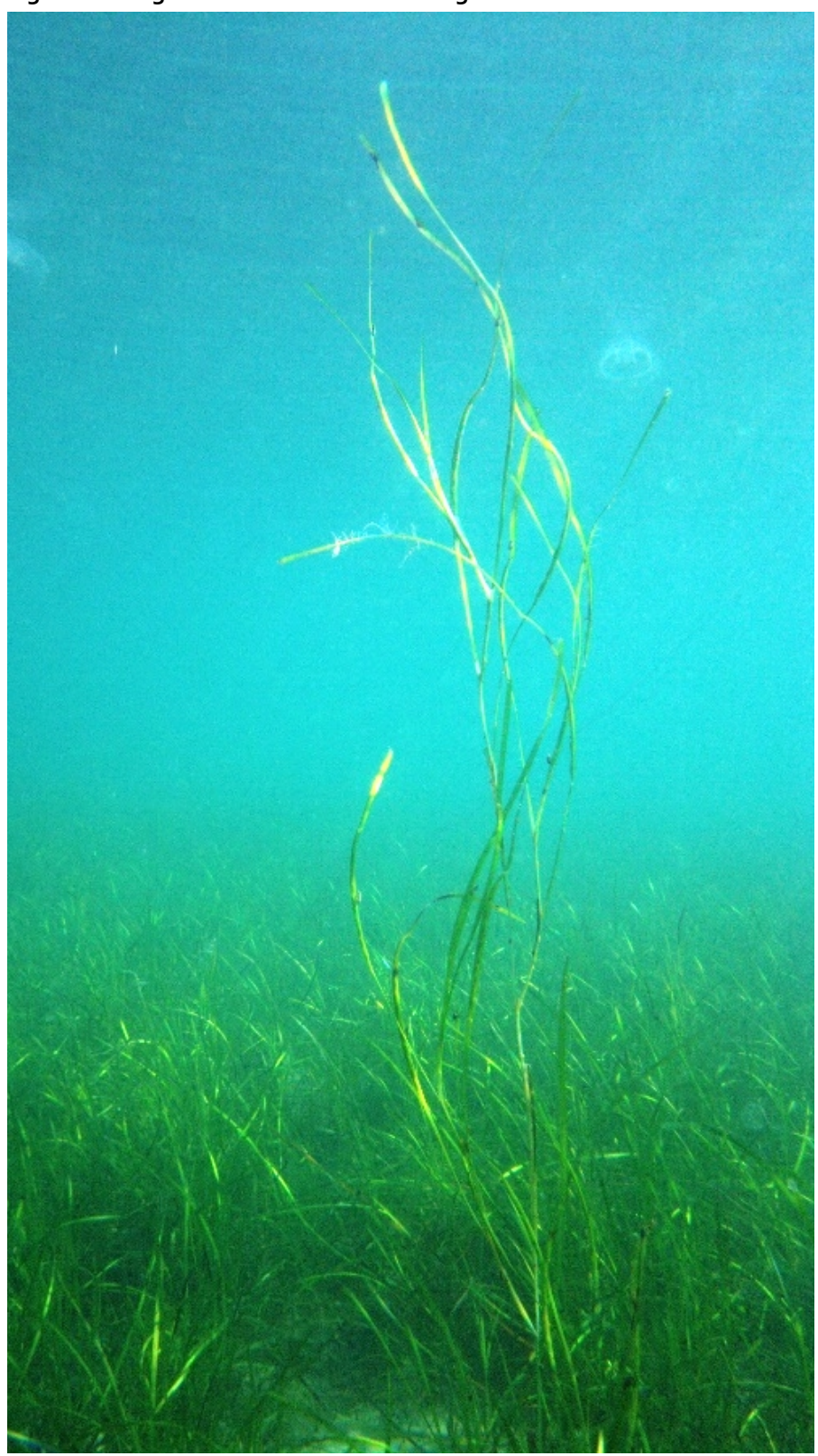

Source: (Photo:) Frithjof Moy. 
Eelgrass has a wide tolerance to the environment. It grows in salinity of 5-35 and the substratum may vary from clean sand to mud. Eelgrass is found in shallow coastal areas of low to moderate wave exposure. Optimum temperature range appears to be between 5 and $30^{\circ} \mathrm{C}$ (Marsh et al. 1986). Zostera marina requires high light levels, and it seldom occurs deeper than $5 \mathrm{~m}$ deep, however some exceptions have been found down to $10-12 \mathrm{~m}$ in clear Atlantic waters. In brackish waters along the Atlantic coast, Zostera marina behaves as an annual plant, shedding its leaves in winter (Jacobs 1982).

\subsection{Threats and challenges}

Threats to eelgrass are to a large extent driven by human-mediated factors such as eutrophication, habitat destruction and overfishing. But also factors such as disease (Labyrinthula sp., Bockelmann et al. 2011) and climate change may affect the eelgrass abundance.

A global study by Waycott et al. (2009) states that accelerating loss of seagrasses across the globe is a major threat to coastal ecosystems, by loss of ecosystem services. A global assessment of 215 studies showed that seagrasses world-wide has been disappearing at a rate of $110 \mathrm{~km}^{2}$ per year since 1980, and the rates of decline have been increasing. Boström et al. (2014) gives an overview of the status within the Nordic countries. Largescale losses have been recorded in Denmark since the 1900's; case studies in west Sweden since the mid-1980's and in Poland point to local losses of 60 to $100 \%$ (Baden et al. 2003, Boström et al. 2003). Baden et al. (2003) found that the areal extension of eelgrass had decreased $58 \%$ along the Swedish Skagerrak coast in only $10-15$ years.

Eutrophication and decreased water quality may explain the decline, as eelgrass meadows are to a large extent governed by light (Dennison 1987), nutrients (Duarte 1995, Krause-Jensen et al. 2008, Orth et al. 2010) and by salinity under brackish conditions (Baden et al. 2010).

Human activities like dredging, boat propellers, anchoring and construction in the coastal zone cause direct damage to the eelgrass meadows or the habitat.

Overfishing may cause trophic cascades causing increased growth of filamentous algae that compete for light and nutrients with the eelgrass meadow (Moksnes et al. 2008, Eriksson et al. 2009), or induce a regime shift where the eelgrass disappear. Overfishing is a world-wide problem and is especially prominent in combination with eutrophication and climate change (Jackson 2008).

Climate change induced factors such as heat waves, increased run-off from land, increased turbidity, and changed salinity may affect the abundance and distribution of eelgrass negatively (Short and Neckles 1999, Orth et al. 2006). 
The challenge is to stop or reduce these factors threatening the eelgrass ecosystem. It is much easier to protect than to restore, and seagrasses are among the most expensive ecosystems to restore (Bayraktarov et al. 2016). Methods to reduce pollution, overfishing or climate change will not be dealt with here.

Eriander et al. (2016) assessed four methods of eelgrass restoration on the northwestern coast of Sweden and found that planting of single shoots without sediment was recommended for shallow habitats and that use of seeds were recommended for deeper habitats. Transplanting cores with eelgrass and sediments has been the most commonly used method for eelgrass restoration (Fonseca 2011) and has been considered less stressful for the plants than the single shoot method in which single shoots are planted without sediment. However, the core method is more labor intensive and costlier (Fonseca et al. 1998). Transplanting shoots with ripe seeds is a less labor intensive method, but the fate is more uncertain. Bioturbation by lugworms (Valdemarsen et al. 2011), predation from crabs (Infantes 2016) and transport of seeds by currents, cause loss of seeds and reduced restoration success.

Van Katwijk et al. (2010) found in seeding experiments in the Wadden Sea a maximum germination of $45 \%$ and maximum seedling survival of $55 \%$. A literature review in Orth et al. (2006) reports a maximum germination of $90 \%$, and maximum seedling survival of $40 \%$ based on worldwide Zostera populations. However, Infantes et al. (2016) reported on average $98 \%$ seed loss in a restoration experiment at the Swedish west coast. Restoration is challenging and suitability of methods in a given area needs to be addressed before large-scale restoration is implemented.

\subsection{Supporting services}

\subsubsection{Habitat and biodiversity}

Eelgrass meadows provide habitat for a wide range of species due to the three dimensional structure it creates on shallow soft bottoms. Hemminga and Duarte (2000) found 10-fold as many animals within an eelgrass meadow as outside the meadow. Eelgrass provides suitable substratum for a rich epifauna and flora (Baden and Boström 2001, Fredriksen et al. 2005, Jephson et al. 2008, Gustafsson and Boström 2009) which in turn support diverse fish communities finding shelter and food within the eelgrass meadows (Pihl et al. 2006).

Boström et al. (2014) found that a number of small crustacean mezograzers, mainly Gammarids and Idoteids varied highly (from 300 to $>16,000$ individuals per $\mathrm{m}^{2}$ ) within Nordic regions (Atlantic, Skagerrak, Kattegat/Belt Sea, southern Baltic, Baltic proper, 
and north-east Baltic). Common gastropods include Rissoa membranacea, Lacuna vincta, Littorina littorea, Theodoxus fluviatilis, and Hydrobia ulvae. Common fish species in the eelgrass meadows (Figure 12) include pipefish, wrasse (mainly goldsinny wrasse Ctenolabrus rupestris), gobiids (black goby Gobius niger, two-spotted goby Gobiusculus flavescens and three-spined stickleback Gasterosteus aculeatus, but also including Atlantic cod Gadus morhua, whiting Merlangius merlangus, polloch Pollachius virens, herring Clupea harengus, eel Anguilla anguilla, sea trout Salmo trutta and different species of flounders (Rönnbäck et al. 2007, Stål et al. 2008).

Figure 12: Fish fauna caught in beach seine in Skagerrak

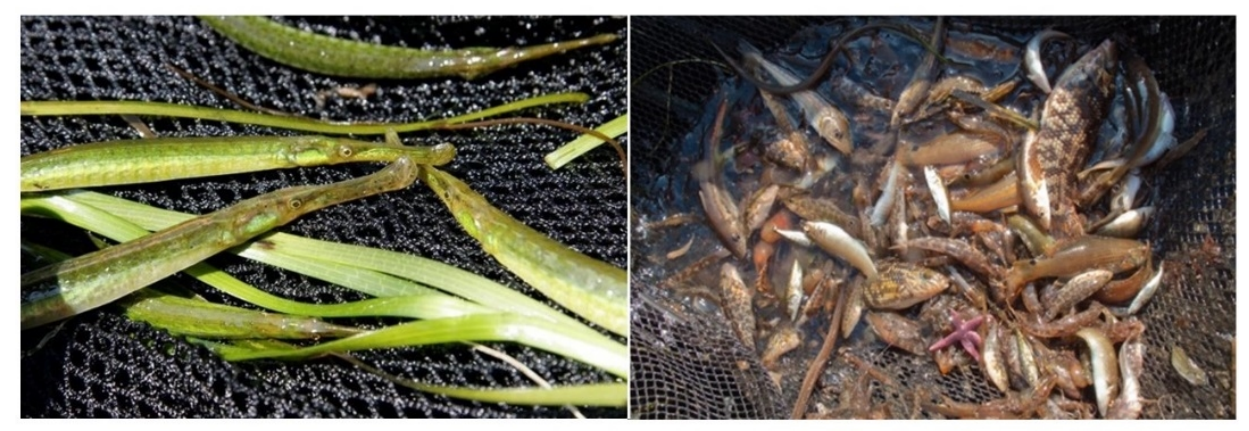

Source: Photo: Øystein Paulsen.

In addition, the complex root systems facilitate the existence of diverse infaunal communities belonging to the faunal groups Annelida, Nemertea, Echinodermata, Crustacea, and Mollusca (Fredriksen et al. 2010). It is uncertain if eelgrass beds facilitate more infaunal species, but clearly it facilitates higher abundance of species (Boström and Bonsdorff 1997, 2000, Fredriksen et al. 2010).

Within the Nordic countries, the shoot densities and shoot biomass may vary significantly from meadow to meadow $\left(72-3,948\right.$ shoots per $\mathrm{m}^{2}, 0.024-0.834 \mathrm{~g}$ dry weight per shoot, 30-120 g DW per $\mathrm{m}^{2}$, Boström et al. 2014) and Boström et al. (2014) found significant differences in biomass between Nordic regions, with the highest eelgrass biomasses found in the Kattegat/Belt Sea. This high variation obviously affects the ecosystem services provided by each single eelgrass meadow. 


\subsubsection{Primary production, food webs and nutrient cycling}

Seagrass meadows are considered the most productive of shallow, sedimentary environments (Figure 13). Eelgrass has a high production building up both above- and belowground biomass during growth season, i.e. during summer. Eelgrass has a continuous production of new leaves every month in each shoot and a continuous production of new shoots with $3-7$ leaves reflecting the environmental conditions (e.g. light, nutrients, sediment quality, and pollution). Hansen et al. (2000) found a 5.5-fold increase in the eelgrass leaf biomass from April to August, and Jacobs (1979) estimated an annual net production of $1.6 \mathrm{~kg}$ dry weight per $\mathrm{m}^{2}$. Pedersen and Borum (1992) found that rel-

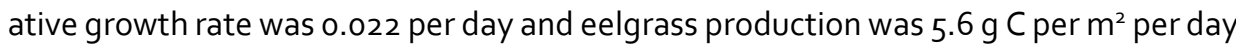
with maximum rates of production during summer. This is in compliance with a compilation by Duarte and Chiscano (1999) of eelgrass studies worldwide. Aboveground production was $5.2 \mathrm{~g} \mathrm{C}$ per $\mathrm{m}^{2}$ per day and belowground production $1.7 \mathrm{~g} \mathrm{C}$ based on 29 and 18 studies, respectively.

Not many species, other than a few birds such as mute swan, ducks, and geese, utilize this high primary production directly (Nienhuis and Groenendijk 1986). In addition, snails and sea urchins feed directly in the eelgrass.

Based on stable carbon isotope and fatty acid analyses the food web in the eelgrass meadow is mainly based on epiphytes and sand microflora (Jaschinski et al. 2008). The contribution from eelgrass (Jaschinski et al. 2008) was found to be negligible, indicating that habitat is the main importance of eelgrass for secondary production. Gastropods and amphipods feed on the epiphytes growing on the leaves, and by that cleaning the leaves. The snail Lacuna vincta contained small amounts of eelgrass fatty acid indicating that it also may damage the leaves while eating the epiphytes (Jaschinski et al. 2008). Fredriksen et al. (2004) found that another gastropod Rissoa membranacea was probably able to deteriorate an eelgrass bed. After a year the meadow had recovered due to undamaged belowground root system.

Plummer et al. (2013) found that increases in nearshore habitats such as eelgrass beds lead to greater biomass of many invertebrate, fish, and bird species that depend on those habitats for refuge or food. They also illustrated by applying food web modeling, how marginal changes in foundational nearshore species such as eelgrass give rise to changes in ecosystem service values. 


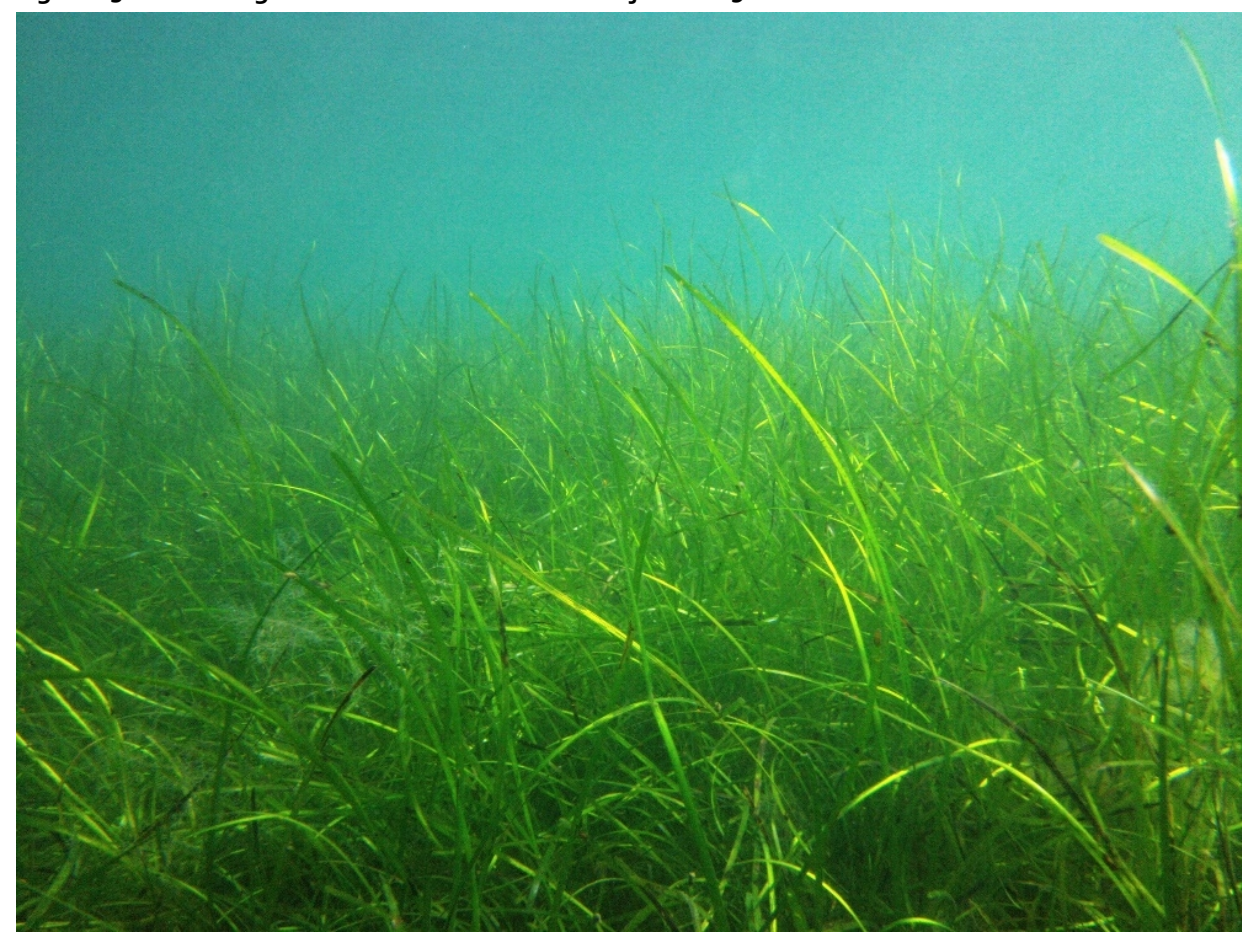

Source: Photo: Frithjof Moy.

There are many attempts to calculate monetary value of ecological functions. Waycott et al. (2009) estimated that seagrass meadows worldwide cycle nutrients equal to USD 1.9 trillion per year. Submersed rooted macrophytes, like eelgrass, link the nutrients in sediments with the overlying water. Flindt et al. (1999) compared nutrient dynamic in bare bottom sediment with eelgrass covered sediment, and the most pronounced difference between the two systems were the nitrate profiles. In the bare bottom system, the constant level of nitrate down to $10 \mathrm{~mm}$ depth indicates the depth of the oxic zone, whereas within the eelgrass bed, the penetration in the sediment reached down to $72 \mathrm{~mm}$ depth. Also the pool of nitrate in the vegetated sediment was four to eight times higher than in the bare bottom system. In addition, the ammonia profiles showed much faster depletion of ammonia in the water column in the vegetated system than in the bare sediment system. Also high ammonia pool in the sediment of the bare bottom system, most likely reflects the oxygen limitation of the nitrification. With phosphorus, the bare bottom sediment showed values of $100-200 \mathrm{mg} \mathrm{PO}_{4}{ }^{3-} \mathrm{P}$ per $\mathrm{m}^{2}$ higher than the eelgrass system. 


\subsubsection{Biological control}

By high primary production, nutrient cycling and providing a three dimensional structure, eelgrass in many ways provide biological control. Orth et al. (1984) reviewed studies relating predator-prey relationships to different features of the seagrass system and summarized that the abundance of many species, both epifauna and infauna, is positively correlated with two distinct aspects of eelgrass morphology: 1 ) the root-rhizome mat, and 2) the plant canopy. Harrison (1982) showed that growth of a microalgae (Platymonas sp.) and many marine bacteria were inhibited by water-soluble extracts of eelgrass leaves, and by that altering the activity of microorganisms directly and indirectly affecting amphipod grazers.

Allen and Williams (2003) found that eelgrass controlled the growth and reproduction of an invasive mussel through food limitation. On the other hand, Boström et al. (2014) summarized studies in Skagerrak and the southern Baltic showing that loss of eelgrass and reduction of crustacean mesograzer were linked and partly explained by the overfishing of cod and subsequent dominance of intermediate fish predators and macroalgae (Baden et al. 2003, 2010, Bobsien 2006, Jephson et al. 2008, Moksnes et al. 2008).

\subsection{Provisioning services}

\subsubsection{Resource utilization and bioprospecting}

Eelgrass is not used as food source due to its high amount of cellulose, which most animals including humans, cannot digest. But eelgrass eco-systems have a wide variety of ecological functions in which living tissues and detritus may be a food source for many marine animals.

Today, harvest of eelgrass is of no value. However it has for centuries, perhaps back to the age of the Vikings, been used as building material for roof covering (see Figure 15), filling and isolation material, for cattle feed and soil amendment. Traditionally, eelgrass flushed on shore was collected, rinsed and dried before use and even exported (Jensen 2012).

No medicament is known from eelgrass but since intact leaves decay very slowly and are widely selected and used as roof materials, it may be a good resource for screening natural antibiotics and some studies have shown effective compounds with nematicidal and antibacterial activity from eelgrass extracts (Harrison 1982, Choi et al. 2009, Liv et al. 2010, Newmaster et al. 2011, Wang et al. 2012). 
Parallel to medical potential, marine macrophytes are rich in a diversified plethora of lipids (Maciel et al. 2016) and the great potential of these lipids as bioactive compounds has been demonstrated, particularly in what concerns their putative use as antiinflammatory, anti-proliferative, anti-microbial, and anti-oxidative. The eelgrass is rich in 18 fatty acids: $\alpha$-linolenic acid (omega- 3, ALA), linoleic acid (omega- 6, LA) and stearic acid (SLA). Omega- 3 fatty acids are important for normal metabolism. Omega- 6 is a group of pro-inflammatory and anti-inflammatory fatty acids, and stearic acid is mainly used in the production of detergents, soaps, and cosmetics.

\subsubsection{Commercial and subsistence fishery}

No commercial or subsistence fishery today is conducted in eelgrass meadows, but eelgrass meadows are key habitats for o-group cod (Wennhage and Pihl 2002) and by that, may be essential for commercial fisheries. Eel has been an economically valuable species and highly dependent on eelgrass beds where the fishery traditionally was performed with fykes, pound net or other traps, but its stocks are dwindling and the market has closed (Cole and Moksnes 2016).

Figure 14: Juvenile cod captured in an eelgrass meadow with a beach seine

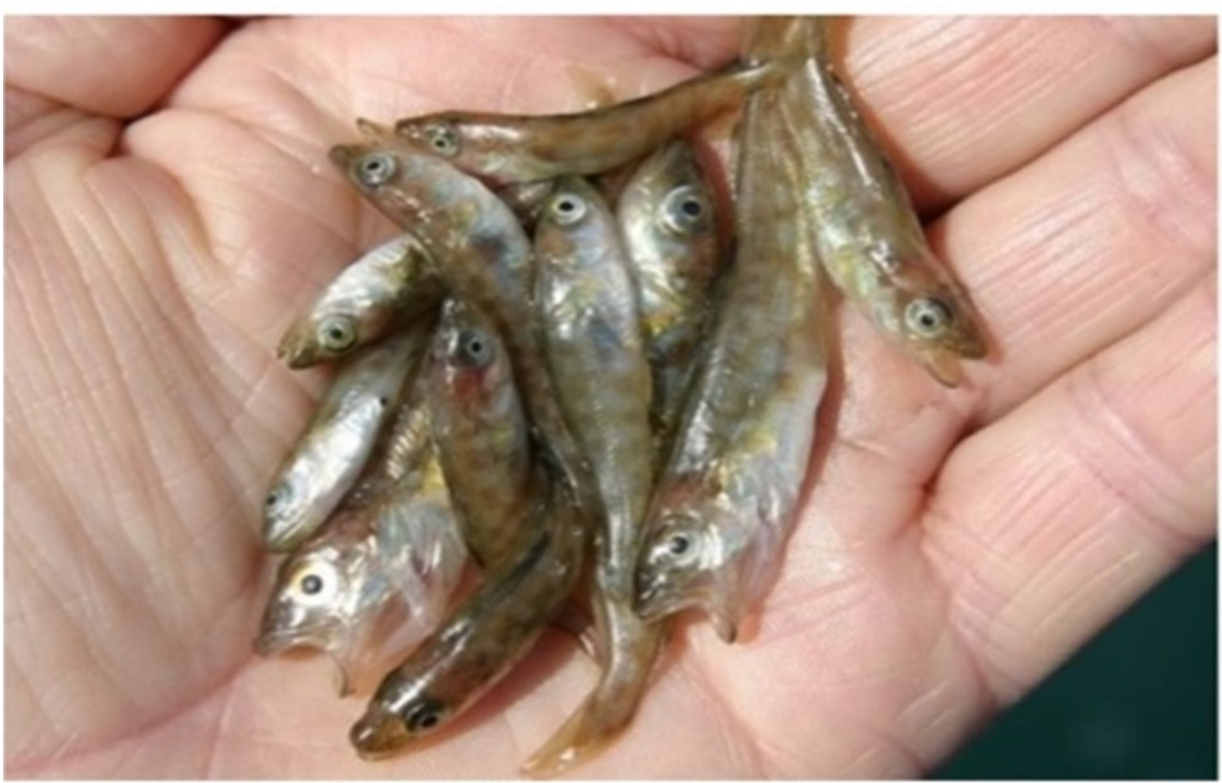

Source: Photo: Ø.Paulsen. 


\subsection{Regulating services}

\subsubsection{Maintenance of resilience}

Manage for resilience is done by increasing buffering capacity (Gunderson 2000) and it is better to protect the eelgrass, than to restore due to many negative feedback mechanisms that make restoration difficult, expensive and by no means guaranteed to succeed. Feedback mechanisms include sediment resuspension that maintains the turbid state (Duarte 1995, Munkes 2005, Carstensen et al. 2013), occurrences of anoxia (Pulido and Borum 2010), unsuitable sediments (Krause-Jensen et al. 2011), and physical disturbance by drifting macroalgae and seed burial by polychaetas that also may hinder eelgrass recolonization (Valdemarsen et al. 2010, 2011).

Moreover, lack of apex predators and thus top-down control on epiphytes and filamentous macroalgae could be an additional burden on eelgrass meadows, as demonstrated along the Swedish west coast (Moksnes et al. 2008). In the Nordic countries eelgrass loss related to food web changes (overfishing and reduction of mesograzers) and subsequent macroalgal blooms have shown a region-specific pattern, with both overfishing and nutrient pollution as equally important stressors in Skagerrak, while overfishing appears to be of minor importance for the formation of macroalgal stress at both ends of the gradient, i.e. Atlantic Norway and the northern Baltic Sea (Moksnes et al. 2008, Baden et al. 2010, Boström et al. 2014).

Manage for resilience also includes genetic diversity, as high genotypic diversity may provide resilience in the face of climatic extremes (Ehlers et al. 2008). There is also another lesson to be learned: small patches can exist on the edge of collapse for many years before they suddenly disappear due to reasons (eutrophication) many years before (van Katwijk et al. 2010). For conservation it is important to recognize that eutrophication may cause seagrass population to collapse and its eventual extinction, even years after nutrient levels are stabilized, or even decreased.

\subsubsection{Carbon storage and sequestration}

Seagrass meadows have high ability to produce, trap and store organic compounds, making them important sinks for carbon. But as there are no known studies of carbon sequestration rates or the carbon content of live eelgrass or eelgrass sediment in Nordic countries, we rely on estimates from other areas (Cole and Moksnes 2016).

Duarte et al. (2010) has calculated the global net community production of seagrass meadows considering a low global seagrass area of $300,000 \mathrm{~km}^{2}$ and a high estimate of $600,000 \mathrm{~km}^{2}$ to respectively $20-50 \mathrm{Tg} C$ per year and 40-100 Tg C per year. A global loss 
of $29 \%$ of the seagrass area represents therefore a major loss of natural carbon sinks in the biosphere (Duarte et al. 2010).

By using the best available estimates of carbon burial rates in seagrass meadows, Kennedy et al. (2010) calculated that between 41 and $66 \mathrm{~g} \mathrm{C} \mathrm{per} \mathrm{m}^{2}$ per year originates from seagrass production. In addition, they estimated that total carbon burial in seagrass meadows was 48-112 Tg per year when including global average for allochthonous carbon trapped in seagrass meadows. This shows that seagrass meadows are natural hot spots for carbon sequestration.

\subsubsection{Eutrophication mitigation}

Due to nutrient cycling and storage, eelgrass by enhancing denitrification, minimizes the efflux of ammonia and phosphate effluxes to the water column, cleans the water and mitigates eutrophication, and possibly reduces growth of opportunistic macroalgae and phytoplankton.

In a Swedish valuation scenario, Cole and Moksnes (2016) calculated that the value of nitrogen storage derived from a hectare of eelgrass to be approximately SEK 5,600 (USD 680) annually, based on a nominal removal of $466 \mathrm{~kg}$ of nitrogen by the eelgrass and the cost to the society of removing an equivalent amount.

\subsubsection{Water purification, filtering and removing of hazardous substances}

Eelgrass absorbs nutrients from the water column for their growth and reproduction (see Chapter 4.3.2 for references). Uptake of nutrients by eelgrass and other submerged aquatic vegetation (SAVs) can help to prevent nuisance algae blooms and can improve water clarity. The presence of eelgrass therefore helps mitigate the impact of excessive nutrient input to the estuary from human activities.

Eelgrass may play an important role in biogeochemical cycling of heavy metals and several works have studied uptake and translocation of heavy metals, among Lyngby and Brix (1982, 1989) and Ferrat et al. (2012).

The plant tissue of eelgrass significantly accumulates high levels of heavy metals when growing on heavy metal-impacted sites. In Puget Sound (USA) eelgrass above/below ground biomass is estimated to $10 / 5$ million $\mathrm{kg}$, respectively. Total accumulation of metals was estimated to be $300 / 30 \mathrm{~kg}$ copper, $2 / 280 \mathrm{~kg}$ lead, and $800 / 0.4 \mathrm{~kg}$ zinc respectively in above/below ground biomass. Three to 10 times calculated aboveground value may be cycled or stored in one year due to growth and shed of old leaves during the growth season. 


\subsubsection{Coastal defense}

The eelgrass leaf canopy and the network of rhizomes and roots fix and stabilize the sediment and reduce the resuspension of the sediment by currents and waves (Borum et al. 2004). Sediments vegetated by eelgrass and other seagrasses are less likely to be mobilized by waves and currents, so seagrasses reduce the erosion of the coastline much in the same way as beachgrass stop drift of sand dunes. The restoration of sea grass meadows has also been pointed out as one potential tool for preventing deterioration of the service (Naturvårdsverket 2008). Accumulation of eelgrass leaves on the beaches represents another way in protection of the shoreline (Borum et al. 2004).

However, there are still many uncertainties in the characterization and quantification of the protection offered by seagrasses, which demands greater attention from science if it is to be applied as a real adaptation option (Ondiviela et al. 2014).

\subsection{Cultural services}

\subsubsection{Recreational fishing}

Ecosystem services provided by the eelgrass biotope, like high biodiversity, shelter and feeding ground for many species implies that the eelgrass meadows are popular fishing sites for recreational fishing (Jackson et al. 2015). This is confirmed through numerous fishing field guides, especially for sea trout, but also for many other fish species.

\subsubsection{Tourism}

Eelgrass meadows play a role in tourism by cleaning the water (eutrophication mitigation and coastal defense) and boosting the biodiversity on sandy beaches and create good sites for bathing and recreational fishing.

Beaumont et al. (2008) state that a significant component of leisure and recreation in the UK, like bird watching, depend upon coastal marine biodiversity. With a loss of marine biodiversity and decline in eelgrass beds, the value of this sector will decrease. 
Little information is currently available on the cultural benefits of marine biodiversity, although this is believed to be indicative of a lack of documented research, as opposed to a lack of value (Beaumont et al. 2008). Especially few data is obtained concerning eelgrass, except for a report by Jensen (2012). In 2012 the "Tang-Triumviratet" at Læsø Island got the prestige Europa Nostra prize for "Tangbanken" and the rescue plan to preserve the last eelgrass roofed buildings (Figure 15). By that, the project brings history and use of eelgrass to life.

Figure 15: Eelgrass used to cover the roof of an old house at Læsø Island in Denmark

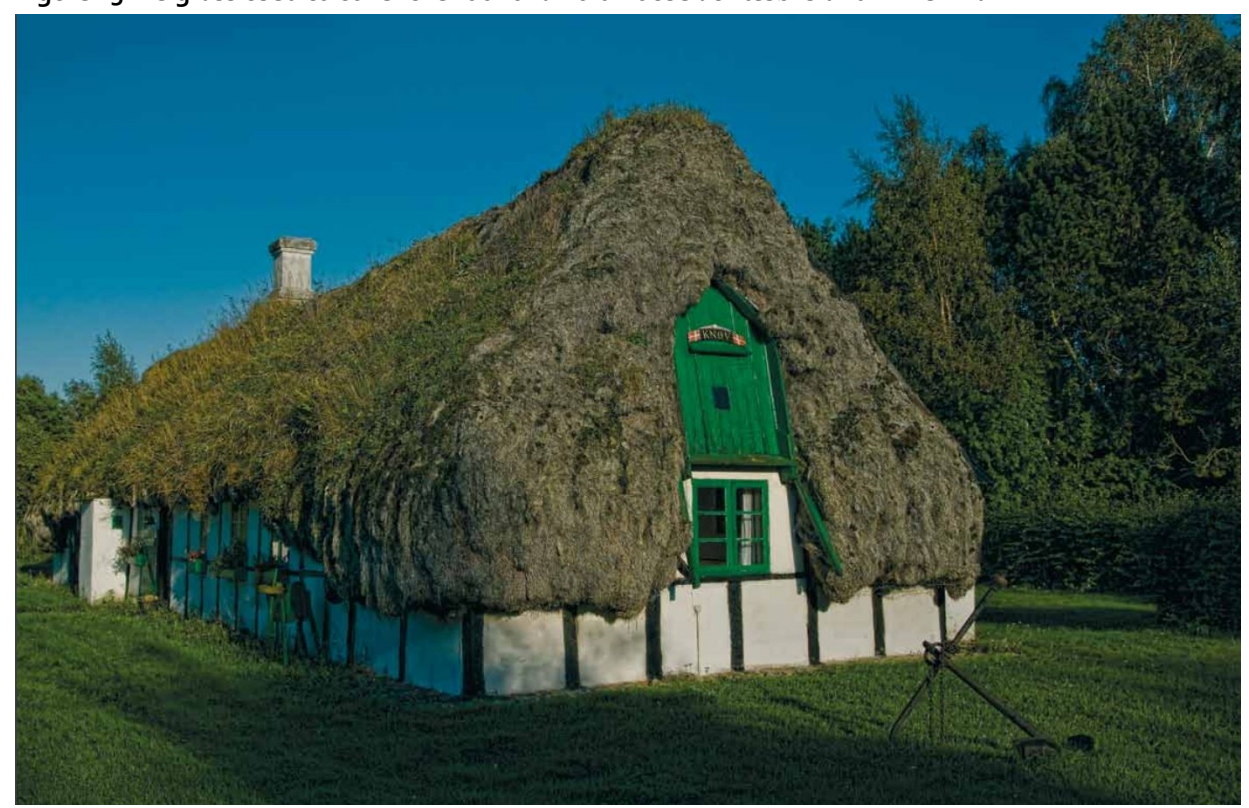

Source: Photo: Peter Wath. 


\section{Ecosystem services of blue mussel beds}

\subsection{Distribution and physical requirements}

Blue mussels are bivalves at the size of up to $10 \mathrm{~cm}$ in length. Wild blue mussels (Mytilus edulis) can be found from the Bay of Biscay in the south, to the Barents Sea in the north, including the coasts of Iceland and at the western Atlantic (Figure 16). These shells are especially common in the Nordic region and are one of our most common marine species. In Skagerrak and Kattegat there are numerous other species of filter feeders, but in the Baltic Sea the blue mussel (Mytilus trossulus) is the only species with this function (Naturvårdsverket 2008). Here, it occurs as far north as Kvarken, and is the most common species in the Baltic Sea and constitutes as much as $70 \%$ of the coastal biomass (Naturvårdsverket 2008).

Figure 16: Global distribution of Mytilus spp

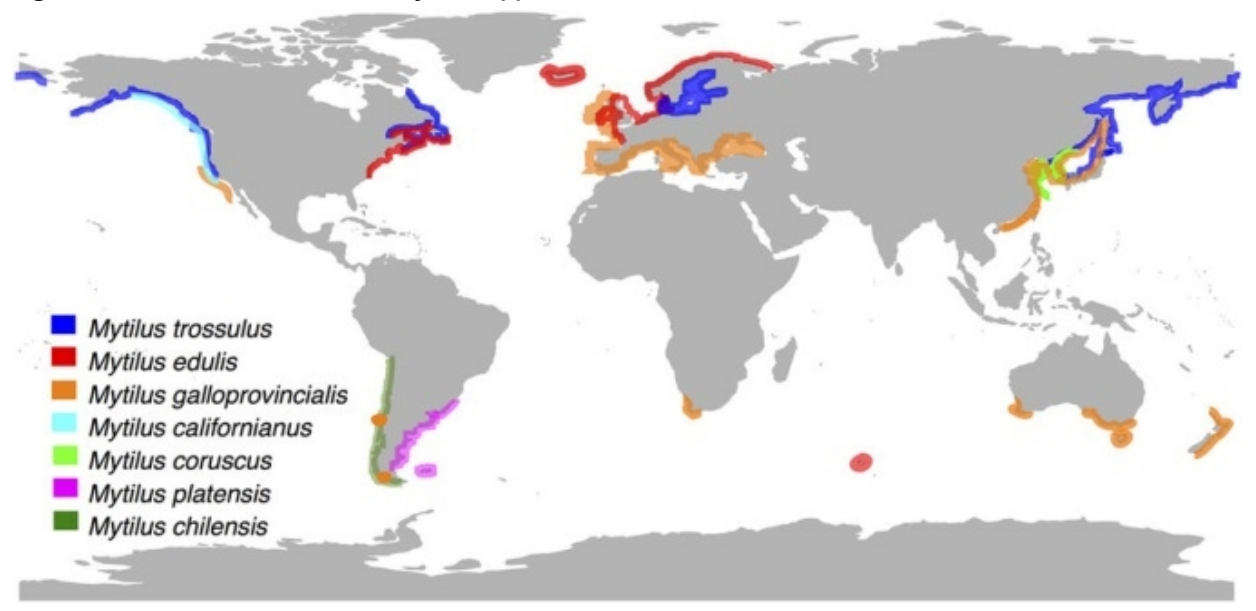

Source: Gaitán-Espitia et al. 2016. 
Blue mussels live in the intertidal zone in clusters attached to rocks and other hard substrates by use of their strong byssal threads. As much as 12,000 individuals can be found in one square meter. These invertebrates are very well adapted to the harsh environment in the intertidal zone, which can be extremely hot during summer and biting cold during winter. The shells can thus withstand a life under and above the sea surface (Figure 17), and in both fresh and salt water, but the optimal is a steady, high, salinity and temperatures around $16-18^{\circ} \mathrm{C}$ (Bergström et al. 2015). The size and growth of the mussels are highly variable and depends on a complex pattern of interactions between the bivalve and a diverse range of environmental factors and functions (see Suchanek 1985 for a review).

Figure 17: Clusters of blue mussels Mytilus edulis above the sea surface at low tide

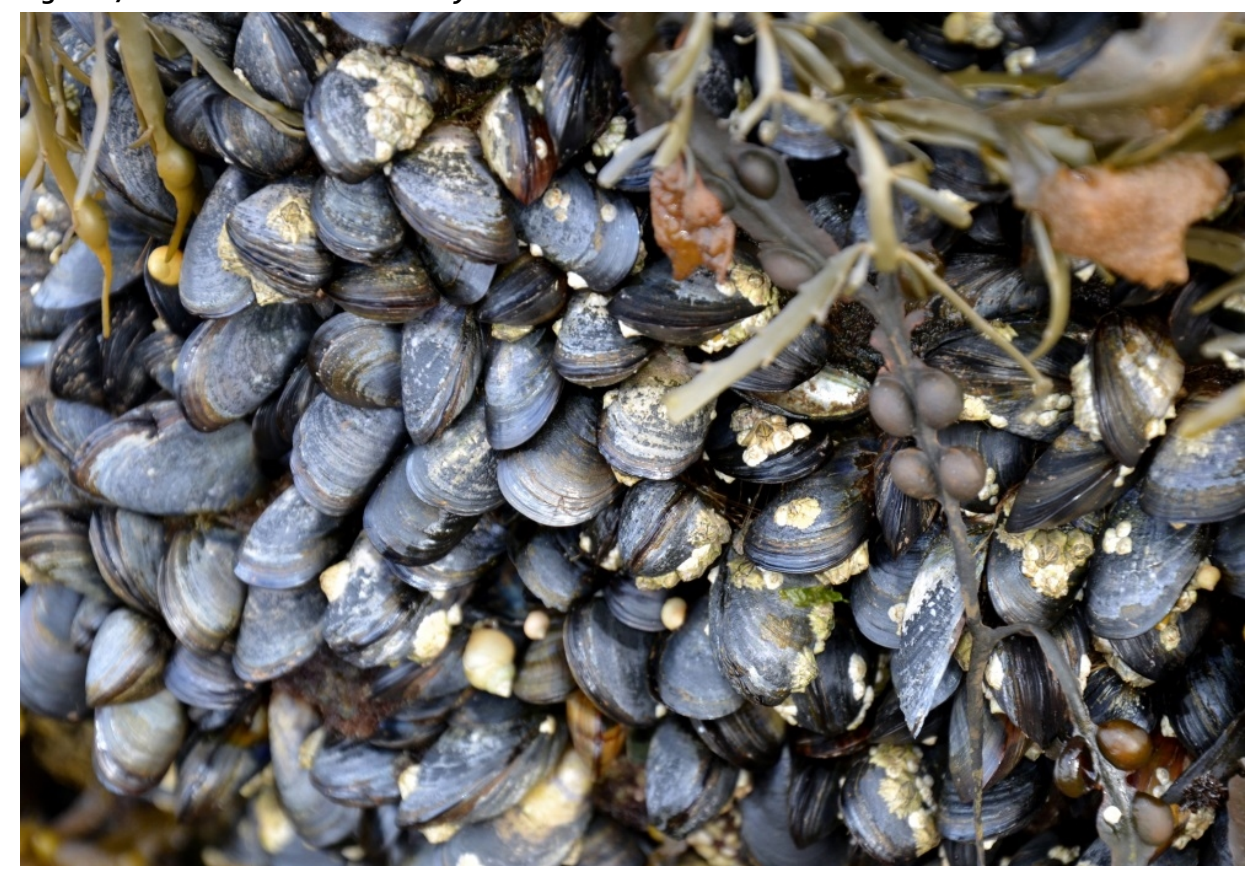

Sourc: Photo: Hans Hillewaert.

Blue mussels are preyed from above from seabirds, like the eider duck (Somateria mollissima), but also from below. For instance by starfish which can suck hole in the shell and slowly eat the mussel from its inside. This explains why mussels are squeezed together in a thin belt within the tidal zone. In the Baltic Sea, where there is no tidal zone and starfish and other marine predators are mainly absent due to the low salinity, blue mussels are most abundant in the depth interval from 3-15 $\mathrm{m}$ (e.g. Westerbom et 
al. 2002, Vuorinen et al. 2002, Lappalainen et al. 2005), but can occur considerably deeper if suitable hard substrate is present (Kautsky 1982, Vuorinen et al. 2002). Apart from sea birds such as eiders, also flounder (Platichtys flesus) and roach (Rutilus rutilus) feed extensively on blue mussels (Lappalainen et al. 2005, Westerbom et al. 2002).

Mussels are filter feeders and feed on phytoplankton (algae), zooplankton, bacteria and remains of dead plants and animals floating in the water. One single shell can filter many liters of sea water each hour.

\subsection{Threats and challenges}

Historically, there have been few threats to blue mussels, being tolerant competitors against most species. However, the recent introduction of the Pacific oyster is about to cause a major threat to blue mussels banks for instance in the Wadden Sea, and all along the Skagerrak coast and most likely also further north, within the next few years (Rinde et al. 2016). The Pacific oyster can form reefs with more than 1,000 individuals per square meter (Bodvin et al. 2014) and there are signs that this species are even more tolerant to freezing than our own mollusks, including the blue mussel. Analyses conducted by NIVA and IMR show that around $30 \%$ of previously recorded blue mussels are in areas that also have high probability of Pacific oysters occurrence (Bodvin et al. 2014). If mussel banks are overgrown by Pacific oysters, the blue mussel habitats, including many of their inherent species, will be lost. However, when it comes to services of blue mussels, many of these are also provided by oysters, which is also a filter feeder. One important difference is the cultural services related to swimming and beach life, where blue mussels have much larger values, since oysters can be extremely unpleasant to walk on and even dangerous due to the sharp edges of the shells.

As demonstrated for other marine invertebrates that create their shell from calcium carbonate $\left(\mathrm{CaCO}_{3}\right)$, shellfish are highly sensitive to acidification. Studies have shown that increasing acidification leads to reduced growth rate and reduced size of adult farmed animals (Gazeau et al. 2007). Also, low pH may disrupt fertilization and larval development of blue mussels (Talmage and Gobler 2009). 


\subsection{Supporting services}

\subsubsection{Habitat and biodiversity}

The blue mussel is one of our most common marine species and an important habitat builder. Although not of the same magnitude as the kelp (Chapter 3 ) and for instance charales (Chapter 6 ), blue mussels increase biodiversity by providing substrate for algae and refuge for small animals (Pettersson 2006). Assemblages of blue mussels change the local environment and create unique habitats. The study of Norling (2009) investigated the role of blue mussels in supporting highly diverse associated communities. The red algae species' richness was shown to correlate with mussel patch size and biomass. Structural properties of blue mussels provide substrate for attachment, shelter and increased habitat complexity, which was found to enhance species diversity, especially in soft sediment systems.

Further, the mussels' filtration of plankton and particulate organic material from the pelagic system improves the light climate for benthic algae and increase production of other benthic organisms (Norling 2009). Changing the system from a turbid, plankton-dominated one to a highly diverse and productive benthic system implies that blue mussels are important for sustaining biodiversity and ecosystem functioning of subtidal habitats, especially in the Baltic coastal zone.

There are also a number of secondary effects of mussel farming (Chapter 5.4.1) that are expected to benefit the biodiversity around the mussel plants. The plants are in themselves physical structures in the water column, which can act as a substrate for epibenthic organisms and hiding for fish in a well-oxygenated environment. Such artificial reefs, can lead to a local increase in biodiversity and the facilitation of path-ways in the form of "stepping stones" (e.g. Petersen and Malm 2006).

\subsubsection{Primary production, food webs and nutrient cycling}

Worldwide, bivalves constitute a functionally important component of benthic assemblages (Gutierrez et al. 2003, Suchanek 1985). Constituting $70 \%$ of the coastal biomass in the Baltic, blue mussels contribute greatly to ecosystem structure and function (Kautsky 1982). The filter feeding bivalves function as ecosystem engineers providing, among other, structural complexity and enhanced habitats by connecting the bottom substrate with the pelagic environment by filtering their food from the surrounding water (Koivisto and Westerbom 2010, Markert et al. 2010). Suspension feeding mussels have the potential to filter considerable quantities of particulate matter from the water column (Cranford et al. 2011). This filtering has the potential to remove large amounts 
of plankton and suspended particles thus affecting the plankton community (Maar et al. 2007, Newell 2004).

Also other biological activities of the mussels, such as biodeposition are affecting positively to the abundance, biomass and functioning of the associated plant and animals in an ecosystem (Norling 2009). Mussel biodeposits are rich in organic nutrients (Kaspar et al. 1985) and show relatively high decay rates compared to decomposing phytoplankton or macroalgae (Giles and Pilditch 2006). The ecological importance of biodeposit mineralization is the availability of regenerated nutrients for primary producers (Prins et al. 1998), thus the contribution of bivalves in nutrient cycling of coastal ecosystems.

Further, blue mussels are important as prey for a range of different animal groups such as echinoderms, crabs, fish and sea birds.

\subsubsection{Biological control}

As many of the other blue mussels' ecosystem services, also its influence on biological control can be attributed to their filtering abilities. By filtering phytoplankton, including toxic algae, filter feeders like blue mussels can inhibit or even prevent harmful blooms. Algal blooms make the water more turbid and reduce the amount of light to plants, algae or corals that live at the bottom, but this effect can be strongly reduced by the short- (acute) and long-time (preventive) effects of filtering blue mussels. Biological control is essential for many other ecosystem services including habitat maintenance, recreation, food provisioning and scenery. The biological control carried out by filter feeders is closely interlinked with mitigation of eutrophication as well as with the control of hazardous substances.

\subsection{Provisioning services}

\subsubsection{Resource utilization and bioprospecting}

The Nordic countries have a long tradition of exploiting the sea, and bivalves are not an exception. In food provision, it is mainly the European flat oyster (Ostrea edulis) which has played a role, whereas blue mussel, horse mussel (Modiolus modiolus) and other mussels have been important as bait for food. The mussels are a good source of iron, selenium and vitamin B12. They have small but healthy fats, with a large proportion of omega-3 fatty acids. 
Denmark has a large fishing for mussels in the Limfjord; where up to 100,000 tons are scraped up each year (Chapter 5.4.2). However, at the global level, shellfish farming is developing rapidly, with China as the leading nation. Mussel production in Europe is between 300,000 and 400,000 tons a year. In Europe, Spain has the largest production of 200000 tons. Figures from Gregersen (2007) show that about 1,300 tons were harvested in Norway along the Skagerrak coast in 2005 , and similarly between 1,000 and 1,500 tons on the Bohuslän coast in Sweden. Denmark produces some 20,000-30,000 tons of mussels each year in the Skagerrak and is a large producer of processed mussels. The Scandinavian countries are assumed to be far below production capacity, and for instance Norway are said to be able to increase to 100000 tons within a few years.

In the 80 's, many mussel farmers failed due to insufficient professional commitment, poor control of algal toxins and the lack of contact with the marked. In recent years, however, these issues have become far better and many companies have much higher professionality in their businesses today. This is not the least through the technique of so-called controlled upwelling when nutrient-rich deep-water are directed up towards the brighter part of the water column, profiting the algae and thereafter the mussels.

Mussels are farmed for various purposes (Figure 18). Mussels from the Skagerrak and Kattegat are mostly sold for consumption, but investigations are in progress to ascertain whether mussels can be used to filter out nutrients, e.g. at sewage works (Naturvårdsverket 2009). However, the sedimentation of organic material from faeces below a mussel farm will also in many cases lead to bottom water hypoxia (Stadmark and Conley 2011). 
Figure 18: Blue mussel farmed in a row of "stockings"

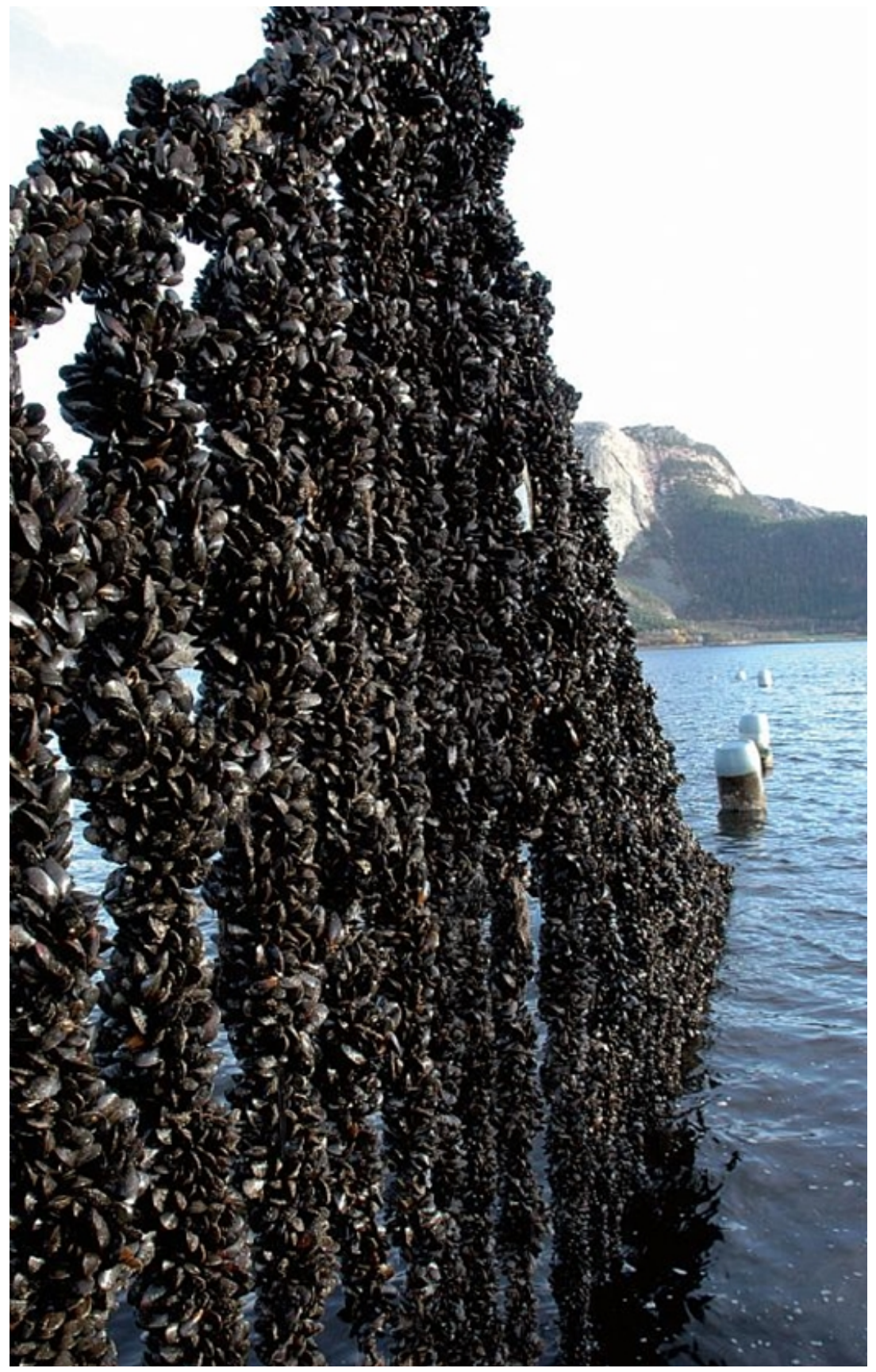

Source: Photo: John Bonardelli, IMR. 
Trials with mussel-based fodder have so far primarily been made in the poultry industry, with satisfactory results (Naturvårdsverket 2008). Thus mussels could in the future become an important source of organic fodder for the production of organic egg and chicken. Similarly, in the aquaculture industry, fodder based on mussels might in the future replace unsustainable use of fodder based on wild caught fish (Naturvårdsverket 2008).

For more than a decade organic farmers on the island of Orust have used mussel scraps as fertilizer, with promising results except for an unpleasant smell from the fields. However, composting is thought to solve this problem (Naturvårdsverket 2008).

Blue mussels are also being explored for possible benefits through marine bioprospecting and researchers have for instance developed a kind of glue, which can stop bleeding wounds in less than 60 seconds, without leaving any visible scars. The glue can for instance be used in dentistry, electronics and construction.

Compared to the farming of carnivorous fish, the farming of shellfish is considered an environmentally friendly form of marine aquaculture. Also, with the energy pyramid in mind, the harvesting of bivalves is energy efficient. In fact, the production of $1 \mathrm{~kg}$ mussels requires $5^{-10} \mathrm{~kg}$ phytoplankton, compared to the $1,000 \mathrm{~kg}$ of phytoplankton required in the production of $1 \mathrm{~kg}$ cod.

But there are also some possible negative effects from mussel cultivation, primarily related to sedimentation below the mussel farm. These effects are for instance increased mineralization and denitrification rates, increased oxygen demand and changes in sediment chemical composition. However, the total sedimentation is assumed to be lower on the basin level.

\subsubsection{Commercial and subsistence fishery}

Commercial fishing of blue mussels is not as big industry as the aquaculture. However, fishermen in the Limfjord in Denmark have for several decades harvested blue mussels for food production and up to 100000 tons are scraped up from the sea floor each year. There are also mussel harvest companies in Norway, e.g. Arctic Shellfish AS, but these do not constitute more than one percent of the Danish industry. 


\subsection{Regulating services}

\subsubsection{Maintenance of resilience}

Since ecological resilience is described as the extent to which ecosystems can absorb perturbations and continue to regenerate (Holling 1973), this service relies on the complexity of the food web, the number of species inhabiting the ecosystem, and the growth and regeneration of the key habitat species. Being an important habitat builder for many other species of algae and fauna (Chapter 5.3.1) the blue mussel beds have relatively high biodiversity and thus the ability to recover after disturbances.

Perhaps more important, the blue mussels have been described to be extremely tolerant and can withstand wide gradients in temperatures, salinities and draining (Suchanek 1985). On the other hand, they are less able to withstand ice scouring, and the scraping off of mussels during harsh winters can cause colonization of spores of fast-growing algae, which can set the mussel colony many years back.

\subsubsection{Carbon storage and sequestration}

Blue mussels bind $\mathrm{CO}_{2}$ when building their shells and this carbon is stored in the shell until the animal dies and are decomposed and released back to the ecosystem. The role of blue mussels in carbon storage is thus supposed to be connected to the amount of carbon stored in blue mussel banks at any time. The amount of carbon released from the decomposed mussel that is sequestrated for the future, however, is believed to be minimal.

In the Lysefjord at the west coast of Norway, researchers claim to have found the key to producing more food while binding carbon. The great opportunities lie in sustainable food production through cultivation of mussels and a positive $\mathrm{CO}_{2}$ effect of this when more biological material sinks to the bottom and stored for long periods in bottom sediment. The test facility in Lysefjord takes up 2,000 tons of $\mathrm{CO}_{2}$ in one season. The number depends on the amount of carbon that goes out of the fjord system in the form of harvested mussels or stored carbon into the sediments. However, there is great uncertainty about whether this method has a long term effect and if $\mathrm{CO}_{2}$ is actually being reduced in the atmosphere. 


\subsubsection{Eutrophication mitigation}

As phytoplankton feeders, mussels play a key role in the ecosystem, particularly in the light of ongoing eutrophication. Worldwide, the economic value of natural mitigation of eutrophication is estimated to be enormous (Costanza et al. 1997). Mitigation of eutrophication, or the removal of excess nitrogen $(N)$ and phosphorus $(P)$ from the sea, occurs through the uptake of nutrients. Mussels can then help to counteract eutrophication by being harvested and used as food, animal feed and fertilizer. Mussels can even be farmed as a way of treating waste water, although they cannot then be used as food (5.4.1).

Large amounts of blue mussels (and other mussels) for instance in Öresund has been described as being of crucial importance to water treatment and water quality in the Baltic Sea and Skagerrak. Considerations around the large and important mussel beds ( 900000 tons of mussels at $73 \mathrm{~km}^{2}$, which survived well, and even were strengthened on bridge piers) were hotly debated in the construction of the Öresund link. Studies in both Sweden (Lysekil and Kalmar) and Denmark (Limfjord) have looked the opportunities to relieve or replace waste water treatment through the cultivation of mussels, and even using payment mechanism between the polluter (the local waste water plant) and the mussel farmer (Zanders et al. 2009).

A pilot study from 2009 (Petersen et al. 2010) reported that from 8000 tons of cultured blue mussels we could expect removal of up to 80 tons of nitrogen and 5 tons of phosphorus including a significant effect on water clarity (Secchi depth), the concentration of chlorophyll and the number of days with anoxia (Petersen et al. 2013). When Danish researchers realized that the Baltic Sea suffered the worst oxygen loss of 100 years, they put out $90 \mathrm{~km}$ of mussel lines into the fjord close to a fish farm and after a year they harvested the mussels and saw that the concentration of algae had decreased and water clarity was improved (Petersen et al. 2014). In Skive Fjord, an 18 ha mussel farm improved water clarity of an area 10 times the size.

Gren et al. (2009) estimated the value of mussel farming for reducing nutrient contents in the Baltic Sea according to the HELCOM Baltic Sea Action Plan. They found that marginal cleaning costs of nutrients by mussel farming can be lower than other abatement measures. The inclusion of mussel farming could decrease total cost of nitrogen and phosphorus reduction by approximately $5 \%$.

\subsubsection{Water purification, filtering and removing of hazardous substances}

Perhaps the most important service of the blue mussel, in addition to reduce eutrophication, is its ability to take up and thereby remove organic pollutants and toxic substances. Consumed or bioturbated, hazardous substances constitute a risk to ecosystem health and function, while decreasing the value of ecosystem services like food fit 
for consumption and enjoyment of recreation. Several toxic substances can be found in algae and exposure to these algal toxins can cause illness among humans and animals (Naturvårdsverket 2008). Through their filter feeding habits, blue mussels can reduce the amount of phytoplankton and cyanobacteria in the water column and thus contribute to water purification, filtering and removing of hazardous substances. Mussels can store relatively large amounts of toxins without themselves being affected. Being longlived, this storage helps preventing the toxic substance from ending up in far more sensitive organisms.

In a study performed by IMR, up to $70-80 \%$ of the algal chlorophyll was retained by mussels in tests where mussels where tanked in flowing water. The same reduction is reported for chlorophyll in water that passed over large natural mussel banks in Øresund in Sweden. The blue mussel banks caused a mixing of the outflowing water, which contributed to the whole water column that came into contact with the shells on the bottom. The water of the Øresund is unusually clear because of the filtering in the mussel banks (Robinson and Brink 2006).

\subsubsection{Coastal defense}

Ecosystem engineering is the modification of the abiotic environment due to biological activity, which is an important mechanism in shaping ecosystems. Mussel beds can influence tidal flow and wave action within estuaries, and modify patterns of sediment deposition, consolidation, and stabilization. In the Netherlands, mussels are being investigated for their abilities as ecosystem engineers and show promising possibilities for a sustainable coastal protection (de Vriend and van Koningsveld 2012).

\subsection{Cultural services}

\subsubsection{Recreational fishing}

Many people find both pleasure and recreation in picking their own mussels along the beaches or from a boat. Although, not so much about economy, this activity is more about the enjoyment of gathering your own food, maybe even right outside your own cabin door. Blue mussels can be used in many different sea food dishes, but also as bait for fishing. 


\subsubsection{Tourism}

The tourism industry benefits from all ecosystems supporting attractive wildlife such as marine mammals and birds, but also habitats that in themselves attract e.g. divers and recreational boaters. Blue mussel beds can be a beautiful sight for divers, but also for snorkelers and swimmers without any equipment, since they are found in shallow waters all the way up to the sea shore, and even above it at low tides (Figure 19).

Figure 19: Blue mussel at the sea shore in Nordland county of Norway

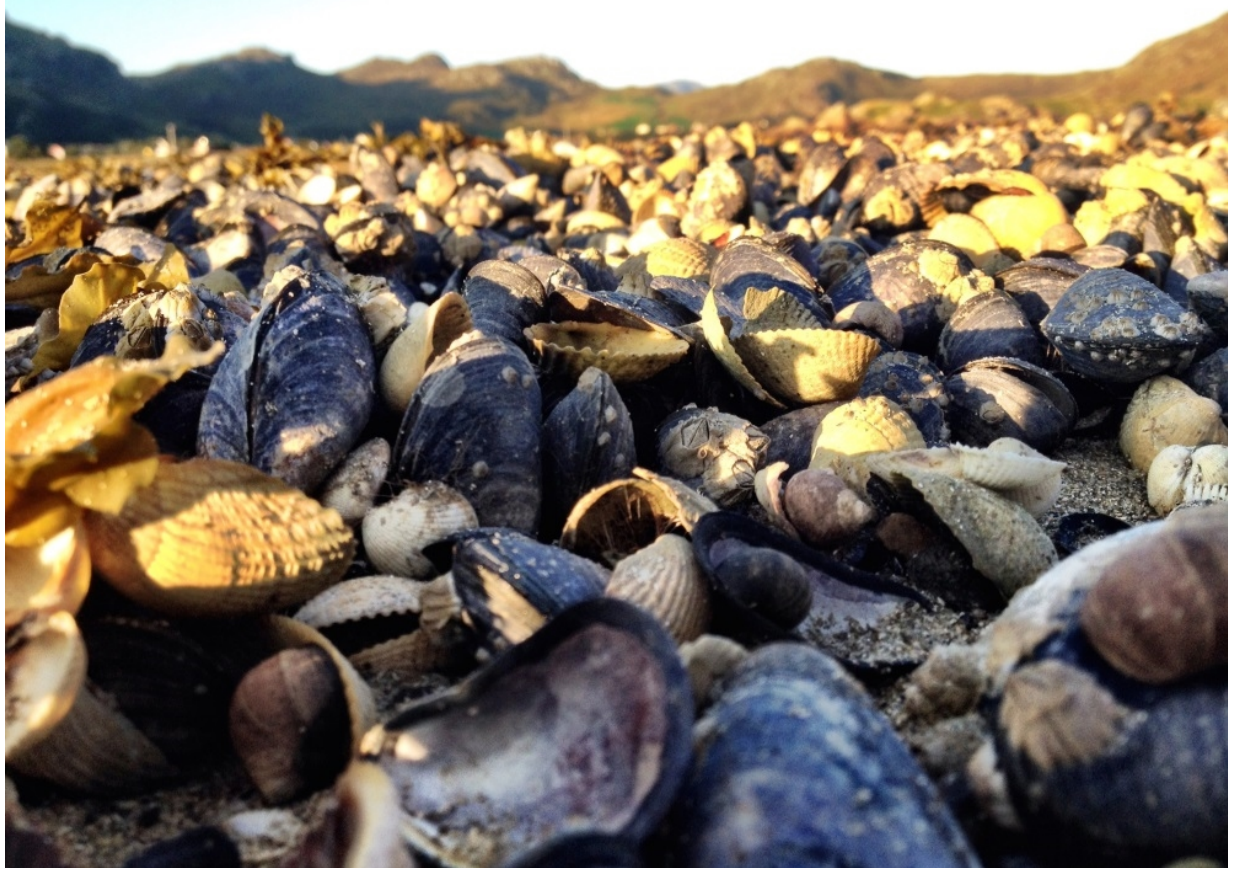

Source: Photo: Hege Gundersen.

In a societal perspective, blue mussels and other bivalves are extremely important in cleaning the water for phytoplankton, including toxic algae, thus helping maintain water fit for swimming and beaching. Especially, in regions of importance for tourism and recreation, and where property prices are related to proximity and condition of the sea, mitigation of eutrophication may be particularly important.

In Limfjorden in Denmark, where blue mussel harvesting have occurred for severeal decades (Chapter 5.4.2) one can find Mussel City, as the residents of Løgstør call their town (Box 5). 


\section{Box 5: Løgstør - the town of mussels}

In the town of Løgstør in Limfjorden in Denmark, one can experience mussels in many different ways, and find a lot of delicious mussel banquets at the city's gastronomes. The city's mussels are also the basis for jewelry, art, festival and much more.

Figure 20: Løgstør is known as "the town of mussels" owing to its location right by the sea where the tasty delicacy is found

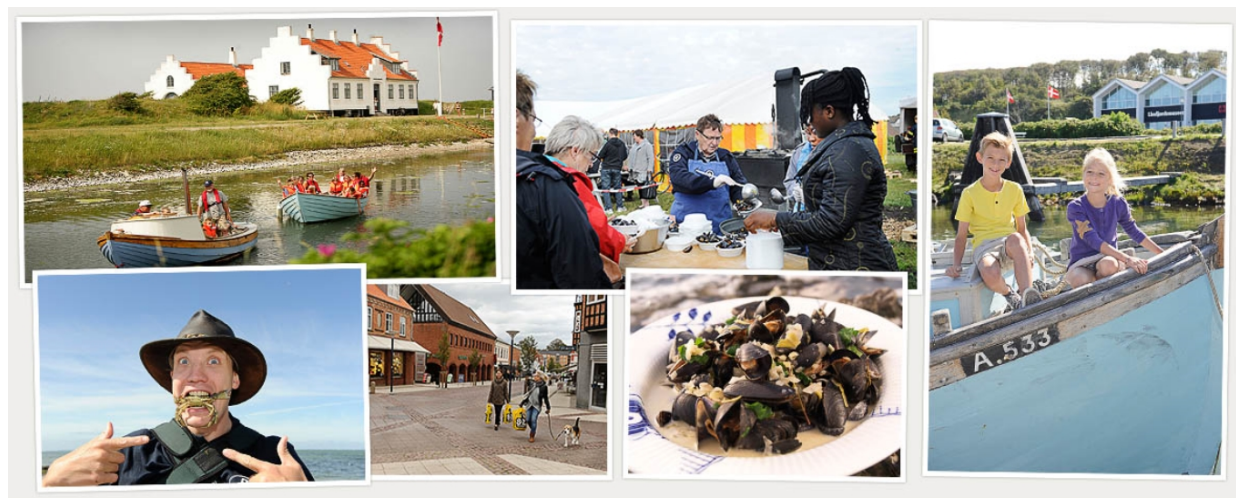

Source: www.visitnordjylland.com 



\section{Ecosystem services of shallow bays and inlets}

\subsection{Distribution and physical requirements}

Shallow and wave sheltered bays and inlets with soft sediments are among the most productive ecosystems in the northern Baltic Sea. These areas host a rich community of vegetation, consisting of submerged rooted plants and charophytes with reed and sedges close to the shore (Appelgren and Mattila 2005, Eriksson et al. 2004), and associated macroinvertebrate fauna (Hansen et al. 2012, 2008). The isolated shallow bays warm early in spring and constitute important recruitment habitats for many species of coastal fish, by functioning as spawning and nursery areas (Härmä et al. 2008, Karås 1996a, 1996b, Karås and Hudd 1993, Lappalainen et al. 2008, Snickars et al. 2009, 2010, Sundblad et al. 2009, 2014).

These bays and inlets provide a number of ecosystem services, especially in relation to supporting services such as biodiversity, habitat and food web dynamics (HELCOM 2009). They also perform important regulating services, e.g. by storing carbon and nutrients in biomass and sediments, and filtering runoff from land (e.g. Kautsky and Kautsky 1991). Also more direct societal benefits and values for human well-being are generated. For instance, both commercial and recreational fisheries are dependent on these areas, as availability to these types of habitats has been shown to limit the sizes of coastal fish populations (Sundblad et al. 2014). Bays and inlets of the northern Baltic Sea are also being intensely used for recreational boating, since the wind and wave sheltered conditions provide suitable places for jetties and small marinas, which, however, simultaneously constitute a threat to the continued delivery of ecosystem services (Bishop and Chapman 2004, Eriksson et al. 2004, Sandström et al. 2005, Sundblad and Bergström 2014).

This chapter focuses on shallow ( $<6 \mathrm{~m}$ depth), wave sheltered and vegetated bays and inlets in the northern Baltic Sea (northern Baltic proper and Gulf of Bothnia). As a result of isostatic land-uplift, approximately 4-9cm per decade (Ekman 1996, Eronen et al. 2001), these areas consist of a variety of partly enclosed environments at different successional stages (Box 6). The most open inlets and bays are called juvenile flads, 
which slowly become flads and later gloes with increasing isolation from the sea, eventually creating a new gloe lake after having been completely cut off from the sea (Munsterhjelm 1997). The Habitats and Species Directive (92/43/EEC) lists four habitat types that encompass these types of environments: Coastal lagoons (EU Habitats Directive code 1150), which specifically mention flads and gloes as Baltic varieties, Large shallow inlets and bays (code 1160), Boreal Baltic narrow inlets (code 1650), and Estuaries (code 1130) with Baltic river mouths as a specific subtype. As these habitats share several functions and processes, and thus provide similar ecosystem services, they will here all be referred to as shallow, wave sheltered bays and inlets in the northern Baltic Sea. Characteristic species include charophytes (e.g. Chara canescens, C. baltica, C. connivens and in flads and gloes also C. tomentosa), angiosperms such as Stuckenia pectinata, Potamogeton spp., Ruppia spp., Myriophyllum spp., Zanichellia palustris, and grasses such as Scirpus spp., Schoenoplectus spp. and Phragmites australis (EUR28, 2013).

In relation to the classification system of HELCOM (HELCOM Underwater Biotopes, HUB) the Habitat Directives codes (Annex I) are directly included in the system as biotope complexes (HELCOM 2013a), and the characteristic vegetation mentioned above primarily overlaps with the HUBs consisting of Baltic photic muddy, coarse and sandy sediments, characterized by emergent vegetation or submerged rooted plants, including charophytes.

Charophytes are a unique group of species in this biotope, where they may be a smaller part of the underwater forests or form dense stands on their own. Charophytes are considered Near Threatened according to the HELCOM red list of underwater biotopes (HELCOM 2013b). Charophytes are algae with complex morphology, closely related to modern land plants. Even though these algae can tolerate salinities from freshwater to hypersaline conditions, they are not known to occur in fully marine habitats (Schubert and Blindow 2003, Kovtun et al. 2011). Dense charophyte stands in the Baltic Sea are often associated with sediments that have a small grain size (sand-clay), and high content of organic matter and nitrogen (Selig et al. 2007). 


\section{Box 6: The successional stages of bays and inlets in a land-uplift area}

- Juvenile flad, a shallow bay which is still connected to surrounding waters through one or more broad inlets.

- Flad, which is the next step in the succession. It is generally shallower and connected to surrounding waters only through one or a few narrow inlets.

- Gloe-flad, no longer connected to the surrounding sea. The sill can still be submerged, but is overgrown with reeds or sedges which counteract water exchange.

- When there is no connection left to the surrounding sea (except the occasional flood event), the gloe-flad has become a gloe lake. The last step is usually a completely overgrown gloe lake.

Figure 21: Illustration of the different successional stages of bays and inlets in a land-uplift area

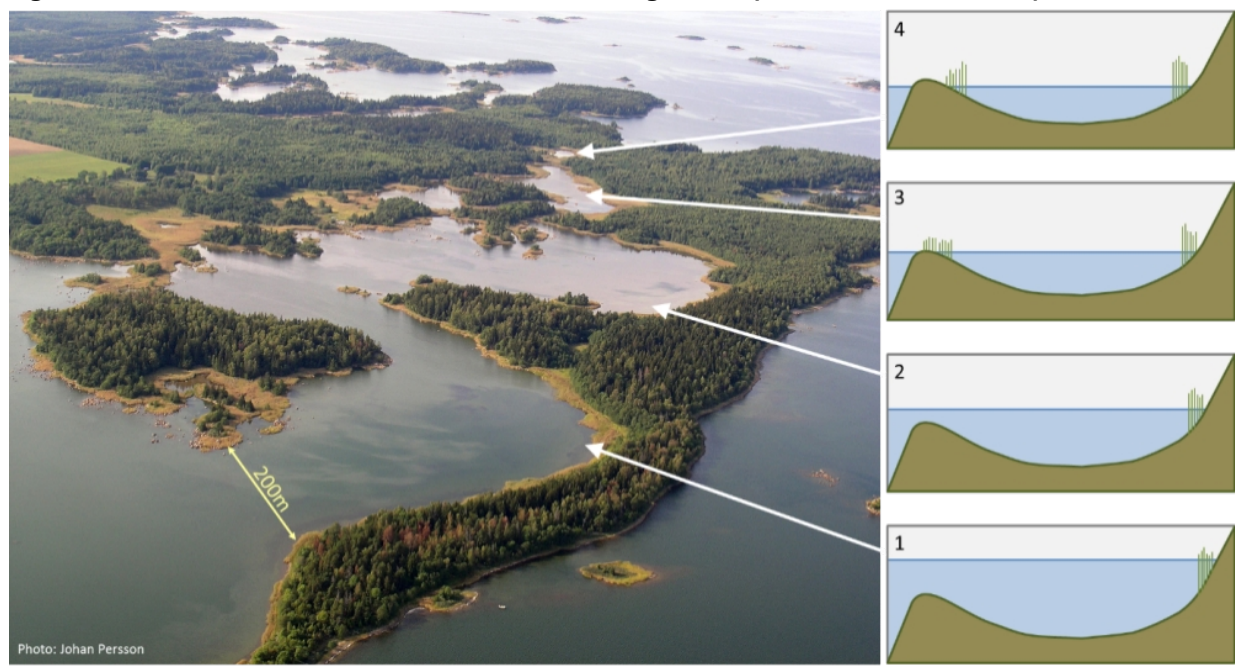

Source: Photo: Johan Persson.

Angiosperms are found in both sheltered areas with finer sediments (e.g. Stuckenia pectinata), as well as wave exposed areas on sandier substrates (e.g. Zanichellia palustris, Myriophyllum spicatum and Zostera marina) (Munsterhjelm 2005). Most angiosperms are of freshwater origin, and the distribution of species in the Baltic Sea is related to salinity, which increases from the north to the south. Eelgrass (Zostera marina) is the only angiosperm of marine origin. Although eelgrass is listed as a typical plant in large shallow inlets and bays, low salinity hinders the existence of habitat forming meadows in the Gulf of Bothnia (Boström et al. 2014). Ecosystem services associated with eelgrass meadows is found in Chapter 4. Macroalgae, particularly bladder wrack (Fucus vesiculosus) and sea laces (Chorda filum), as well as the recently described species $F$. radicans, endemic to the Baltic Sea (Bergström et al. 2005, Pereyra et al. 2009), can also 
occur in these types of environment but only to a lesser extent compared to angiosperms (Rosqvist et al. 2010, Snickars et al. 2009, 2010).

Lagoons, estuaries and embayments of various sizes are common coastal habitats all over the world, including the Nordic countries. This chapter is focused on shallow wave sheltered bays and inlets in the northern Baltic Sea, although e.g. charophytes and angiosperms may be found in similar biotopes along the coast of Norway, in areas strongly influenced by freshwater runoff, as well as along the German coastline.

Shallow and wave sheltered bays and inlets are primarily found in the archipelago areas of the Baltic proper and Gulf of Bothnia, in particular along the Swedish east coast, the Åland Islands and the Finnish coast. Within the Finnish and Swedish archipelagos, two main gradients determine the abiotic conditions of the bays, namely the degree of habitat isolation (i.e. flad to gloe developmental stage, which influence water exchange with the adjacent sea), and archipelago position from the inner to the outer archipelago. Together, isolation and position have a strong influence on vegetation and juvenile fish composition (Appelgren and Mattila 2005, Rosqvist et al. 2010, Snickars et al. 2009), although biotic couplings also play a vital part (Bonsdorff and Blomqvist 1993). The degree of isolation and archipelago position is correlated with salinity, which is a particularly important driver for the large scale distribution of species in the Baltic Sea (Sandman et al. 2012, Pecuchet et al. 2016).

\subsection{Threats and challenges}

Coastal development and eutrophication are among the major threats to bays and inlets of the northern Baltic Sea (Bergström et al. 2013, Eriksson et al. 2004, Sandström et al. 2005, Sundblad and Bergström 2014), which are also poorly protected by the Natura 2000 network of marine protected areas (Sundblad et al. 2011). These ecosystems are subject to heavy exploitation through shoreline development, and habitat degradation rates due to constructions are accelerating (Sundblad and Bergström 2014).

Boating and navigational activities can change vegetation community composition and have negative effects on the development of macrophytic vegetation. These activities can decrease the height and coverage of Chara spp. and Potamogeton spp., as well as juvenile fish abundance (Eriksson et al. 2004, Sandström et al. 2005).

Negative effects of eutrophication are related to reduced light penetration and increased system productivity, which can occur when nutrient loads exceed the filtering capacity of the primary producers (McGlathery et al. 2007). However the effects of eutrophication on these habitats, serving as fish recruitment areas, and thus indirectly on 
fish stock sizes, are multifaceted, with some species losing and others actually gaining from the effects of eutrophication (Bergström et al. 2013, Candolin et al. 2008).

Fishing, as an additional type of pressure, further complicates the picture by the fact that it may indirectly lead to a decrease in the quality of the ecosystem by relaxing the top-down control of filamentous nuisance algae maintained by predatory fish (Eriksson et al. 2009, 2011, Östman et al. 2016). Nevertheless, these biotope complexes (sensu HELCOM 2013b) are all red-listed as threatened due to adverse effects of eutrophication and constructions.

Since human uses can adversely impact ecosystem processes and functions, there is a need to find a long-term sustainable balance between the use and preservation of these ecosystems and associated services for a continued human well-being.

\subsection{Supporting services}

\subsubsection{Habitat and biodiversity}

A multitude of ecosystem services are provided by shallow, wave sheltered bays and inlets in the northern Baltic Sea. The most important ecosystem services include their supporting role in biodiversity, providing habitat and food for various organisms. The vegetation community in bays and inlets of the northern Baltic Sea maintains (for the species-poor Baltic Sea) a relatively high biodiversity, with many species forming a three dimensional habitat equivalent to underwater forests (like the kelp forests, Chapter 3 ) in which many other organisms thrive (Figure 22).

The rich vegetation community provides habitat and shelter from predators and increases macroinvertebrate biodiversity, from a mixture of marine and freshwater species with high total biomass in open inlets, to macrophyte and macroinvertebrate communities with larger proportions of a few freshwater taxa with lower total biomass in isolated bays (Hansen et al. 2008, 2012). Both seasonal variation in invertebrate biomass and species composition have been shown to be related to Chara spp. biomass in freshwaters (Van den Berg et al. 1997), and freshwater charophytes may also serve as food for a number of organisms, such as herbivorous fish (Lake et al. 2002), snails (Baker et al. 2010), water-fowl (Noordhuis et al. 2002, Schmieder et al. 2006, Matuszak et al. 2012, Rodrigo et al. 2013) and crayfish (Cirujano et al. 2004, Chucholl 2013). 
Figure 22: Shallow, wave sheltered bays and inlets of the northern Baltic sea often consist of dense underwater forests which provide shelter and food for many other organisms, and function as nursery habitats for many coastal fish species - illustrated here by juvenile roach and angiosperms such as Stuckenia pectinata, Potamogeton perfoliatus and Myriophyllum spp

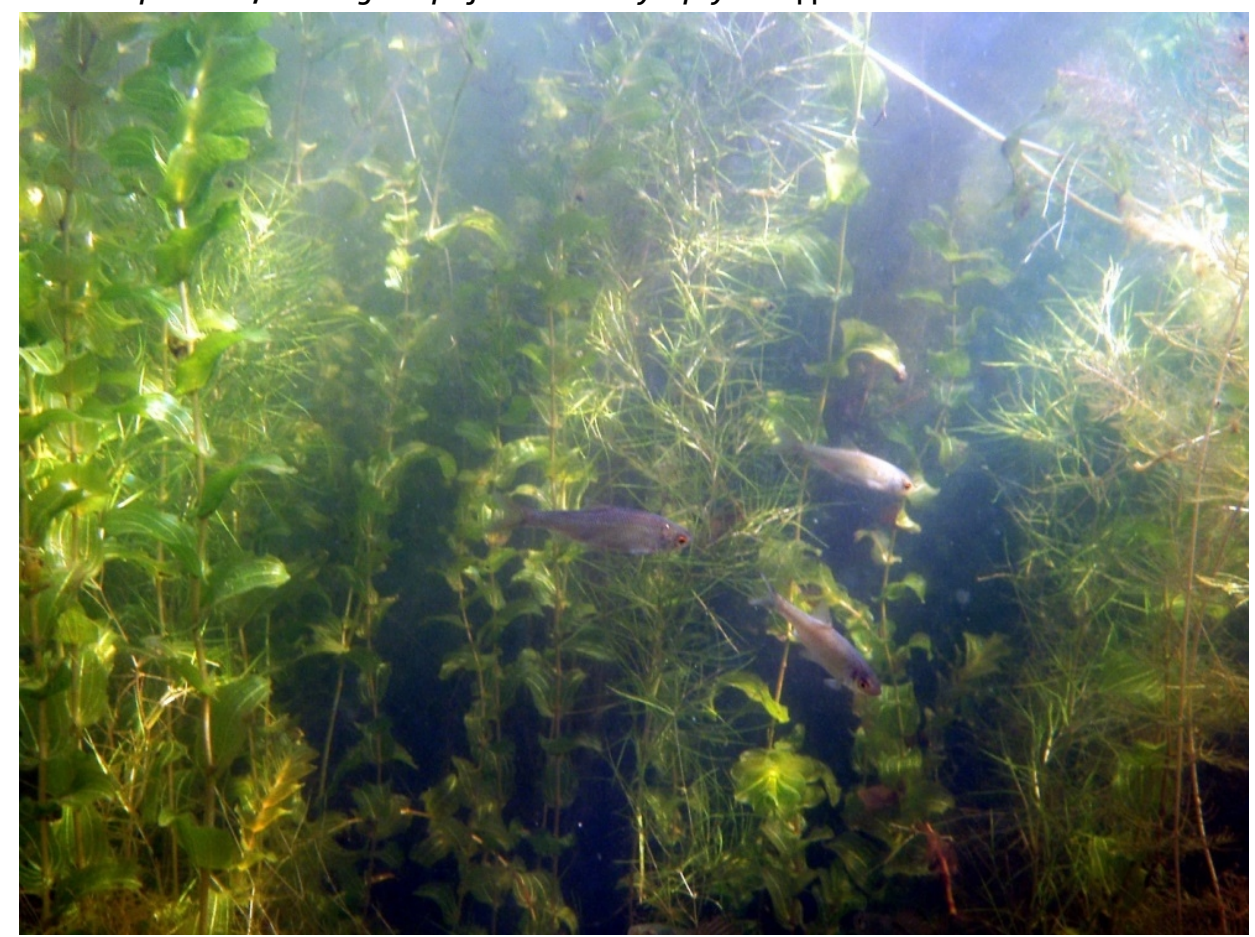

Kilde: Photo: Göran Sundblad (Holmöarna, Kvarken).

\subsubsection{Primary production, food webs and nutrient cycling}

Recent research shows that the primary production in shallow, vegetated bays and inlets is considerably higher than previously known. Ask et al (2016) found that benthic habitats, especially benthic microalgae but also microalgae and submerged rooted plants, contributed to $31 \%$ of the total primary production of the Bothnian Bay, which is three times higher than past estimates.

Primary production rates of vegetation in Baltic bays and inlets vary among species; Potamogeton filiformis, P. perfoliatus, and Myriophyllum spicatum have maximum production rates of 1-5 $\mathrm{mg}$ carbon (C) per $\mathrm{g}$ dry weight per hour, while Stuckenia pectinata, Ruppia sp., Zannichellia sp. and Zostera marina produce below $2 \mathrm{mg} \mathrm{C} \mathrm{per} \mathrm{g} \mathrm{dry} \mathrm{weight}$ per hour (Wallentinus 1979). Therefore, an important source of uncertainty is the con- 
sideration of small spatial scale patchiness. Wijnbladh et al. (2006) provide an illustrative example of this in two water bodies along the Swedish east coast, were $10 \%$ of one large bay (Granholmsfjärden) was covered by patches of Potamogeton spp. and reed (Phragmites australis), yet accounted for $70 \%$ of the benthic primary production. Similarly, in the other water body (Borholmsfjärden), charophyte stands covered $40 \%$ of the area yet accounted for $80 \%$ of the total primary production in that water body. Quantification of primary production rates for vegetation in Baltic bays and inlets is of importance for the estimation of other ecosystem services such as eutrophication mitigation and carbon sequestration.

The three dimensional vegetation structure of Baltic bays and inlets also provide shelter from predation for juvenile fish, as well as suitable spawning substrate during spring, e.g. by providing structures on which the female perch (Perca fluviatilis) can attach her single gelatinous egg strand (Snickars et al. 2004, 2010) (Figure 23).

Figure 23: Reed Phragmites australis is a highly suitable spawning substrate for perch Perca fluviatilis

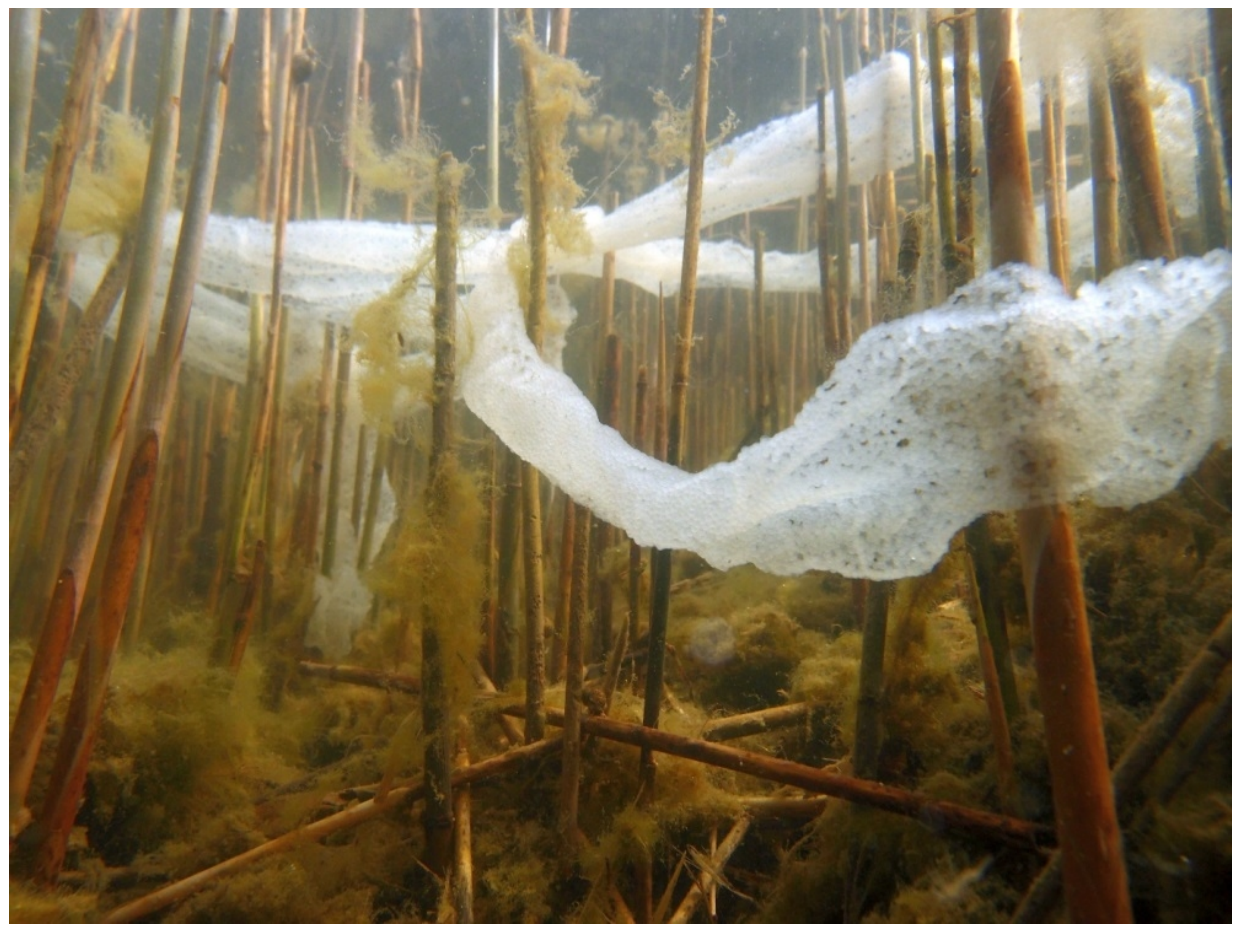

Source: Photo: Ulf Bergström. 


\subsubsection{Biological control}

Shallow, wave sheltered bays and inlets of the northern Baltic Sea serve as essential habitat for several species of coastal fish, including large predatory fish, i.e. piscivorous, fish-eating, species. The ecological function of fish production can be considered among the most important services provided by these ecosystems, since the predatory fish in turn provide a large number of ecosystem services that either directly or indirectly benefit human well-being and life style (Holmlund and Hammer 1999).

Perhaps one of the most important indirect services of large predatory fish lies in the regulatory service of top down control, whereby decline of predatory fish promotes the production of nuisance algae by decreasing invertebrate grazer control, leading to worsened eutrophication symptoms (Eriksson et al. 2009, 2011). A recent meta-study assessed the magnitude of bottom-up processes relative to the loss of top-down control and showed that top-down effects are on average on par with fertilization effects on ephemeral algae (Östman et al. 2016), and that the loss of large predatory fish can yield similar eutrophication symptoms as nutrient enrichment. Increased overgrowth of ephemeral, filamentous algae on larger, more structurally complex vegetation, reduces the quality of the habitat for fish production (Snickars et al. 2010), and filamentous algae are generally perceived as negative for the recreational value of the water (Söderqvist et al. 2005). The supporting service of biological (top-down) control provided by predatory fish thus impacts the food web and, hence, influences several other services.

The system is, however, more complicated than that. Biological control exerted by predatory fish on mesopredators, such as three-spined sticklebacks (Gasterosteus aculeatus), is multidirectional but size dependent. Sticklebacks also reproduce in shallow coastal habitats and the timing in spring, when they arrive from the open sea, can have severe consequences for the recruitment of perch, since sticklebacks can feed on larvae and the juvenile stages of perch (Bergström et al. 2015, Byström et al. 2015). However, as perch and other predatory fish grow in size, they instead feed on sticklebacks. The preservation of bays and inlets, and their associated ecosystem components, is therefore vital for the long-term provision of several ecosystem services, including both supporting services. 


\subsection{Provisioning services}

\subsubsection{Resource utilization and bioprospecting}

Although the ecosystem components found in bays and inlets of the northern Baltic Sea are, to our knowledge, today not used as medicinal resources, there may be future potential. Charophytes may effectively remove organic chemicals, such as hexachlorobenzene (Schneider and Nizzetto 2012), and metals, such as uranium (Kalin et al. 2005), nickel, cadmium, lead and zinc, from the water (Baker et al. 2012, Gao and Yan 2012, Sooksawat et al. 2013, Clabeaux et al. 2013, Laffont-Schwob et al. 2015). Charophytes may mitigate cyanobacterial blooms in surface waters (Pakdel et al. 2013), reduce the viability of Pythium (a parasitic oomycete that can cause rotting of plant roots, Juan et al. 2014), as well as reduce the development of benthic biofilms (Gette-Bouvarot et al. 2015).

In contrast to the use today, charophytes have previously been of larger importance. Zaneveld (1940) summarized nine ways in which charophytes have been of more or less economic value. These included fish culture, water purification, food for aquatic animals as well as farm stock, fertilizers, polishes, mud baths, therapeutic applications, sugar purification, and insect control. For example, between the 18th and the 2oth century, charophytes were harvested in Lake Constance in the Alps, dried, and used as fertilizer on vegetable fields (Schmieder 2004). However, this is not a common practice any longer.

\subsubsection{Commercial and subsistence fishery}

Both commercial and subsistence fisheries are dependent on recruitment of the target species, most of which are spring spawners. Perch, pike (Esox lucius), roach (Rutilus rutilus), rudd (Scardinius erythropthal-mus), tench (Tinca tinca), breams (Abramis brama and $A$. bjoerkna) and other cyprinids, generally benefit from warm water temperatures due to positive effects on egg development and growth, and the enclosed bays and inlets thus provide suitable reproduction areas as the water quickly warms with the onset of spring (Karås 1996a, Karås and Hudd 1993). The juvenile fish spend their first summer in these habitats, and first year growth is critical for survival and year-class-strength (Hudd et al. 1996, Kjellman et al. 2003). On a larger scale (10-30 km) the amount of suitable spawning and nursery habitats has been shown to be a limiting factor for the abundance of large fish, explaining almost half of the variation in adult fish abundance (Sundblad et al. 2014). 
On the Swedish east coast the commercial landings in 2014 of perch and pike were 87 and 46 tons, respectively, while the catches in recreational and subsistence fishing were about 12 times larger for perch and 27 times larger for pike (Andersson et al. 2015). The latter is equivalent to the recreational fishery for mackerel on the Swedish west coast.

\subsection{Regulating services}

\subsubsection{Maintenance of resilience}

Ecological resilience is the amount of disturbance a system can absorb without losing its function (Holling 1973, Folke et al. 2002). Ecological resilience assumes the existence of more than one stable state and is a measurement of to what extent a system is capable of absorbing or resisting changes that causes shifts between these states (Gunderson 2000). Resilience is often a result of slowly renewable resources, such as nutrient stored in the ground, species diversity or genetic diversity (Folke et al. 2002). Slow losses of resilience set the stage for large changes that occur when the ecosystem crosses a threshold, e.g. due to a random event such as climate fluctuation (Carpenter et al. 2006, Folke et al. 2004). As a system flips from one state to another, biological productivity could be lost (Arrow et al. 1996). An interesting example is provided by Biggs et al. (2009), using a theoretical system of fish recruitment habitats impacted by the slow managed driver shoreline development, and a fast managed variable of fishing, in relation to two states dominated by piscivorous fish or planktivorous fish. Their study showed that for drivers such as shoreline development, which slowly alters the environment (e.g. Sundblad and Bergström 2014); management action is needed well before a regime shift in order to avert it.

\subsubsection{Carbon storage and sequestration}

Uptake and storage of carbon in vegetation and sediments is an important service in relation to climate change. To our knowledge there is no comprehensive summary with respect to carbon uptake and storage for bays and inlets in the Baltic Sea. However, several studies have measured carbon uptake and storage for particular species and areas, which taken together indicate the potential importance of shallow and wave sheltered bays and inlets in the Baltic Sea for carbon sequestration. For instance, inner and outer archipelago basins were compared in the context of a safety assessment project for a proposed nuclear waste repository on the south east coast of Sweden (Wijnbladh et al. 2006). In the inner basins of this archipelago, primary production was dominated 
by macrophytes in shallow and sheltered soft bottom areas with a high net production, which also had the highest biomass per square meter, typically 40-100 g C per $\mathrm{m}^{2}$ in Characeae and Vaucheria sp. stands, and over $500 \mathrm{~g}$ in reed belts. Comparatively the red

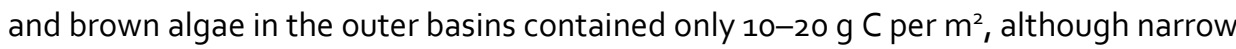
belts of bladder wrack (Fucus vesiculosus) had up to $280 \mathrm{~g} \mathrm{C} \mathrm{per} \mathrm{m}^{2}$.

Because many charophytes are evergreen, calcify heavily and phosphorus is coprecipitated with lime, carbon and phosphorus may be effectively stored over a long time in the sediment of charophyte meadows. Although vascular plants like Potamogeton spp. and Myriophyllum spp. calcify, charophytes can precipitate large amounts of calcium carbonate $\left(\mathrm{CaCO}_{3}\right)$, taking up carbon dioxide $\left(\mathrm{CO}_{2}\right)$ in the process, and thus enhancing water clarity (Rodrigo et al. 2015) and decreasing the concentration of $\mathrm{Ca}^{2+}$ (Pełechaty et al. 2014). Additionally, charophytes may create very dense beds, and biomasses exceeding $2 \mathrm{~kg}$ per $\mathrm{m}^{2}$ have been reported from lakes (Pukacz et al. 2014). Similarly, lake charophyte biomass (Chara tomentosa) in summer has been reported to contain $287 \mathrm{~g}$ Ca per $\mathrm{m}^{2}$ (Kufel et al. 2016). Assuming that all of it is deposited in bottom sediments after plant decay, since $\mathrm{Ca}$ is present as $\mathrm{CaCO}_{3}$, this should roughly equal to $86 \mathrm{~g} \mathrm{C}$ per $\mathrm{m}^{2}$, results that are similar to the archipelago basins reported in Wijnbladh et al. (2006, above). However, because calcite encrustation is species specific and also the concentration of calcium-bound phosphorus per gram of calcite shows significant interspecific differences (Kufel et al. 2016) it may be difficult to generalize charophyte carbon storage for bays and inlets of the northern Baltic Sea.

To complicate it further, lime encrustation of charophytes also depends on water chemistry. Calcite encrustation of charophytes is positively correlated with water calcium concentrations, but presence of magnesium $(\mathrm{Mg})$ in the water inhibits calcite encrustation (Asaeda et al. 2014). Magnesite $\left(\mathrm{MgCO}_{3}\right)$ was not deposited on the plants, however, when plants of Chara fibrosa, a non-Baltic species, were grown in water containing high concentrations of calcium, shoot elongation was retarded and chlorophyll content was relatively low, indicating that plant growth may be retarded (Asaeda et al. 2014). In addition, calcite formation is negatively correlated with the SRP (soluble reactive phosphorus) concentration in lake water (Kufel et al. 2016). This means that, with increasing eutrophication, charophytes may contribute less to carbon removal, and this effect may be exacerbated by the general decline of charophyte biomass in eutrophic environments.

In summary, carbon storage in bays and inlets of the northern Baltic Sea may be substantial, but Baltic scale estimates on their quantitative importance are lacking. By obtaining relevant measures for the vegetation in Baltic bays and inlets, quantitative estimates of carbon sequestration attributed to these types of ecosystems, including also the associated economic value, could be given in the future (Cole and Moksnes 2016). 


\subsubsection{Eutrophication mitigation}

Removal of nutrients contributes to decreasing eutrophication symptoms and improving water quality. Phosphorus $(P)$ can be removed via assimilation by submerged aquatic plants. In wetlands, apart from direct uptake, other mechanisms for $P$ reduction include microbial degradation, filtering, co-precipitation with $\mathrm{CaCO}_{3}$, and UV oxidation (Gu and Dreschel 2008).

In a study of phosphorus concentration in seven aquatic plant species, addition of $P$ resulted in increased uptake only in two species, one Myriophyllum sp. and one Potamogeton sp. (Caines 1965), suggesting that the potential for $\mathrm{P}$ retention is species specific. Also, Schwoerbel and Tillmanns (1972) found that Potamogeton perfoliatus absorbed $\mathrm{NH}_{4}{ }^{+}$rather than $\mathrm{NO}_{3}{ }^{-}$ions, which indicates better utilization of enriched waters (Wallentinus 1979). In wetlands, the uptake capacity of submerged macrophytes has been estimated to $10 \mathrm{~g}$ per $\mathrm{m}^{2}$ per year for phosphorous and $70 \mathrm{~g}$ for nitrogen (Brix 1997). A significant part of the total phosphorus in charophytes has been shown to be associated with $\mathrm{CaCO}_{3}$ a fraction that is insensitive to redox changes and may be stored in sediments for a long period of time (Kufel et al. 2013). About half of the total P contained in Chara spp. is incorporated in organic matter, $26 \%$ is loosely bound inorganic $\mathrm{P}$, while calcium-bound $\mathrm{P}$ constitutes about $21 \%$ of Total $\mathrm{P}$, respectively. These fractions differed, however, among species and lakes, and newer results showed that roughly $40 \%$ of Total $P$ in charophytes is present as calcium-bound $P$ (Kufel et al. 2016). Ca-bound $\mathrm{P}$ may be considered a $\mathrm{P}$ sink in lake sediments after plant decay. Kufel et al. (2016) assumed that at least $12 \%$ of the organic $P$, and $68 \%$ of the inorganic $P$ contained in charophytes are permanently stored in lake sediments. To which degree these numbers are transferable to brackish water environments is not known. However, increasing $\mathrm{CO}_{2}$ levels in the Baltic Sea are expected to enhance the photosynthetic activity of charophytes (Pajusalu et al. 2015) such that charophytes are likely to play a role as phosphorus and carbon sink also in a future high $\mathrm{CO}_{2}$ world.

\subsubsection{Water purification, filtering and removing of hazardous substances}

The removal of suspended particles and nutrients from the water column through sedimentation is a process tied to several ecosystem services. Sedimentation in vegetated patches can reduce the risk of resuspension, increase water visibility, as well as bind nutrients in the sediments, thereby reducing eutrophication and increasing the perceived water quality for swimming and other recreational activities. 
The processes involved can however be complicated since aquatic macrophytes and water movements interact as water movements affect macrophytes, e.g. by reducing plant growth at high velocities and, simultaneously, that macrophytes affect water movement, e.g. by reducing water velocities, leading to increased sedimentation and reduced turbidity (see for example review by Madsen et al. 2001). Nevertheless, macrophytes, including charophyte beds, can through their structure reduce water motion in shallow benthic areas, leading to enhanced particle deposition, reduced resuspension, as well as reduce the risk for erosion (Brix 1997, Vermaat et al. 2000, Hemminga and Duarte 2000, Koch et al. 2009, Orth et al. 2006).

Although the extent to which vegetation purifies the water is dependent on several factors, the effects can be substantial. For example, resuspension in areas with submerged vegetation has been shown, in Finnish lakes, to be reduced by more than half compared to unvegetated areas (Horppila and Nurminen 2003). The mechanisms involved for stabilizing the sediments are related to roots and rhizomes of macrophytes (Folke et al. 2004, Rönnbäck et al. 2007), which also release oxygen, counteracting reduced oxygen conditions and the accumulation of toxic compounds (Duarte 2000).

Water purification is not only related to the removal of suspended particles. For instance, charophytes can excrete substances that lead to an overall decrease in phytoplankton biomass, including cyanobacteria, as shown by Rojo et al. (2013). They also showed that, compared to monocultures, the effect was greater in a mixed culture consisting of Myriophyllum spicatum (Eurasian watermilfoil) and four charophytes, including C. baltica, which is found in the Baltic Sea. Phytoplankton is essential for the Baltic Sea ecosystem in their role as primary producers, but can cause problems during mass occurrences, so called blooms. Phytoplankton blooms regularly occur in the Baltic Sea, and local blooms can occur also in shallow, wave sheltered bays and inlets in the northern Baltic Sea (Dahlgren and Kautsky 2004).

Besides the production of toxins (from blooms of harmful algae) which has a direct negative effect on swimming and related ecosystem services, high phytoplankton densities can cause reduced light conditions, with potential negative effects on the larger, more structurally complex, benthic macrophytes. The relationship between reduced light availability, and distribution and abundance of macroalgae and seagrass species has been reviewed by Krause-Jensen et al. (2008); seagrasses and macroalgae generally grow deeper, are more abundant and more widely distributed in clear waters compared to more turbid and nutrient-rich ecosystems. Reduced light conditions need however not have long-term effects. Effects of decreased water clarity on production of charophytes was examined by in situ measurements on the Estonian coast (Kovtun-Kante et al. 2014), by simulating reduced light conditions. The results showed that net photosynthetic production of charophytes was reduced, but only within the first 24 hours. 
Within two weeks, the charophyte community recovered in spite of a constant reduction of light down to $25 \%$ of the natural irradiance, suggesting that charophytes are able to adapt to a low light environment and recover their photosynthetic performance even under stressful brackish conditions (Kovtun-Kante et al. 2014).

\subsubsection{Coastal defense}

All structures dampening wave and current energy favor sediment retention and coastal protection. Generally, leaf biomass reduces wave energy and root systems act to stabilize the sediment, counteract erosion and mitigate disturbance from storms and floods. Although not well documented, there is reason to believe that many of the submerged rooted plants of the bays and inlets will have such sediment stabilizing effects (Madsen et al. 2001). On the other hand, it is also known that these environments, in specific the charales, are very sensitive to erosion from boats (Eriksson et al. 2004), so the coastal defense benefits from this ecosystem are not believed to be extensive.

\subsection{Cultural services}

\subsubsection{Recreational fisheries}

Recreational sea fishing is a high-value leisure activity in the Nordic countries (Toivonen et al. 2004). Recreational fishers generally express a higher willingness to pay for the preservation of the existing fish stocks, although non-participants are also willing to pay even if it represents non-use values (Toivonen et al. 2004). In Sweden, 1.6 million people (17\%) between the ages $16-80$ years old fished recreationally during 2013 (total population 9.6 million (SwAM 2014)), which is a lower proportion of the population compared to Finland, where $28 \%$ of the population undertook recreational fishing in 2012 (FGFRI 2014).

The total number of fishing days along the Swedish coast and in the sea was 4 million, and the most important species for sea based fishing were perch, pike, mackerel (Scomber scombrus), sea trout and herring. Total expenditure was SEK 5.8 billion, but the amount which can be attributed to the fish production of shallow, wave sheltered bays and inlets of the northern Baltic Sea remains unknown. Nevertheless, the value of non-market benefits such as improving the preservation of currently "pristine" areas, habitat forming vegetation and large predatory fish stocks is considered high, albeit variable, among citizens in Finland, Sweden and Lithuania (Kosenius and Olikainen 2015), suggesting that a long-term sustainable balance between the use and preservation of these ecosystems and associated services for human well-being is a priority. 


\subsubsection{Tourism}

Apart from recreational fishing (Box 7), shallow bays and inlets and their surroundings are used for other types of recreational activities. Due to their sheltered character, bays and inlets are popular for e.g. boating and swimming.

In 2010, Swedish households altogether owned approximately 881000 boats (Transportstyrelsen 2010). Sweden and Finland are among the countries with highest number of boats per capita with about one recreational boat per seven people, compared to e.g. Denmark and Germany with one boat to 155 and 182 people respectively (Naturvårdsverket 2008). From May to September 2010, 3.3 million overnight stays with recreational boats were made in natural harbors (compared to 2.1 million in marinas; Transportstyrelsen 2010), where shallow, sheltered bays and inlets are included.

Boating, swimming, kayaking and other activities in the shallow, sheltered bays and inlets are dependent on healthy ecosystems providing regulating services such as water filtering and eutrophication mitigation. Clear and clean coastal waters are valued as important (Söderqvist et al. 2005).

These shallow coastal areas are also important breeding areas for bird species bound to dense vegetation and reed belts, as well as shelter and foraging areas for migrating birds (Degerlund 2002), which makes them popular spots for bird watching.

\section{Box 7: Indirect benefits from fish in bays and inlets}

Piscivorous fish, such as perch and pike provide both direct and indirect ecosystem services and benefits for human well-being. Direct ecosystem services are often easier to measure, such as fish for food, using commercial fisheries as measures of economic value. Another direct use of fish is subsistence and recreational fishing, targeting coastal fish species that are dependent on bays and inlets for their recruitment. The direct contribution to human well-being from fish production is thus very high, although estimating a total economic value is more difficult. Through their impact on the food web, piscivorous fish also provide indirect services, by affecting both regulating and supporting services such as eutrophication mitigation, habitat and biological control.

The supporting services of biological (top down) control impacts many other services generated by these ecosystems. Piscivorous fish can, through the food web, indirectly affect water and habitat quality by feeding on smaller fish, which in turn feed on grazers that consume filamentous nuisance algae. Nuisance algae are not only directly negative from a recreational perspective, for example by reducing bathing water quality; they can also reduce the quality of the fish recruitment habitat, potentially leading to negative feedback loops as piscivorous fish is limited by recruitment habitat availability. Excessive outtake of piscivorous fish, or habitat destruction, e.g. through coastal development, are thus threats to many types of ecosystem services generated by shallow, wave sheltered, bays and inlets of the northern Baltic Sea. 
The contradiction between how the utilization and benefits of some services are in conflict with the maintenance of others, highlights how different kinds of activities in the coastal zone needs to be balanced. Framing the sometimes complex ecological relationships in the ecosystem services concept can thus be used to illustrate how human well-being is dependent on functioning ecosystems in an integrated perspective.

Figure 24: Conceptual figure of the food web and some associated ecosystem services provisioned by shallow, wave sheltered bays and inlets of the northern Baltic Sea, in relation to human activities and management actions

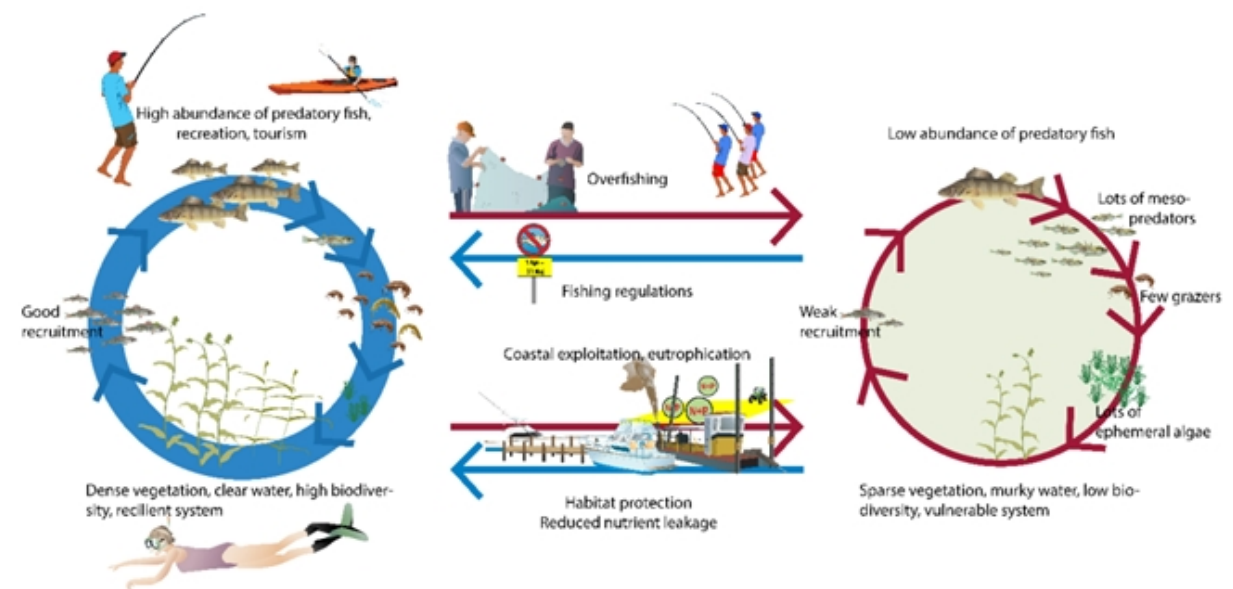

Source: Illustration: Joakim Hansen/Stockholm University Baltic Sea Centre, developed within the Formas funded research project PlantFish (http://www. plantfish.se/). 


\section{Discussion}

The aim of the report has been to give an overview of the available information on the benefits and values of kelp forests, eelgrass meadows, blue mussel beds, and shallow bays and inlets, which all are ecosystems of great importance for the condition and management of key ecological functions in the Nordic countries and together cover large parts of the Nordic countries' coastal areas.

\subsection{Conclusions}

This section sums up the services provided by the different ecosystems described in Chapters $3-6$. In order to make the results more comparable, the relative importance of the different ecosystem services of each ecosystem is attempted to be evaluated in Table 7.1. It is important to note that the results in this table, despite being based on a long range of literature, merely are the result of the subjective perception of the authors involved, and that these results might have been different if other groups of scientists or persons had performed the assessment.

Many of the service types were categorized as "High" or "Medium" for a majority of the ecosystems. This is reasonable since the four ecosystems actually were selected based on their importance and the fact that they are relatively widely distributed along the Nordic coasts. Further, the term "Low" in this setting, does not necessarily mean that they are not important, rather that they are less important than the others.

Since kelp forests have a more widespread distribution, at least compared to eelgrass meadows and blue mussel beds, their total contribution will often exceed that of the other ecosystems. The total biomass and extent of the ecosystem are thus taken in to consideration in the evaluation.

The ecosystem which have a three dimensional structure, i.e. kelp forests, eelgrass meadows and bays and inlets, score high on their supporting services due to their abilities of housing a high diversity of species.

When it comes to provisioning services, kelp and mussels are particularly interesting due to their potentials within harvesting and cultivation, whereas eelgrass is important due to its more documented provision of nursing grounds for commercial fish species. 
Of the regulating services, kelp and seagrass are very important due to their carbon storage and sequestration abilities. For kelp, this is mostly because of the large amount of carbon stored in live plants. For seagrass, the well documented long-term storage (sequestration) of carbon is regarded as the most important. All four ecosystems play a major role in eutrophication mitigation, water purification, filtering and removing of hazardous substances, being photosynthetic (kelp, eelgrass and for instance the charales of bays and inlets) or filtering (blue mussels) abilities. The role of coastal defense is assumed to be especially high for eelgrass due to its role in stabilizing the sediment and reducing resuspension by currents and waves.

In the direct sense, the four ecosystems investigated are probably not the most important among the coastal ecosystems when it comes to cultural services. However, indirectly they contribute enormously, especially through their regulating abilities resulting in clean water for a range of different recreational activities. Also, recreational fishing in shallow bays and inlets of the Baltic Sea are highly appreciated by a large number of people. 
Tabel 1: Degree of importance of ecosystem services provided by the four different ecosystems covered in this study. Be aware that these are subjective judgements based on a few scientists' opinions

\section{Ecosystem service \\ Kelp forests \\ Eelgrass meadows \\ Blue mussel beds Bays and inlets}

Supporting

Habitat and Biodiversity

High

High

Medium

High

Primary production, food webs

High

High

High

High

Biological control

High

High

Medium

High

Provisioning

Resource utilization and

High

Medium

High

Low

bioprospecting

Commercial and subsistence

Medium

High

Low

Medium

fishery

Regulating

Maintenance of resilience

Medium

Medium

Medium

Medium

Carbon storage and

High

High

Medium

Medium

sequestration

High

High

High

High

Water purification, filtering and

High

High

High

High

substances

Coastal defense

Medium

High

Medium

Medium

Cultural

Recreational fishing

Low

Medium

Low

High

Tourism

Medium

Medium

Medium

Medium 


\subsection{Knowledge gaps}

Although this study has shown that there exists much knowledge on the services of coastal ecosystems in the Nordic countries, it also shows that there are numerous of unanswered questions and knowledge gaps. The seminal paper from Hooper et al. (2005), on the effects of biodiversity on ecosystem functioning, states that "further study of the marine realm is necessary". Despite this 10 year old statement, this is still relevant today. Marine ecosystems are under-studied in comparison to terrestrial ones, meaning that knowledge of functional relationships which have been widely used to map terrestrial services, is poor (Guerry et al. 2012). Thus, there is concern that when data are lacking for marine coastal ecosystem services they will be neglected in policy decisions.

In general, more studies need to be completed focusing on the valuation of marine ecosystem services and the added value provided to the local community, including monetary values, to ensure greater integration into decision-making processes. As most studies on marine ecosystem services require an interdisciplinary approach involving researchers within both ecology and socio-economy, more studies using an interdisciplinary approach are thus needed.

The need for knowledge on coastal ecosystem services is tightly connected with the need for knowledge on the ecosystems' ecology. Naturvårdsverket (2008) states that by directing research effort towards the less understood fundamental services, like food web dynamics, habitat, biodiversity and resilience, valuable information about other services may concurrently be obtained.

There are a number of factors impacting ecosystems and these factors often interact in ways that are not always integrated into ecosystem models. This includes the interaction between the habitat and environmental factors and their variation in space and time. Climatic changes will certainly affect most ecosystems, either positively or negatively, and through both direct and indirect effects. As a result, there is a need to assess the future risk of some ecosystem services given the combined influence of predicted climate changes, including warmer water, coastal zone pressure, invasive species, eutrophication, and different management options of ecosystems.

As different factors influencing ecosystem services interact and the services are interdependent, the profit from one service is commonly obtained at the expense of another. These trade-offs are not straightforward and relevant knowledge in the face of these changes needs to be researched.

A prerequisite to evaluate ecosystem services for a region is often related to the access to reliable distribution maps of a resource. Such maps are preferably based on a carefully considered and planned study design. Effort should be made both to gather 
more high quality data (preferably both presence and absence data) and to analyze existing data by the use of spatial distribution modelling (SDM), which offers a cost-effective way for an efficient large-scale mapping (Guisan and Zimmermann 2000). Also, when resources are set aside to create a distribution map, the study/project should always also include a verification of the model using an independent dataset, which is too seldom prioritized.

Certain black-listed invasive species, such as Pacific oyster Crassostrea gigas and Japanese wireweed Sargassum muticum represent both a threat and a potential economic resource to coastal ecosystems. To evaluate management options with respect to protection or exploitation of habitats and invasive species, there is a need for knowledge on the ecosystem services and associated values in the coastal zone and how these might be affected. This insight can be used to explore how to balance threats and potential added value in relation to ecosystem services and values.

Although clear relationships have been demonstrated in other parts of the world, there is a need to further establish the links between the loss of sublittoral vegetation (seagrass, macroalgae) and coastal erosion in the Baltic Sea and Skagerrak (Naturvårdsverket 2008). The identification of these links might motivate increased protection and restoration of valuable sublittoral vegetation.

In a report from Naturvårdsverket (2008), the results from a subproject in Economic Marine Information where presented. One of the main purposes of the report was to identify knowledge gaps in terms of economic effects related to different ecosystem services and marine environmental issues. The following ecosystem services were suggested as important priority areas for further studies: diversity, habitat, food, recreation, aesthetic value, cultural heritage and the legacy of nature. Further details can be found in the report, including specific considerations from each of the countries involved, including most of the Nordic countries.

Due to the high diversity of organisms, all ecosystems treated in this report have a significant potential when it comes to bioprospecting and there are good reasons to believe that marine organisms, such as algae, bacteria, fungi, viruses, plants, shellfish and fish, possess features and characteristics which can be utilized for different products and processes. The Nordic countries are considered to have excellent opportunities to compete internationally within this field. This is particularly relevant for kelp and blue mussels, which have huge potentials when it comes to value creation through large scale cultivation for commercial use. Studies that result in improved and more effective cultivation techniques, including logistics and marketing challenges, are therefore necessary. Also, there is a need to identify (e.g. map) areas suitable for commercial harvesting and cultivation of resources like kelp and blue mussels. Furthermore, enhanced investment in improving large-scale restoration techniques is needed. There is still a 
huge knowledge gap regarding which methods, and under what conditions, actually have positive and long-lasting effects.

Below are listed some more specific knowledge gaps related to each of the four ecosystems discussed in this report.

\subsubsection{Kelp forests}

Smale et al. (2016) states that we need a better understanding of the ecological structure of kelp forests in relation to environmental factors which is crucial for quantifying, valuing and protecting the ecosystem services they provide. Generally, we know that kelp forests are important for many different fish stocks and other commercially important marine species. However, there exists a major knowledge gap in the link between the quality and quantity of habitat and the actual value the harvested species/resources.

Many terrestrial and marine ecosystems have been shown to be major contributors to carbon storage and sequestration (Nellemann et al. 2009). Kelp forests, however, are far less understood, mostly due to the fact that the dead plant materials are transferred to other (soft sediment) areas than where they grow (on hard substrate) and are therefore difficult to quantify. The need for more empirical data to assess kelp forests contribution to carbon sequestration is therefore highly needed (Gundersen et al. 2011).

Rinde et al. (2010) summarize knowledge gaps on the interaction between sea urchins $S$. droebachiensis and the distribution and (re-)growth of the two kelp species $L$. hyperborea and S. latissima. The report recommends studies, including experiments, which uncover how environmental/geographical factors affect the distribution of kelp, both alone and in jointly.

See also the more general knowledge gaps discussed in the introductory section of Chapter 7.2.

\subsubsection{Eelgrass meadows}

Enhanced investment in both improving restoration practices and large-scale restoration is needed (Bayraktarov et al. 2016). We need to address the high seed loss and shoot mortality of seagrass before restoration using seeds can be recommended for large-scale restoration (Infantes et al. 2016). Also, genetic diversity within and between eelgrass meadows is of great importance for management and restoration (Olsen et al. 2016) and needs to be further investigated.

Overfishing and poor top predator fish populations in Skagerrak need to be explored further (Moksnes et al. 2008, Jackson 2008). 
There is a need for monitoring changes in eelgrass abundance and distribution, and chemical-physical factors. The lesson learned for conservation is to recognize that eutrophication may be a cause for seagrass population collapse and its eventual extinction, even years after nutrient levels stabilized, or even decreased (van Katwijk et al. 2010).

Also, there is a need for mapping regional and local tolerance limits to eutrophication, pollution and physical disturbance for regional sustainable management under a changing climate.

Finally, we should raise awareness of the eelgrass ecosystem at all levels and stimulate a dialogue between scientists and the wide variety of stakeholders. Public awareness of eelgrass importance is poor, as seagrass ecosystems do not hold the status of iconic ecosystems such as coral reefs, despite the fact that they are equally productive. It is therefore critical that communication both in the form of public outreach as well as policy making facilitates cooperative legislation that will ensure sustainable use and preservation of eelgrass systems (Boström et al. 2014).

See also the more general knowledge gaps discussed in the introductory section of Chapter 7.2.

\subsubsection{Blue mussel beds}

Changes in salinity and temperature due to global warming may affect both biomass and filtration capacity of blue mussels, and thus the related ecosystem service. Possible effects need to be quantified on a regional scale.

There is a need for evaluating negative and positive influences of future scenarios for distribution of the invasive Pacific oyster, and of coastal zone development on ecosystem services.

Further research on the potential use of blue mussels in integrated aquaculture should be emphasized, both to minimize the environmental effects from fish farms and for producing sustainable ingredients for fish fodder.

A recent concern is the sudden reduced frequency of blue mussels seen in the Skagerrak region. Whether this is just due to local, stochastic climatic events, or part of a larger regional and long-lasting trend should be investigated.

See also the more general knowledge gaps discussed in the introductory section of Chapter 7.2. 


\subsubsection{Shallow bays and inlets}

Recreational fisheries are dependent on the presence and abundance of fish, which in turn is dependent on suitable habitat for recruitment. However, we have little knowledge of the actual value of shallow bays and inlets as a specific habitat.

There is a lack of synthesis of the magnitude and value of carbon sequestration and eutrophication mitigation occurring in the bays and inlets.

In general, there is a lack of economic value figures. Estimating the value of bays and inlets in particular is difficult, especially since the generated ecosystem services are interconnected and sometimes mutually exclusive.

See also the more general knowledge gaps discussed in the introductory section of Chapter 7.2. 


\section{References}

Ahtiainen H, Artell J, Czajkowski M, Hasler B, Hasselström L, Huhtala A, Meyerhoff J, Smart J, Söderqvist T, Alemu M, Angeli D, Dahlbo K, Fleming-Lehtinen $V$, Hyytiäinen K, Karlõševa $A$, Khaleeva Y, Maar M, Martinsen L, Nõmmann T, Pakalniete K, Oskolokaite I, Semeniene D. 2014. Benefits of meeting nutrient reduction targets for the Baltic Sea - a contingent valuation study in the nine coastal states. J. Environ. Econ. Policy.

http://dx.doi.org/10.1080/21606544.2014.901923

Allen BJ, Williams SL. 2003. Native eelgrass Zostera marina controls growth and reproduction of an invasive mussel through food limitation.

Andersson J, Axenrot T, Beier U, Bergenius M, Degerman E, Edsman L, Florin A-B, Karlsson M, Lingman A, Lundström K, Petersson E, Sandström A, Sjöstrand B, Sundelöf A, Svedäng $H$, Walther $Y$, Wennhage $H$, Wikström H. 2015. Fisk- och skaldjursbestånd i hav och sötvatten 2015: Resursöversikt. Havs- och vattenmyndigheten.

Appelgren K, Mattila J. 2005. Variation in vegetation communities in shallow bays of the northern Baltic Sea. Aquatic Botany 83:1-13.

Arrow K, Bolin B, Costanza R, Dasgupta P, Folke C, Holling CS, Jansson B-O, Levin SA, Maler KG, Perrings C, Pimentel D. 1996. Economic growth, carrying capacity, and the environment. Ecological Applications 6:13.

Asaeda T, Senavirathna MDHJ, Kaneko Y, Rashid MH. 2014. Effect of calcium and magnesium on the growth and calcite encrustation of Chara fibrosa. Aquatic Botany 113:100-106.

Ask J, Rowe O, Brugel S, Strömgren M, Byström P, Andersson A. 2016. Importance of coastal primary production in the northern Baltic Sea. Ambio. doi:10.1007/s13280-016-0778-5.

Baden S, Boström C, Tobiasson S, Arponen H, Moksnes P. 2010. Relative importance of trophic interactions and nutrient enrichment in seagrass ecosystems: a broad-scale field field experiment in the Baltic-Skagerrak area. Limnology and Oceanography 55:1435-1448.

Baden S, Boström C. 2001. The leaf canopy of seagrass beds: faunal community structure and function in a salinity gradient along the Swedish coast. In Ecological Comparisons of Sedimentary Shores, Reise K (ed.). Ecological Studies 151, Springer Verlag: Berlin/Heidelberg.

Baden S, Gullström M, Lundén B, Pihl L, Rosenberg R. 2003. Vanishing seagrass Zostera marina, L. in Swedish coastal waters. Ambio 32:374-377.

Baker LF, Ciborowski JJH, MacKinnon MD. 2012. Petroleum coke and soft tailings sediment in constructed wetlands may contribute to the uptake of trace metals by algae and aquatic invertebrates. Science of the Total Environment 414:177-186.

Baker P, Zimmanck F, Baker SM. 2010. Feeding rates of an introduced freshwater gastropod Pomacea insularum on native and nonindigenous aquatic plants in Florida. J. Mollus. Stud. 76:138-143.

BalticSTERN. 2013. The Baltic Sea -Our Common Treasure. Economics of Saving the Sea. Report 2013:4. 140 pp.

Baltrenas P, Misevicius A. 2015. Biogas production experimental research using algae. Journal of Environmental Health Science and Engineering 13, article number 18. 
Baumann HA, Morrison L, Stengel DB. 2009. Metal accumulation and toxicity measured by PAM-Chlorophyll fluorescence in seven species of marine macroalgae. Ecotoxicology and Environmental Safety 72:1063-1075.

Bayraktarov E, Saunders MI, Abdullah S, Mills M, Beher J, Possingham HP, Mumby PJ, Lovelock CE. 2016. The cost and feasibility of marine coastal restoration. Ecological Applications. 26:1055-1074.

Beaudoin Y, Pendleton L. (eds.) 2012. Why value the oceans? A discussion paper. TEEB 2012. 33 pp.

Beaumont NJ, Austen MC, Mangi SC, Townsend M. 2008 Economic valuation for the conservation of marine biodiversity. Marine Pollution Bulletin 56:386-396.

Bekkby T, Moy F. 2011. Developing spatial models of sugar kelp (Saccharina latissima) potential distribution under natural conditions and areas of its disappearance in Skagerrak. Estuarine, Coastal and Shelf Science 95:477-483.

Bekkby T, Moy FE, Olsen H, Rinde E, Bodvin T, Bøe R, Steen H, Grefsrud ES, Espeland SH, Pedersen A, Jørgensen NM. 2013. The Norwegian Programme for mapping of marine habitats - providing knowledge and maps for ICZMP. In: Global challenges in integrated coastal zone management. Wiley-Blackwell. ISBN 978-0-470-65756-0. Chapter 2:21-30.

Bekkby T, Rinde E, Erikstad L, Bakkestuen V. 2009. Spatial predictive distribution modelling of the kelp species Laminaria hyperborea. ICES J. Mar. Sc. 66:2106-2115.

Bergström L, Tatarenkov A, Johannesson K, Jönsson RB, Kautsky L, 2005. Genetic and Morphological Identification of Fucus Radicans Sp. Nov. (fucales, Phaeophyceae) in the Brackish Baltic Sea. Journal of Phycology 41:1025-1038.

Bergström P, Lindegarth S, Lindegarth M. 2015. Modeling and predicting the growth of the mussel, Mytilus edulis: implications for planning of aquaculture and eutrophication mitigation. Ecology and Evolution 5:5920-5933.

Bergström U, Sundblad G, Downie A-L, Snickars M, Boström C, Lindegarth M. 2013. Evaluating eutrophication management scenarios in the Baltic Sea using species distribution modelling. J Appl Ecol 50:680-69o.

Biggs R, Carpenter SR, Brock WA. 2009. Turning back from the brink: Detecting an impending regime shift in time to avert it. Proceedings of the National Academy of Sciences 106:826-831.

Bishop MJ, Chapman MG. 2004. Managerial decisions as experiments: an opportunity to determine the ecological impact of boat-generated waves on macrobenthic infauna. Estuarine Coastal and Shelf Science 61:613-622.

Bobsien IC. 2006. The role of small fish species in eelgrass food webs of the Baltic Sea. Dissertation zur Erlangung des Doktorgrades. Christian-Albrechts-Universität zu Kiel.

Bockelmann AC, Beining K, Reusch TBH. 2011. Widespread occurrence of endophytic Labyrinthula spp. in northern European eelgrass Zostera marina beds. Marine Ecology Progress Series 445:109-116.

Bodvin T, Rinde E, Mortensen S. 2014. Faggrunnlag stillehavsøsters (Crassostrea gigas). Rapport fra havforskningen 32-2014.

Bonsdorff E, Blomqvist EM. 1993. Biotic couplings on shallow water soft bottoms - examples from the northern Baltic Sea. Oceanogr. Mar. Biol. Annu. Rev. 31:153-176.

Borum J, Duarte C, Krause-Jensen D, Greve TM. 2004. European Seagrasses: an introduction to monitoring and management. M\&MS project. www.seagrasses.org 
Boström C, Baden S, Bockelmann A-C, Dromph K, Fredriksen S, Gustafsson C, Krause-Jensen D, Möller T, Nielsen SL, Olesen B, Olsen J, Pihl L, Rinde E. 2014. Distribution, structure and function of Nordic eelgrass (Zostera marina) ecosystems: implications for coastal management and conservation. Aquatic Conserv: Mar. Freshw. Ecosyst. 24:410-434.

Boström C, Baden S, Krause-Jensen D. 2003. The seagrasses of Scandinavia and the Baltic Sea. In: Green \& Short (Eds.), World Atlas of Seagrasses, University of California Press, Berkeley, USA. pp. 27-37.

Boström C, Bonsdorff E. 1997. Community structure and spatial variation of benthic invertebrates associated with Zostera marina (L.) beds in the northern Baltic Sea. Journal of Sea Research, 37:153-166.

Boström C, Bonsdorff E. 200o. Zoobenthic community establishment and habitat complexitythe importance of seagrass shoot-density, morphology and physical disturbance for faunal recruitment. Mar Ecol Prog Ser. 205:123-138.

Brix H. 1997. Do macrophytes play a role in constructed treatment wetlands? Water science and technology 35:11-17.

Bryhn A, Lindegarth M, Bergström L, Bergström U. 2015. Ekosystemtjänster från svenska hav: status och påverkansfaktorer. Havs- och vattenmyndighetens rapport 2015:12. 93 pp.

Byrnes JE, Reed DC, Cardinale BJ, Cavanaugh KC, Holbrook SJ, Schmitt RJ. 2011. Climatedriven increases in storm frequency simplify kelp forest food webs. Global Change Biology 17:2513-2524.

Byström P, Bergström U, Hjälten A, Ståhl S, Jonsson D, Olsson J. 2015. Declining coastal piscivore populations in the Baltic Sea: Where and when do sticklebacks matter? Ambio 44:462471.

Caines LA. 1965 . The phosphorus content of some aquatic macrophytes with special reference to seasonal fluctuations and applications of phosphate fertilizers. Hydrobiologia 25:289-301.

Candolin U, Engström-Öst J, Salesto T. 2008. Human-induced eutrophication enhances reproductive success through effects on parenting ability in sticklebacks. Oikos 117:459-465.

Cardinale BJ, Duffy JE, Gonzalez A, Hooper DU, Perrings C, Venail P, Narwani A, Mace GM, Tilman D, Wardle DA, Kinzig AP, Daily GC, Loreau M, Grace JB, Larigauderie A, Srivastava DS, Naeem S. 2012. Biodiversity loss and its impact on humanity. Nature 486:59-67.

Carlsson F, Kataria M, Lampi E. 2010. Dealing with ignored attributes in choice experiments on valuation of Sweden's environmental quality objectives. Environmental and Resource Economics 47:65-89.

Carpenter SR, Bennett EM, Peterson GD. 2006. Scenarios for Ecosystem Services: An Overview. Ecology and Society 11:29.

Carstensen J, Krause-Jensen D, Markager S, Timmerman K, Windolf J. 2013. Water clarity and eelgrass responses to nitrogen reductions in the eutrophic Skive Fjord, Denmark. Hydrobiologia 704:293-309.

Chapman A, Stévant P, Larsen WE. 2015. Potensial for makroalger som mat i en nordisk sammenheng. Møreforsking report 15-06. 49 pp.

Chen W, Ruldoph D, Haggett C, Seifert-Dähnn I, Golmen L, Daria J, Quevedo E, Grito JH Ying F, Lu S-Y, Mintenbeck K. 2014. D6.4 A framework for describing the social impacts with concrete examples that apply for the Canary Island, EU FP7 TROPOS project.

Choi HG, Lee JH, Park HH, Sayegh FAQ. 2009. Antioxidant and Antimicrobial Activity of Zostera marina L. Extract. Algae 24:179-184 
Christie H, Norderhaug KM, Fredriksen S. 2009. Macrophytes as habitat for fauna Mar. Ecol. Prog. Ser. 396:221-233.

Christie H, Gundersen H, Rinde E, Norderhaug KM, Fagerli CW, Bekkby T, Gitmark JK, Pedersen $T$. Can multitrophic interactions and ocean warming influence large-scale kelp and sea urchin distribution? In preparation.

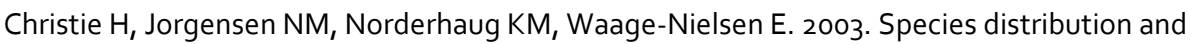
habitat exploitation of fauna associated with kelp (Laminaria hyperborea) along the Norwegian coast. J Mar Biol Assoc UK 83:687-699.

Chucholl C. 2013. Feeding ecology and ecological impact of an alien 'warm-water' omnivore in cold lakes. Limnologica 43:219-229.

Cirujano S, Camargo JA, Gomez-Cordoves C. 2004. Feeding preference of the redswamp crayfish Procambarus clarkii (Girard) on living macrophytes in a Spanish wetland. J. Freshw. Ecol. 19:219-226.

Clabeaux BL, Navarro DA, Aga DS, Bisson MA. 2013. Combined effects of cadmium and zinc on growth, tolerance, and metal accumulation in Chara australis and enhanced phytoextraction using EDTA. Ecotoxicology and Environmental Safety 98:236-243.

Cole SG, Moksnes PO. 2016. Valuing Multiple Eelgrass Ecosystem Services in Sweden: Fish Production and Uptake of Carbon and Nitrogen. Front. Mar. Sci. 2:121.

Costanza R, d'Arge R, de Groot R, Farber S, Grasso M, Hannon B, Limburg K, Naeem S, O'Neill RV, Paruelo J, Raskin RG, Sutton P, van den Belt M. 1997. The value of the world's ecosystem services and natural capital. Nature 387:253-26o.

Costanza R, de Groot R, Sutton P, van der Ploeg S Anderson SJ, Kubiszewski I, Farber S, Turner RK. 2014. Changes in the global value of ecosystem services. Global Environmental Change 26:152-158.

COWI. 2007. Unprecedented demand for cruises in the Baltic. Weblink:

http://www.cowi.com/menu/newsandmedia/news/newsarchive/unprecedenteddemandforcruisesinthebaltic

Cranford P, Ward JE, Shumway SE. 2011. Bivalve filter feeding: variability and limits of the aqvaculture biofilter. In: Shumway SE (ed.). 2011. Shellfish aquaculture and the environment. Oxford: Wiley-Blackwell.

Dahlgren S, Kautsky L. 2002. Distribution and recent changes in benthic macrovegetation in the Baltic Sea basins - a literature review. Dept. of Bothany, Stockholm University.

Dahlgren S, Kautsky L. 2004. Can different vegetative states in shallow coastal bays of the Baltic Sea be linked to internal nutrient levels and external nutrient load? Hydrobiologia 514:249258.

Dame RF, Prins TC. 1998. Bivalve carrying capacity in coastal ecosystems. Aquat. Ecol. 31:409421.

Dawes CJ. 1998. Marine Botany, 2nd Edition. Wiley NY. 496 pp.

Dayton PK. 1985. Ecology of kelp communities. Annu Rev Ecol Syst 16:215-245.

De Vriend HJ, Van Koningsveld M. 2012. Building with Nature: Thinking, acting and interacting differently. EcoShape, Building with Nature, Dordrecht, the Netherlands.

Degerlund M. (ed). 2002. Viktiga vikar. Arbetet för viknaturen i Svenskfinland 2000-2002. Slutrapport för jubileumskampanjen 30 vikar. Natur och miljö, Riksorganisation för mijövård, Helsinki. 
DeLucca AJ, Connick WJ, Fravel DR, Lewis JA, Bland J. 1990. The use of bacterial alginates to prepare biocontrol formulations. Journal of Industrial Microbiology and Biotechnology 6:129134.

Dennison WC. 1987. Effects of light on seagrass photosynthesis, growth and depth distribution. Aquatic Botany 27:15-26.

Desmond MJ, Pritchard DW, Hepburn CD. 2015. Light Limitation within Southern New Zealand Kelp Forest Communities. PLoS ONE 10(4): e0123676

Duarte CM, Chiscano CL. 1999. Seagrass biomass and production: a reassessment. Aquatic Botany 65:159-174.

Duarte CM, Marbà N, Gacia E, Fourqurean JW, Beggins J, Barrón C, Apostolaki ET. 2010. Seagrass community metabolism: Assessing the carbon sink capacity of seagrass meadows. Global Biogeochemical Cycles, 24, GB4032, doi:10.1029/2010GBo03793, 2010

Duarte CM. 1995. Submerged aquatic vegetation in relation to different nutrient regimes. Ophelia 41:87-112.

Duarte CM. 2000. Marine biodiversity and ecosystem services: an elusive link. Journal of experimental marine Biology and Ecology 250:117-131.

Eggert H, Olsson B. 2009. Valuing multi-attribute marine water quality. Marine Policy 33:201206.

Ehlers A, Worm B, Reusch TBH. 2008. Importance of genetic diversity in eelgrass Zostera marina for its resilience to global warming. Mar. Ecol. Prog. Ser. 355:1-7.

Ekman M. 1996. A consistent map of the postglacial uplift of Fennoscandia. Terra Nova 8:158165.

Elmgren R.1989. Man's Impact on the Ecosystem of the Baltic Sea: Energy Flows Today and at the Turn of the Century. AMBIO: A Journal of the Human Environment 18:326-332.

Eriander L, Infantes E, Olofsson M, Olsen JL, Moksnes P-O. 2016. Assessing methods for restoration of eelgrass (Zostera marina L.) in a cold temperate region. Journal of Experimental Marine Biology and Ecology 479:76-88.

Eriksson B, Sieben K, Eklöf J, Ljunggren L, Olsson J, Casini M, Bergström U. 2011. Effects of Altered Offshore Food Webs on Coastal Ecosystems Emphasize the Need for Cross-Ecosystem Management. AMBIO 40:786-797.

Eriksson BK, Ljunggren L, Sandström A, Johansson G, Mattila J, Rubach A, Råberg S, Snickars M. 2009. Declines in predatory fish promote bloom-forming macroalgae. Ecological Applications 19:1975-1988.

Eriksson BK, Sandström A, Isæus M, Schreiber H, Karås P. 2004. Effects of boating activities on aquatic vegetation in the Stockholm archipelago, Baltic Sea. Estuarine, Coastal and Shelf Science 61:339-349.

Eronen M, Gluckert G, Hatakka L, Plassche OVD, Plicht JVD, Rantala P. 2001. Rates of Holocene isostatic uplift and relative sea-level lowering of the Baltic in SW Finland based on studies of isolation contacts. Boreas 30:17-30.

EUR28. 2013. Interpretation manual of European union habitats. European Commission, DG Environment, Nature ENV B.3.

Fagerli CW, Norderhaug KM, Christie H. 2013. Lack of sea urchin settlement may explain kelp forest recovery in overgrazed areas in Norway Marine Ecology Progress Series 488:119-132.

Falklind E, Gustafsson J. 2006. Turistnäringen i Göteborg. Kandidatuppsats i Företagsekonomi. Handelshögskolan vid Göteborgs universitet. 
FAO. 2014. The State of World Fisheries and Aquaculture: Opportunities and Challenges. Food and Agriculture Organization of the United Nations, Rome. 243 pp.

FAO. 2015. Fisheries and Aquaculture Information and Statistics Service. http://www.fao.org/fishery/statistics/en

Ferrat L, Wyllie-Echeverria S, Cates Rex G, Pergent-Martini C, Pergent G, Zou J, Romeo M, Pasqualini V, Fernandez C. 2012. Posidonia oceanica and Zostera marina as Potential Biomarkers of Heavy Metal Contamination in Coastal Systems. In Voudouris (ed): Ecological Water Quality - Water Treatment and Reuse. ISBN 978-953-51-0508-4.

FGFRI (Finnish Game and Fisheries Research Institute). 2014. Recreational Fishing 2012. Official statistics of Finland. Finnish Game and Fisheries Research Institute, Helsinki.

Flindt MR, Pardal MA, Lillebø Al, Martins I, Marques JC. 1999. Nutrient cycling and plant dynamics in estuaries: A brief review. Acta Oecologica 20:237-248.

Folke C, Carpenter SR, Elmqvist T, Gunderson LH, Holling CS, Walker B. 2002. Resilience and sustainable development: building adaptive capacity in a world of transformations. Ambio 31:437-40.

Folke C, Carpenter SR, Walker B, Scheffer M, Elmqvist T, Gunderson LH, Holling CS. 2004. Regime Shifts, Resilience and Biodiversity in Ecosystem Management. Annual Review of Ecology, Evolution and Systematics 35:557-581.

Fonseca MS, Kenworthy WJ, Thayer GW. 1998. Guidelines for the conservation and restoration of seagrasses in the United States and adjacent waters. NOAA Coastal Ocean Program Decision Analysis Series No. 12, NOAA Coastal Ocean Office, Silver Spring, Maryland.

Fonseca MS. 2011. Addy revisited: what has changed with seagrass restoration in 64 years? Ecol. Restor. 29:73-81.

Fredriksen S, Christie H, Boström C. 2004. Deterioration of eelgrass (Zostera marina L.) through destructive grazing by the gastropod Rissoa membranacea (J. Adams), Sarsia 89:218-222.

Fredriksen S, Christie H, Sæthre BA. 2005. Species richness in macroalgae and macrofauna assemblages on Fucus serratus L. (Phaeophyceae) and Zostera marina L. (Angiospermae) in Skagerrak, Norway, Marine Biology Research, 1:2-19.

Fredriksen S, De Backer A, Boström C, Christie H. 2010. Infauna from Zostera marina L. meadows in Norway. Differences in vegetated and unvegetated areas. Marine Biology Research 6:189-200.

Fredriksen S. 2003. Food web studies in a Norwegian kelp forest based on stable isotope $\left(\delta_{13} C\right.$ and $\delta_{15} \mathrm{~N}$ ) analysis. Mar Ecol Prog Ser. 260:71-81.

Fry JM, Joyce PJ, Aumonier S. 2012. Carbon footprint of seaweed as a biofuel. Prepared by Environmental Resources Management Limited (ERM) for the Crown Estate.

Gao Y, Yan X. 2012. Response of Chara globularis and Hydrodictyon reticulatum to lead pollution: their survival, bioaccumulation, and defense. Journal of Applied Phycology 24:245-251.

Gazeau F, Quiblier C, Jansen JM, Gattuso JP, Middelburg JJ, Heip CHR. 2007. Impact of elevated $\mathrm{CO}_{2}$ on shellfish calcification. Geophysical Research 34 (7): Lo7603

Gette-Bouvarot M, Mermillod-Blondin F, Lemoine D, Delolme C, Danjean M, Etienne L, Volatier L. 2015. The potential control of benthic biofilm growth by macrophytes - a mesocosm approach. Ecological Engineering 75:178-186.

Giles H, Pilditch CA. 2006. Effects of mussel (Perna canaliculus) biodeposit decomposition on benthic respiration and nutrient fluxes. Mar Biol 150:261-271. doi: 10.1007/s00227-006-0348-7. 
Gorgula SK, Connell SD. 2004. Expansive covers of turf-forming algae on human-dominated coast: the relative effects of increasing nutrient and sediment loads. Marine Biology 145:613619.

Green EP, Short FT. 2003. World atlas of seagrasses. University of California Press.

Gregersen (Ed.) 2007. Blåskjelldyrking i Skagerrakregionen. Forum Skagerrak II. Arbeidsgruppe 3-Fisk og skalldyr. $13 \mathrm{pp}$.

Gren IM, Lindahl O, Lindqvist M. 2009. Values of mussel farming for combating eutrophication: an application to the Baltic Sea. Ecological Engineering 35:935-945.

Gren IM, Turner RK, Wulff F. 2000. Managing a sea: the ecological economics of the Baltic. Earthscan, London.

Gu B, Dreschel T. 2008. Effects of plant community and phosphorus loading rate on constructed wetland performance in Florida, USA. Wetlands 28:81-91.

Guerry et al. 2012

Guisan A, Zimmermann NE. 2000. Predictive habitat distribution models in ecology. Ecological Modelling 135: 147-186.

Gutiérrez JL, Jones CG, Strayer DL, Iribarne OO. 2003. Mollusks as ecosystem engineers: the role of shell production in aquatic habitats. Oikos 101:79-90.

Gundersen $\mathrm{H}$, Christie HC, de Wit H, Norderhaug KM, Bekkby T, Walday MG. 2011. $\mathrm{CO}_{2}$ uptake in marine habitats - an investigation. NIVA report no. 6070-2010. 25 pp. (In Norwegian)

Gunderson LH. 2000. Ecological resilience - in theory and application. Annual Reviews in Ecology and Systematics 31:425-439.

Gustafsson C, Boström C. 2009. Effects of plant species richness and composition on epifaunal colonization in brackish water angiosperm communities. Journal of Experimental Marine Biology and Ecology 382:8-17.

Hansen J, Wikström S, Kautsky L. 2012. Taxon composition and food-web structure in a morphometric gradient of Baltic Sea land-uplift bays. Boreal environment research 17:1-20.

Hansen JP, Wikström SA, Kautsky L. 2008. Effects of water exchange and vegetation on the macroinvertebrate fauna composition of shallow land-uplift bays in the Baltic Sea. Estuarine, Coastal and Shelf Science 77:535-547.

Hansen JW, Pedersen AGU, Berntsen J, Rønbøg IS, Hansen LS, Lomstein BA. 2000. Photosynthesis, respiration, and nitrogen uptake by different compartments of a Zostera marina community. Aquatic Botany 66:281-295.

Harrison PG. 1982. Comparative growth of Zostera japonica Aschers. \& graebn. and Z. marina L. under simulated intertidal and subtidal conditions. Aquatic Botany 14: 373-379.

Hasler B, Ahtiainen H, Hasselström L, Heiskanen A-S, Soutukorva Å, Martinsen L. 2016. Marine Ecosystem Services. Marine ecosystem services in Nordic marine waters and the Baltic Sea possibilities for valuation. TemaNord 2016:501. $159 \mathrm{pp}$.

Hasselström, L. (Ed.) 2008. Tourism and recreation industries in the Baltic Sea area - How are they affected by the state of the marine environment? An interview study. Swedish Environmental Protection Agency.

Hasselström L, Söderqvist T, Malm T (manuscript) Welfare consequences of a resilient ecological state: the case of filamentous red algae on beaches in Öland, Sweden.

HVMFS (Havs- och vattenmyndigheten) 2012:18. Havs- och vattenmyndighetens föreskrifter om vad som kännetecknar god miljöstatus samt miljökvalitetsnormer med indikatorer för Nordsjön och Östersjön. 
HVMFS (Havs- och vattenmyndigheten) 2012:19. God havsmiljö 2020. Marin strategi för Nordsjön och Östersjön. Del 1: Inledande bedömning av miljötillstånd och socioekonomisk analys. $334 \mathrm{pp}$.

HELCOM. 2003. The Baltic Sea environment 1999-2002, Baltic Sea Environment Proceedings, No. 87, Helsinki Commission Baltic Marine Environment Protection Commission, Helsinki, Finland, $48 \mathrm{pp}$.

HELCOM. 2007. HELCOM Baltic Sea Action Plan. Report from HELCOM Ministerial Meeting, Krakow, Poland, 15 November 2007. 101 pp.

HELCOM. 2009. Biodiversity in the Baltic Sea - An integrated thematic assessment on biodiversity and nature conservation in the Baltic Sea (No. No 116B), Baltic Sea Environmental Proceedings.

HELCOM, 2010. Ecosystem Health of the Baltic Sea 2003-2007: HELCOM Initial Holistic Assessment. Balt. Sea Environ. Proc. No. 122.

HELCOM. 2013a. HELCOM HUB - Technical Report on the HELCOM Underwater Biotope and habitat classification. (No. 139), Baltic Sea Environmental Proceedings.

HELCOM. 2013b. Red List of Baltic Sea underwater biotopes, habitats and biotope complexes (No. Baltic Sea Environmental Proceedings No. 138).

HELCOM. 2014. Eutrophication status of the Baltic Sea 2007-2011 - A concise thematic assessment. Baltic Sea Environment Proceedings No. 143ICES 2014. Report of the Workshop to draft recommendations for the assessment of Descriptor $\mathrm{D}_{3}(\mathrm{WKD} 3 \mathrm{R}), 13-17$ January 2014, Copenhagen, Denmark. ICES CM 2014/ACOM:50. 153 pp.

Hemminga MA, Duarte CM. 2000. Seagrass Ecology. Cambridge University Press.

Hily C, van Katwijk MM, den Hartog C. 2003. In: Green, E.P., Short, F. (Eds.), World Atlas of Seagrasses. University of California Press, pp. 48-58.

Hjorleifsson E, Kassa O, Gunnarsson K. 1995. Grazing of kelp by green sea urchins in Eyyjafjordu. Pp.593-597 in Skjoldal HR, Hopkins C, Erikstad KK, Leinass HP (eds.) Ecology of fjords and coastal waters. Elsevier Science, Amsterdam, the Netherlands.

Holling CS. 1973. Resilience and stability of ecological systems. Annual Review of Ecology and Systematics 4:1-23.

Holmlund CM, Hammer M. 1999. Ecosystem services generated by fish populations. Ecological Economics 29:253-268.

Hooper DU, Chapin FS, Ewel JJ, Hector A, Inchausti P, Lavorel S, Lawton JH, Lodge D, Loreau M, Naeem S, Schmid B, Setälä H, Symstad AJ, Vandermeer J, Wardle DA. 2005. Effects of biodiversity on ecosystem functioning: A consensus of current knowledge. Ecol Monogr 75:3-35.

Horppila J, Nurminen L. 2003. Effects of submerged macrophytes on sediment resuspension and internal phosphorus loading in Lake Hiidenvesi (southern Finland). Water research 37:4468-4474.

Hudd R, Kjellman J, Urho L. 1996. The increase of coincidence in relative year-class strengths of coastal perch (Perca fluviatilis L.) stocks in the Baltic Sea. Annales Zoologici Fennici 33:383387.

Hyytiainen K, Blyh K, Hasler B, Ahlvik L, Ahtiainen H, Artell J, Ericsdotter S. 2014. Environmental economic research as a tool in the protection of the Baltic Sea - costs and benefits of reducing eutrophication. TemaNord 2013:504. 76 pp. 
Härmä M, Lappalainen A, Urho L. 2008. Reproduction areas of roach (Rutilus rutilus) in the northern Baltic Sea: potential effects of climate change. Canadian Journal of Fisheries and Aquatic Sciences 65:2678-2688.

Infantes E, Eriander L, Moksnes P-O. 2016. Eelgrass (Zostera marina L.) restoration methods using seeds on the west coast of Sweden. Mar. Ecol. Prog. Ser. 546:31-45.

IPCC. 2013: Climate Change 2013: The Physical Science Basis. Contribution of Working Group I to the Fifth Assessment Report of the Intergovernmental Panel on Climate Change. Cambridge University Press, Cambridge, UK, $1535 \mathrm{pp}$.

Jackson EL, Rees SE, Wilding C, Attrill MJ. 2015. Use of a seagrass residency index to apportion commercial fishery landing values and recreation fisheries expenditure to seagrass habitat service. Conserv Biol. 29:899-909.

Jackson JB. 2008. Ecological extinction and evolution in the brave new ocean. PNAS 105:1145811465.

Jacobs RPWM 1979. Distribution and aspects of the production and biomass of eelgrass, Zostera marina L., at Roscoff, France. Aquatic Botany 7:151-172.

Jacobs RPWM. 1982. Reproductive strategies of two seagrass species (Zostera marina and Z. noltii) along West European coasts. In Studies on aquatic vascular plants. pp. 150-155. Royal Botanical Society of Belgium Brussels.

Jansson AM, Kautsky N. 1977. Quantitative survey of hard bottom communities in a Baltic archipelago, in: Keegan, B.F., Ceidigh, P.O., Boaden, P.J.S. (Eds.), Biology of Benthic Organisms: 11th European Symposium on Marine Biology, Galway, October 1976, European Marine Biology Symposia. Pergamon Press, Oxford, UK, pp. 359-366.

Jäppinen J-P, Heliölä J. (Eds.) 2015. Towards a sustainable and genuinely green economy. The value and social significance of ecosystem services in Finland (TEEB for Finland). Synthesis and roadmap. The Finnish Environment 1en/2015. The Finnish Ministry of Environment, Helsinki. $144 \mathrm{p}$.

Jaschinski S, Brepohl DC, Sommer U. 2008. Carbon sources and trophic structure in an eelgrass Zostera marina bed, based on stable isotope and fatty acid analyses. Mar Ecol Prog Ser 358:103-114.

Jensen JK. 2012. Tængemænd og vaskerpiger. WERKs Grafiske Hus AS. Pp 34. ISBN: 978-87995309-0-8

Jephson T, Nyström P, Moksnes PO, Baden SP. 2008. Trophic interactions in Zostera marina beds along the Swedish coast. Mar Ecol Prog Ser. 369:63-76.

Juan M, Casas JJ, Elorrieta MA, Bonachela S, Gallego I, Fuentes-Rodriguez F, Fenoy E. 2014. Can submerged macrophytes be effective for controlling waterborne phytopathogens in irrigation ponds? An experimental approach using microcosms. Hydrobiologia 732:183-196.

Kain JM. 1971. The biology of Laminaria hyperborea VI. Some Norwegian populations. J. Mar. Biol. Ass. UK 51: 387-408.

Kalin M, Wheeler WN, Meinrath G. 2005. The removal of uranium from miningwaste water using algal/microbial biomass. J. Environ. Radioact. 78:151-177.

Kaspar HF, Gillespie PA, Boyer IC, Mackenzie AL. 1985. Effects of mussel aquaculture on the nitrogen-cycle and benthic communities in Kenepuru sound, Marlborough sounds, New-Zealand. Mar Biol. 85:127-136. doi:10.1007/BFo0397431

Karås P, Hudd R. 1993. Reproduction areas of fresh-water fish in the Northern Quark (Gulf of Bothnia). Aqua Fennica 23:39-49. 
Karås P. 1996a. Basic abiotic conditions for production of perch (Perca fluviatilis L.) young-ofthe-year in the Gulf of Bothnia. Annales Zoologici Fennici 33:371-381.

Karås P. 1996b. Recruitment of perch (Perca fluviatilis L.) from Baltic coastal waters. Archiv für hydrobiologie 138:99-121.

Kautsky H. 1988. Factors structuring phytobenthic communities in the Baltic Sea (Dissertation). Department of Zoology, Stockholm University, Stockholm.

Kautsky N. 1981. On the trophic role of the blue mussel (Mytilus edulis L) in a Baltic coastal e cosystem and the fate of the organic matter produced by the mussels, Kieler Merresforshungen Sonderheft 5:454-461.

Kautsky N. 1982. Quantitative studies on gonad cycle fecundity, reproductive output and recruitment in a Baltic Mytilus edulis population, Mar. Biol., 68: 143-160.

Kautsky U, Kautsky H. 1991. Coastal production in the Baltic Sea, in: The Biology and Ecology of Shallow Coastal Waters, 28th European Marine Biology Symposium. Olsen \& Olsen, Crete, pp. 31-38.

Kennedy H, Beggins J, Duarte CM, Fourqurean JW, Holmer M, Marbà N, Middelburg JJ. 2010. Seagrass sediments as a global carbon sink: isotopic constraints. Glob Biogeochem Cycles 24:1-8.

Kettunen M, Vihervaara P, Kinnunen S, D'Amato D, Badura T, Argimon M, Ten Brink P. 2012. Socio-economic importance of ecosystem services in the Nordic countries. Synthesis in the context of The Economics of Ecosystems and Biodiversity (TEEB). TemaNord 2012:559. 293 pp.

Kjellman J, Lappalainen J, Urho L, Hudd R. 2003. Early determination of perch and pikeperch recruitment in the northern Baltic Sea. Hydrobiologia 495:181-191.

KleinYL, Osleeb JP, Viola MR. 2004. Tourism-generated earnings in the coastal zone: a regional analysis. Journal of coastal Research 20:1080-1088.

Koch EW, Barbier EB, Silliman BR, Reed DJ, Perillo GM, Hacker SD, Granek EF, Primavera JH, Muthiga N, Polasky S, Halpern BS, Kennedy CJ, Kappel CV, Wolanski E. 2009. Non-linearity in ecosystem services: temporal and spatial variability in coastal protection. Frontiers in Ecology and the Environment 7:29-37.

Koivisto ME, Westerbom M. 2010. Habitat structure and complexity as determinants of biodiversity in blue mussel beds on sublittoral rocky shores. Marine Biology 157:1463-1474.

Korpinen S, Jormalainen V, Honkanen T. 2007. Bottom-up and cascading top-down control of macroalgae along a depth gradient. Journal of Experimental Marine Biology and Ecology 343:52-63.

Kosenius A-K, Ollikainen M. 2015. Ecosystem benefits from coastal habitats - A three-country choice experiment. Marine Policy 58:15-27.

Koundouri P, Chen W, Dávila OG, Giannouli A, Brito J, Kotoroni E, Mailli E, Mintenbeck K, Papagianni C, Souliotis I. 2016. A Socio-Economic Framework for Integrating Multi-Use Offshore Platforms in Sustainable Blue Growth Management: Theory and Applications. In: Nunes, P.A.L.D., Kumar, P., Svensson, L.E. (eds.). Handbook on the Economics and Management for Sustainable Oceans. Edward Elgar Publishing Limited.

Kovtun A, Torn K, Martin G, Kullas T, Kotta J, Suursaar U. 2011. Influence of abiotic environmental conditions on spatial distribution of charophytes in the coastal waters of West Estonian Archipelago, Baltic Sea. Journal of Coastal Research Special Issue 64:412-416.

Kovtun-Kante A, Torn K, Kotta J. 2014. In situ production of charophye communities under reduced light conditions in a brackish-water ecosystem. Estonian journal of ecology 63:28-38. 
Krause-Jensen D, Carstensen J, Nielsen SL, Dalsgaard T, Christensen PB, Fossing H, Rasmussen MB. 2011. Sea bottom characteristics affect depth limits of eelgrass Zostera marina L. Marine Ecology Progress Series 425:91-102.

Krause-Jensen D, Sagert S, Schubert H, Boström C. 2008. Empirical relationships linking distribution and abundance of marine vegetation to eutrophication. Ecological Indicators 8:515529 .

KrumhansI KA, Scheibling RE. 2012. Production and fate of kelp detritus. Mar. Ecol. Prog. Ser. 467:281-302.

Kufel L, Biardzka E, Strzalek M. 2013. Calcium carbonate incrustation and phosphorus fractions in five charophyte species. Aquatic Botany 109:54-57.

Kufel L, Kufel I. 2002. Chara beds acting as nutrient sinks in shallow lakes - a review. Aquat. Bot. 72:249-260.

Kufel L, Strzalek M, Biardzka E. 2016. Site- and species-specific contribution of charophytes to calcium and phosphorus cycling in lakes. Hydrobiologia 767:185-195.

Kulmala S, Haapasaari P, Karjalainen TP Kuikka S, Pakarinen T Parkkila K, Romakkaniemi A, Vuorinen PJ. 2012, Ecosystem services provided by Baltic salmon - a regional perspective to the socio-economic benefits associated with a keystone migratory species. Socio-economic importance of ecosystem services in the Nordic Countries. Synthesis in the context of The Economics of Ecosystems and Biodiversity (TEEB). TemaNord 2012:559, Nordic Council of Ministers.

Laffont-Schwob I, Triboit F, Prudent P, Soulie-Maersche I, Rabier J, Despreaux M, Thiery A. 2015. Trace metal extraction and biomass production by spontaneous vegetation in temporary Mediterranean stormwater highway retention ponds: Freshwater macroalgae (Chara spp.) vs. cattails (Typha spp.). Ecological Engineering 81:173-181.

Lake MD, Hicks BJ, Wells RDS, Dugdale TM. 2002. Consumption of submerged aquatic macrophytes by rudd (Scardinius erythrophthalmus L.) in New Zealand. Hydrobiologia 470:13-22.

Lappalainen A, Härmä M, Kuningas S, Urho L. 2008. Reproduction of pike (Esox lucius) in reed belt shores of the SW coast of Finland, Baltic Sea: a new survey approach. Boreal Environment Research 13:370-380.

Lappalainen A, Westerbom M, Heikinheimo O. 2005. Roach (Rutilus rutilus) as an important predator on blue mussel (Mytilus edulis) populations in a brackish water environment, the northern Baltic Sea, Marine Biology 147: 323-330.

Lewis AR, Baulcomb C, Fletcher R, Margońsk P Glenk K, Nadolma KA, Luzeńczyk AM, Hussain S. 2013. Identifying and Valuing Marine Cultural Ecosystem Services: Poland and the Baltic Sea. Rural Policy Centre Research Briefing, July 2013.

Ling SD, Johnson CR, Frusher SD, Ridgway KR. 2009. Overfishing reduces resilience of kelp beds to climate-driven catastrophic phase shift. Proc. Natl Acad. Sci. USA 106:22341-22345.

Liu Y, Jiang G, Wu Z. 2010. Antibacterial Activity of Extracts from Zostera marina Against Pathogens of Apostichopus japonicas Skin Ulceration Disease. J. Ocean Univ. China (Oceanic and Coastal Sea Research) DOI 10.1007/s11802-010-0068-y

Lorentsen S-H, Sjøtun K, Gremillet D. 2010. Multi-trophic consequences of kelp harvest. Biol. Conserv. 143:2054-2062.

Lyngby JE, Brix H. 1982. Seasonal and environmental variation in cadmium, copper, lead and zinc concentrations in eelgrass (Zostera marina L.) in the Limfjord Denmark. Aquatic Botany, $14: 59-74$ 
Lyngby JE, Brix H. 1989. Heavy metals in eelgrass (Zostera marina L.) during growth and decomposition. Hydrobiologia 176/177:189-196.

Løvås SM, Tørum A. 2001. Effect of the kelp Laminaria hyperborea upon sand dune erosion and water particle velocities. Coast. Eng. 44:37-63.

Maar M, Nielsen TG, Bolding K, Burchard H, Visser AW. 2007. Grazing effects of blue mussel Mytilus edulis on the pelagic food web under different turbulence conditions. Marine Ecology Progress Series 339:199-213.

Mace GM, Norris K, Fitter AH. 2012. Biodiversity and ecosystem services: a multilayered relationship. Trends in Ecology and Evolution 27:19-26.

Maciel E, Leal MC, Lillebø Al, Domingues P, Domingues MR, Calado R. 2016. Bioprospecting of Marine Macrophytes Using MS-Based Lipidomics as a New Approach. Mar Drugs 14:49.

Madsen JD, Chambers PA, James WF, Koch EW, Westlake DF. 2001. The interaction between water movement, sediment dynamics and submersed macrophytes. Hydrobiologia 444:71-84.

Magnussen K, Christie H, Eikrem W, Norling P, Norling K. 2012. Økosystemtjenester i Nordsjøen - Skagerrak. Beskrivelse, vurdering og verdsetting. Sweco rapport nr. 146281-1.

Malm T, Råberg S. Fell S, Carlsson P. 2004. Effects of beach cast cleaning on beach quality, microbial food web, and littoral macrofaunal biodiversity. Estuarine Coastal and Shelf Science 6o:339-347.

Markert A, Wehrmann A, Kröncke I. 2010 Recently established Crassostrea-reefs versus native Mytilus-beds: differences in ecosystem engineering affects the macrofaunal communities (Wadden Sea of Lower Saxony, southern German Bight). Biol Invasions 12: 15-32.

Marsh JA Jr, Dennison WC, Alberte RS. 1986. Effects of temperature on photosynthesis and respiration in eelgrass (Zostera marina L.). Journal of Experimental Marine Biology and Ecology, 101:257-267.

Matuszak A, Mortl M, Quillfeldt P, Bauer HG. 2012. Exclosure study on the exploitation of macrophytes by summering and moulting waterbirds at Lower Lake Constance. Hydrobiologia 697:31-44.

Mazza L, Bröckl M, Ahvenharju S, ten Brink P, Pursula T. 2013. Nordic capital in a Nordic context - Status and Challenges in the Decade of Biodiversity. A study prepared by Gaia Consulting Oy and the Institute for European Environmental Policy (IEEP) for the Nordic Council of Ministers, Copenhagen.

McGlathery KJ Sundbäck K, Anderson IC. 2007. Eutrophication in shallow coastal bays and lagoons: the role of plants in the coastal filter. Mar Ecol Prog Ser 348:1-18.

McHugh DJ. 2003. A guide to the seaweed industry Rome, FAO Fisheries Technical Paper No. 441.

MEA. 2005. Ecosystems and Human Well-being: Synthesis. Island Press, Washington, DC.

Meld. St. 37. 2012-2013. Integrated management of the marine environment of the North Sea and Skagerrak (management plan).

Meld. St. 8. 2005-2006. Integrated management of the marine environment of the Barents Sea and areas outside Lofoten (management plan).

Meld. St. 10. 2010-2011. Integrated management of the marine environment of the Barents Sea and areas outside Lofoten (an update).

Meld. St. 14. 2015-2016. Natur for livet - Norsk handlingsplan for naturmangfold.

Meld. St. 20. 2014-2015. Oppdatering av forvaltningsplanen for Barentshavet og havområdene utenfor Lofoten med oppdatert beregning av iskanten. 
Meld. St. 37. 2008-2009. Integrated management of the marine environment of the Norwegian Sea (management plan).

Mineur F, Arenas F, Assis J, Davies AJ, Engelen AH, Fernandes F, Malta EJ, Thibaut T, Van Nguyen T, Vaz-Pinto F, Vranken S, Serrao EA, De Clerck O. 2015. European seaweeds under pressure: Consequences for communities and ecosystem functioning. Journal of Sea Research 98:91-108.

Moksnes PO, Gullström M, Tryman K, Baden S. 2008. Trophic cascades in a temperate seagrass community. Oikos 11:763-777.

Moy FE, Christie H. 2012. Large-scale shift from sugar kelp (Saccharina latissima) to ephemeral algae along the south and west coast of Norway. Marine Biology Research 8:309-321.

Moy FE, Steen H. 2014. Tareskogen yter til økosystem og industri. Havforskningsrapporten 2014:68-69.

Moy F, Christie H, Steen H, Stålnacke P, Aksnes D, Alve E, Aure J, Bekkby T, Fredriksen S, Gitmark J, Hackett B, Magnusson J, Pengerud A, Sjøtun K, Sørensen K, Tveiten L, Øygarden L, Åsen PA. 2008. Sluttrapport fra Sukkertareprosjektet. SFT-rapport TA-2467/2008, NIVA report 5709. $131 \mathrm{pp}$.

Munkes B. 2005. Eutrophication, phase shift, the delay and the potential return in the Greifswalder Bodden, Baltic Sea. Aquatic Science 67:372-381.

Munsterhjelm R. 1997. The aquatic macrophyte vegetation of flads and gloes, S coast of Finland. Acta Botanica Fennica 157:1-68.

Munsterhjelm R. 2005. Natural succession and human-induced changes in the soft-bottom macrovegetation of shallow brackish bays on the southern coast of Finland. Walter och Andrée de Nottbecks stiftelse.

Naeem S, Duffy JE, Zavaleta E. 2012. The functions of biological diversity in an age of extinction. Science 336:1401-1406.

Naturvårdsverket. 2008. Ecosystem services provided by the Baltic Sea and Skagerrak (Environmental Protection Agency Report No. 5873). Swedish Environmental Protection Agency, Stockholm.

Naturvårdsverket. 2009. What's in the Sea for Me? Ecosystem Services Provided by the Baltic Sea and Skagerrak. (Environmental Protection Agency Report No. 5872). Swedish Environmental Protection Agency, Stockholm.

Naturvårdsverket. 2010. Undersökning av utsjöbankar. Inventering, modellering och naturvärdesbedömning. (Environmental Protection Agency Report No. 6385). Swedish Environmental Protection Agency, Stockholm.

Naturvårdsverket 2012. Utbredning av marina arter och naturtyper på bankar i Kattegatt. En modelleringsstudie. (Environmental Protection Agency Report No. 6489). Swedish Environmental Protection Agency, Stockholm.

Naturvårdsverket. 2015. Guide för värdering av ekosystemtjänster. (Environmental Protection Agency Report No. 669o). Swedish Environmental Protection Agency, Stockholm.

Nellemann C, Corcoran E, Duarte CM, Valdés L, De Young C, Fonseca L, Grimsditch G. (Eds). 2009. Blue Carbon. A Rapid Response Assessment. United Nations Environment Programme, GRID-Arendal, www.grida.no.

Neori A, Chopin T, Troell M, Buschmann A, Kraemer GP, Halling C, Shpigel M, Yarish C. 2004. Integrated aquaculture: rationale, evolution and state of the art emphasizing seaweed biofiltration in modern mariculture. Aquaculture 231:361-391. 
Newell RIE. 2004. Ecosystem influences of natural and cultivated populations of suspensionfeeding bivalve molluscs: A review. Journal of Shellfish Research 23:51-61.

Newmaster AF, Berg KJ, Ragupathy S, Palanisamy M, Sambandan K, Newmaster SG. 2011. Local Knowledge and Conservation of Seagrasses in the Tamil Nadu State of India. J Ethnobiol Ethnomed 7:37.

Nienhuis PH, Groenendijk AM. 1986. Consumption of eelgrass (Zostera marina) by birds and invertebrates: an annual budget. Mar. Ecol. Prog. Ser. 29:29-35.

Noordhuis R, van der Molen DT, Van den Berg MS. 2002. Response of herbivorous water-birds to the return of Chara in Lake Veluwemeer, the Netherlands. Aquat.Bot. 72:349-367.

Norderhaug KM, Christie H, Fosså JH, Fredriksen S. 2005. Fish-macrofauna interactions in a kelp (Laminaria hyperborea) forest. J Mar Biol Ass UK. 85:1279-1286.

Norderhaug KM, Christie H. 2009. Sea urchin grazing and kelp re-vegetation in the NE Atlantic. Mar. Biol. Res. 5:515-528.

Norderhaug KM, Christie H. 2011. Secondary production in a Laminaria hyperborea kelp forest and variation according to wave exposure. Estuarine Coastal and Shelf Science 951:135-144.

Norling P. 2009. Importance of blue mussels for biodiversity and ecosystem functioning in subtidal habitats. PhD thesis, Stockholms universitet, Naturvetenskapliga fakulteten, Systemekologiska institutionen. $49 \mathrm{pp}$.

NOU 2013:10 Naturens goder - om verdier av økosystemtjenester. Norges offentlige utredninger 2013: 10. Miljøverndepartementet.

Olafsen T. 2012. Verdiskaping basert på produktive hav i 2050. Rapport fra en arbeidsgruppe oppnevnt av Det Kongelige Norske Videnskabers Selskab (DKNVS) og Norges Tekniske Vitenskapsakademi (NTVA). 79 pp.

Olsen JJ, Rouzé P, Verhelst B, Lin YC, Bayer T, Collen J, Dattolo E, De Paoli E, Dittami S, Maumus F, Michel $G$, et al. 2016. The genome of the seagrass Zostera marina reveals angiosperm adaptation to the sea. Nature 530:331-335.

Ondiviela B, Losada IJ, Lara JL, Maza M, Galván C, Bouma TJ, van Belzen J. 2014. The role of seagrasses in coastal protection in a changing climate. Coastal Engineering 87:158-168.

Orth RJ, Carruthers TJB, Dennison WC, Duarte CM, Fourqurean JW, Heck KL, Hughes AR, Kendrick GA, Kenworthy WJ, Olyarnik S, Short FT, Waycott M, Williams SL. 2006. A global crisis for seagrass ecosystems. BioScience 56:987-996.

Orth RJ, Heck KL, van Montfrans J. 1984. Faunal communities in seagrass beds: A review of the influence of plant structure and prey characteristics on predator-prey relationships. Estuaries and Coasts 7:339-350.

Orth RJ, Williams MR, Marion SR, Wilcox DJ, Carruthers TJB, Moore KA, Kemp WM, Dennison WC, Rybicki N, Bergstrom P, Batiuk RA. 2010. Long-term trends in submersed aquatic vegetation (SAV) in Chesapeake Bay, USA, related to water quality. Estuaries and Coasts 33:11441163 .

Ottersen G, Postmyr E, Irgens M. (eds.). 2010. Faglig grunnlag for en forvaltningsplan for Nordsjøen og Skagerrak: Arealrapport. Fisken og havet nr. 6/2010. 190 pp.

Pajusalu L, Martin, G, Pollumaee A, Torn K, Paalme T. 2015. Direct effects of increased $\mathrm{CO}_{2}$ concentrations in seawater on the net primary production of charophytes in a shallow, coastal, brackish-water ecosystem. Boreal Environment Research 20:413-422. 
Pakdel FM, Sim L, Bearda J, Davis J. 2013. Allelopathic inhibition of microalgae by the freshwater stonewort, Chara australis, and a submerged angiosperm, Potamogeton crispus. Aquatic Botany 110:24-30.

Pecuchet L, Törnroos A, Lindegren M. 2016. Patterns and drivers of fish community assembly in a large marine ecosystem. Marine Ecology Progress Series 546:239-248.

Pedersen MF, Borum J. 1992. Nitrogen dynamics of eelgrass Zostera marina during a late summer period of high growth and low nutrient availability. Mar. Ecol. Prog. Ser. 80:65-73.

Pehlke C, Bartsch I. 2008. Changes in depth distribution and biomass of sublittoral seaweeds at Helgoland (North Sea) between 1970 and 2005. Climate Research 37:135-147.

Pełechaty M, Ossowska J, Pukacz A, Apolinarska K, Siepak M. 2014. Site-dependent species composition, structure and environmental conditions of Chara tomentosa L. meadows, western Poland. Aquat. Bot. 120:92-100.

Pelechaty M, Pukacz A, Apolinarska K, Pelechata A, Siepak M. 2013. The significance of Chara vegetation in the precipitation of lacustrine calcium carbonate. Sedimentology 60:1017-1035.

Pereyra RT, Bergström L, Kautsky L, Johannesson K. 2009. Rapid speciation in a newly opened postglacial marine environment, the Baltic Sea. BMC Evolutionary Biology 9:70.

Petersen JK, Hasler B, Timmermann K, Nielsen P Tørring DB, Larsen MM, Holmer M. 2014. Mussels as a tool for mitigation of nutrients in the marine environment. Marine Pollution Bulletin 82:137-143.

Petersen JK, Maar M, Holmer M. 2010. Muslinger som virkemiddel - Et pilotstudie. By- og Landskabsstyrelsen, Miljøministeriet. $41 \mathrm{pp}$.

Petersen JK, Malm T. 2006. Off-shore windmill farms: threats or possibilities to the marine environment. Ambio 35:75-80.

Petersen JK, Timmermann K, Holmer M, HaslerB, Göke C, Zandersen M. 2013. Miljømuslinger. Muslinger som supplerende virkemiddel. Notat fra DCE - Nationalt Center for Miljø og Energi. $38 \mathrm{pp}$.

Pettersson P. 2006. Role of Mytilus for biodiversity in sediment habitats of the Skagerrak and Baltic Sea. Doctoral thesis. Department of Systems Ecology. Stockholm University.

Pihl L, Baden S, Kautsky N, Rönnbäck P, Söderqvist T, Troell M, Wennhage H. 2006. Shift in fish assemblage structure due to loss of seagrass Zostera marina habitats in Sweden. Estuarine, Coastal and Shelf Science 67:123-132.

Plummer ML, Harvey CJ, Anderson LE, Guerry AD, Ruckelshaus MH. 2013. The Role of Eelgrass in Marine Community Interactions and Ecosystem Services: Results from Ecosystem-Scale Food Web Models. Ecosystems 16:237-251.

Prins TC, Smaal AD, Dame RF. 1998. A review of the feedbacks between bivalve grazing and ecosystem processes, Aquatic Ecology 31:349-359.

Pukacz A, Pelechaty M, Frankowski M. 2014. Carbon dynamics in a hardwater lake: effect of charophyte biomass on carbonate deposition. Polish Journal of Ecology 62:695-705.

Pulido C, Borum J. 2010. Eelgrass Zostera marina tolerance to anoxia. Journal of Experimental Marine Biology and Ecology 385:8-13.

Rinde E, Bekkby T, Christie H. 2010. Kunnskapsstatus og forskningsbehov for tareskog og kråkebollebeiting - workshop på CIENS, Oslo, 20.aug. 2010. NIVA report no. 6031-2010. 55 pp.

Rinde E, Christie H, Fagerli CW, Bekkby T. Gundersen H, Norderhaug KM, Hjermann D. 2014. The influence of physical factors on kelp and sea urchin distribution in previously and still grazed areas in the NE Atlantic. PLoS ONE 9:1-15. 
Rinde E, Tjomsland T, Hjermann DØ, Kempa M, Norling P, Kolluru VS. 2016. Increased spreading potential of the invasive Pacific oyster (Crassostrea gigas) at its northern distribution limit in Europe due to warmer climate. Marine and Freshwater Research. doi.org/10.1071/MF15071.

Robinson AR, Brink KH. 2006. The Sea. Ideas and observations on prpgress in the study of the seas. Volume 14, part B. Harvard University Press, Cambridge MA.

Rodhe J, Winsor P. 2002. On the influence of the freshwater supply on the Baltic Sea mean salinity. Tellus 54A:175-186.

Rodrigo MA, Rojo C, Alonso-Guillen JL, Vera P. 2013. Restoration of two small Mediterranean lagoons: The dynamics of submerged macrophytes and factors that affect the success of revegetation. Ecological Engineering 54:1-15.

Rodrigo MA, Rojo C, Segura M, Alonso-Guillén JL, Martin M, Vera P. 2014. The role of charophytes in a Mediterranean pond created for restoration purposes. Aquat. Bot. 120:101-111.

Rodrigo MA, Rojo C, Segura M, Alonso-Guillén JL, Martín M, Vera P. 2015. The role of charophytes in a Mediterranean pond created for restoration purposes. Aquatic Botany, Charophytes and their environmental impact: past records and modern status 120, Part A_101-111.

Rojo C, Segura M, Rodrigo MA. 2013. The allelopathic capacity of submerged macrophytes shapes the microalgal assemblages from a recently restored coastal wetland. Ecological Engineering 58:149-155.

Rosqvist K, Mattila J, Sandström A, Snickars M, Westerbom M. 2010. Regime shifts in vegetation composition of Baltic Sea coastal lagoons. Aquatic Botany 93:39-46.

Rönnbäck P, Kautsky N, Pihl L, Troell M, Söderqvist T, Wennhage H. 2007. Ecosystem goods and services from Swedish coastal habitats: Identification, valuation, and implications of ecosystem shifts. AMBIO: A Journal of the Human Environment 36:534-544.

Sanderson JC, Dring MJ, Davidson K, Kelly MS. 2012. Culture, yield and bioremediation potential of Palmaria palmata (Linnaeus) Weber \& Mohr and Saccharina latissima (Linnaeus) C.E. Lane, C. Mayes, Druehl \& G.W. Saunders adjacent to fish farm cages in northwest Scotland. Aquaculture 354-355:128-135.

Sandman AN, Wikström SA, Blomqvist M, Kautsky H, Isaeus M. 2012. Scale-dependent influence of environmental variables on species distribution: a case study on five coastal benthic species in the Baltic Sea. Ecography 36:354-363.

Sandström A, Eriksson BK, Karås P, Isæus M, Schreiber H. 2005. Boating and navigation activities influence the recruitment of fish in a Baltic Sea archipelago area. Ambio 34:125-130.

Saunders M, Metaxas A. 2008. High recruitment of the introduced bryozoan Membranipora membranacea is associated with kelp bed defoliation in Nova Scotia, Canada. Marine Ecology Progress Series 369:139-151.

Schmieder K, Werner S, Bauer HG. 2006. Submersed macrophytes as a foodsource for wintering waterbirds at Lake Constance. Aquat. Bot. 84:245-250.

Schmieder K. 2004. Die Characeen des Bodensees (Charophytes of Lake Constance). Rostock. Meeresbiolog. Beitr. 13:179-194 (in German).

Schneider SC, Nizzetto L. 2012. Bioconcentration and intra-cellular storage ofhexachlorobenzene in charophytes and their potential role in monitoring andremediation actions. Environ. Sci. Technol. 46:12427-12434.

Schubert H. Blindow I (eds.). 2003. Charophytes of the Baltic Sea. The Baltic Marine Biologists Publication No. 19. Gantner Verlag, Ruggell. 326 pp. 
Schwoerbel J, Tillmanns GC. 1972. Ammonium-Adaptation bei submersen Phanerogamen in situ. Arch Hydrobiol Suppl 42:139-141.

Selig U, Schubert M, Eggert A, Steinhardt T, Sagert S, Schubert H. 2007. The influence of sediments on soft bottom vegetation in inner coastal waters of Mecklenburg-Vorpommern (Germany). Estuarine Coastal and Shelf Science 71:241-249.

SFS 2010:1341. Havsmiljöförordning. Stockholm, Miljödepartementet.

SFS 2012:373. Förordning om ändring i havsmiljöförordningen (2010:1341). Stockholm, Miljödepartementet.

Short FT, Neckles HA. 1999. The effects of climate change on seagrasses. Aquatic Botany 63:169-196.

Sivertsen K. 1997. Geographical and environmental factors affecting the distribution of kelp beds and barren grounds and changes in biota associated with kelp reduction at sites along the Norwegian coast. Can. J. Fish. Aquat. Sc. 54:2872-2887.

Sjøtun K, Christie H, Fosså JH. 2006. Effects of kelp recruitment and sea urchin grazing on stability in kelp forest (Laminaria hyperborea). Mar. Biol. Res. 2: 24-32.

Skarpaas O, Christie H, Fageras K, Follestad A, Gundersen H, Rinde E, Skar B, Svarstad H, Qvenild M. 2014. Resultatrapport fra Vega 2045: Tverrfaglig framstidsforskning. NINA Mini report 518. 8 pp.

Smale DA, Burrows MT, Evans AJ, King N, Sayer MDJ, Yunnie ALE, Moore PJ. 2016. Linking environmental variables with regional-scale variability in ecological structure and standing stock of carbon within UK kelp forests. Marine Ecology Progress Series 542:79-95.

Smale DA, Burrows MT, Moore P, O'Connor N, Hawkins SJ. 2013. Threats and knowledge gaps for ecosystem services provided by kelp forests: a northeast Atlantic perspective. Ecol Evol 3:4016-4038.

Smale DA, Vance T. 2015. Climate-driven shifts in species' distributions may exacerbate the impacts of storm disturbances on North-east Atlantic kelp forests. Marine and Freshwater Research 67:65-74.

Snickars M, Sandström A, Lappalainen A, Mattila J, Rosqvist K, Urho L. 2009. Fish assemblages in coastal lagoons in land-uplift succession: The relative im-portance of local and regional environmental gradients. Estuarine, Coastal and Shelf Science 81:247-256.

Snickars M, Sandström A, Mattila J. 2004. Antipredator behaviour of o+ year Perca fluviatilis: effect of vegetation density and turbidity. Journal of Fish Biology 65:1604-1613.

Snickars M, Sundblad G, Sandström A, Ljunggren L, Bergström U, Johansson G, Mattila J. 2010. Habitat selectivity of substrate-spawning fish: modelling requirements for the Eurasian perch Perca fluviatilis. Marine Ecology Progress Series 398:235-243.

Sooksawat N, Meetam M, Kruatrachue M, Pokethitiyook P, Nathalang K. 2013. Phy-toremediation potential of charophytes: Bioaccumulation and toxicity studies of cadmium, lead and zinc. Journal of Environmental Sciences-China 25:596-604.

SOU 2013:68. Making the value of ecosystem services visible. Proposals to enhance well-being through biodiversity and ecosystem services. Swedish Government Inquiries Report 2013:68.

Stadmark J, Conley DJ. 2011. Mussel farming as a nutrient reduction measure in the Baltic Sea: Consideration of nutrient biogeochemical cycles. Marine Pollution Bulletin 62:1385-1388. doi:10.1016/j.marpolbul.2011.05.001.

Steneck RS, Graham MH, Bourque BJ, Corbett D, Erlandson JM, Estes JA, et al. 2002. Kelp forest ecosystems: biodiversity, stability, resilience and future. Environ. Conserv. 29:436-459. 
Stål J, Paulsen S, Pihl L, Rönnbäck P, Söderqvist T, Wennhage H. 2008.Coastal habitat support to fish and fisheries on the Swedish west coast. Ocean and Coastal Management, 51:594-60o.

Suchanek TH. 1985. Mussels and their role in structuring rocky shore communities. In: Moore, P.G., Seed, R. (Eds.), The Ecology of Rocky Coasts: Essays Presented to J.R: Lewis. Hodder and Stoughton, Sevenoaks, pp. $70 e 96$.

Sundblad G, Bergström U, Sandström A, Eklöv P. 2014. Nursery habitat availability limits adult stock sizes of predatory coastal fish. ICES Journal of Marine Science 71:672-68o.

Sundblad G, Bergström U, Sandström A. 2011: Ecological coherence of marine pro-tected area networks: a spatial assessment using species distribution models. Jour-nal of Applied Ecology 48:112-120.

Sundblad G, Bergström U. 2014. Shoreline development and degradation of coastal fish reproduction habitats. Ambio 43:1020-1028.

Sundblad G, Härmä M, Lappalainen A, Urho L, Bergström U. 2009. Transferability of predictive fish distribution models in two coastal systems. Estuarine, Coastal and Shelf Science 83:90-96.

SwAM (Swedish Agency for Marine and Water Management). 2012. Marine tourism and recreation in Sweden. A study for the Economic and Social Analysis of the Initial Assessment of the Marine Strategy Framework Directive. SwAM Report 2012:2.

SwAM (Swedish Agency for Marine and Water Management). 2014. Recreational fishing in Sweden 2013. Sveriges officiella statistik, statistiska meddelanden JO 57 SM 1401.

SwAM (Swedish Agency for Marine and Water Management). 2016. Swedish sea-fisheries during 2015. Definitive data. Sveriges officiella statistik, statistiska meddelanden JO 55 SM 1601.

Syvertsen EE, Gabestad H, Bysveen I, Salmer MP. 2009. Vurdering av tiltak mot bortfall av sukkertare. Klif report 2585. $96 \mathrm{pp}$.

Söderqvist T, Eggert H, Olsson B, Soutukorva Å. 2005. Economic Valuation for Sustainable Development in the Swedish Coastal Zone. Ambio 34:169-175.

Talmage SC, Gobler CJ. 2009. The effects of elevated carbon dioxide concentrations on the metamorphosis, size, and survival of larval hard clams (Mercenaria mercenaria), bay scallops (Argopecten irradians), and Eastern oysters (Crassostrea virginica). Limnol Oceanogr 54:20722080.

TEEB. 2010. The Economics of Ecosystems and Biodiversity. Pushpam Kumar (red.). Earthscan, London and Washington.

Tegner MJ, Dayton PK. 2000. Ecosystem effects of fishing in kelp forest communities. ICES Journal of Marine Science 57: 579-589.

Teh CLT, Sumaila UR. 2013. Contribution of marine fisheries to worldwide employment. Fish and Fisheries 14:77-88.

Toivonen AL Appelblad H, Bengtsson B, Geertz-Hansen P, Gudbergsson G, Kristofersson D, Kyrkjebø H, Navrud S, Roth E, Tuunainen P, Weissglas G. 2000. The Economic Value of Recreational Fisheries in the Nordic Countries. TEMA Nord Report 2000.

Toivonen AL, Roth E, Navrud S, Gudbergsson G, Appelblad H, Bengtsson B, Tuunainen P. 2004. The economic value of recreational fisheries in Nordic coun-tries. Fisheries Management and Ecology 11:1-14.

Transportstyrelsen 2010. Båtlivsundersökningen 2010, en undersökning om svenska fritidsbåtar och hur de används. 
Troell M, Joyce A, Chopin T, Neori A, Buschmann AH, Fang J-G. 2009. Ecological engineering in aquaculture - Potential for integrated multi-trophic aquaculture (IMTA) in marine offshore systems. Aquaculture 297:1-9.

UN SEEA. 2014. System of Environmental-Economic Accounting 2012 UN SEEA.

UNEP. 2006. Marine and Coastal Ecosystems \& Human Well-being: A synthesis report based on the findings of the Millenium Ecosystem Assessment. UNEP. 76 pp.

UNEP-WCMC. 2011. Marine and coastal ecosystem services: Valuation methods and their application. UNEP-WCMC Biodiversity Series No. 33.46 pp.

Valdemarsen T, Canal-Vergés P, Kristensen E, Holmer M, Kristiansen MD, Flindt MR. 2010. Vulnerability of Zostera marina seedlings to physical stress. Marine Ecology Progress Series 418:119-130.

Valdemarsen T, Wendelboe K, Egelund JT, Kristensen E, Flindt MR. 2011. Burial of seeds and seedlings by the lugworm Arenicola marina hampers eelgrass (Zostera marina) recovery. Journal of Experimental Marine Biology and Ecology 410:45-52.

Van den Berg MS, Coops H, Noordhuis R, van Schie J, Simons J. 1997. Macroinvertebrate communities in relation to submerged vegetation in two Chara-dominated lakes. Hydrobiologia 342:143-150.

van Katwijk MM, Bos AR, Kennis P, de Vries R. 2010. Vulnerability to eutrophication of a semiannual life history: A lesson learnt from an extinct eelgrass (Zostera marina) population. Biological Conservation 143:248-254.

Vea J, Ask E. 2011. Creating a sustainable commercial harvest of Laminaria hyperborea, in Norway. J. Appl. Phycol. 23:489-494.

Vermaat JE, Santamaria L, Roos PJ. 2000. Water flow across and sediment trapping in submerged macrophyte beds of contrasting growth form. Archiv für Hydrobiologie 148:549-562.

von Quillfeldt CH, Olsen E, Dommasnes A, Vongraven D. 2009. Integrated ecosystem-based management of the Barents Sea-Lofoten area. pp. 545-562. In Sakshaug E, Johnsen G, Kovacs K. (eds) Ecosystem Barents Sea. Tapir Academic Press, Trondheim, Norway.

Vuorinen I, Antsulevich AE, Maximovich NV. 2002. Spatial distribution and growth of the common mussel Mytilus edulis L. in the archipelago of SW-Finland, northern Baltic Sea. Boreal environment research 7:41-52.

Wallentinus I. 1979. Environmental influences on benthic macrovegetation in the Trosa-Askö area, northern Baltic proper II. The ecology of macroalgae and sub-mersed phanerogams. Contributions from the Askö Laboratory, University of Stockholm 25:1-210.

Wang J, Pan X, Han Y, Guo D, Guo Q, Li R. 2012. Rosmarinic Acid from Eelgrass Shows Nematicidal and Antibacterial Activities against Pine Wood Nematode and Its Carrying Bacteria. Mar. Drugs 10:2729-2740.

Wargacki AJ, Leonard E, Win MN, Regitsky DD, Santos CNs, Kim PB, et al. 2012. An engineered microbial platform for direct biofuel production from brown macroalgae. Science 335:308-313.

Waycott M, Duarte CM, Carruthers TJB, Orth RJ, et al. 2009. Accelerating loss of seagrasses across the globe threatens coastal ecosystems. PNAS 106:12377-12381.

Wennhage $H$, Pihl L. 2002. Fish feeding guilds in shallow rocky and soft bottom areas on the Swedish west coast. Journal of Fish Biology 61:207-228. 
Wernberg T, Russell BD, Moore PJ, Ling SD, Smale DA, Campbell A, Coleman MA, Steinberg PD, Kendrick GA, Connell SD. 2011. Impacts of climate change in a global hotspot for temperate marine biodiversity and ocean warming. Journal of Experimental Marine Biology and Ecology 400:7-16.

Wernberg T, Smale DA, Tuya F, Thomsen MS, Langlois TJ, de Bettignies T, Bennett S, Rousseaux CS. 2013. An extreme climatic event alters marine ecosystem structure in a global biodiversity hotspot. Nature Climate Change 3:78-82.

Westerbom M, Kilpli M, Mustonen O. 2002. Blue mussels, Mytilus edulis, at the edge of the range: population structure, growth and biomass along a salinity gradient in the north-eastern Baltic Sea, Marine ecology 140:991-999.

Wijnbladh E, Jönsson BF, Kumblad L. 2006. Marine ecosystem modeling beyond the box: using GIS to study carbon fluxes in a coastal ecosystem. Ambio 35:484-495.

Yu Q, Matheickal JT, Yin P, Kaewsarn P. 1999. Heavy metal uptake capacities of common marine macroalgal biomass. Water Res., 33:1534-1537.

Zanders M, Bråten KG, Lindhjem H. 2009. Payment for and Management of Ecosystem Services. Issues and Options in the Nordic Context. TemaNord 2009:571. 123 pp.

Zaneveld JS. 1940. The charophyta of Malaysia and adjacent countries. Blumea 4:1-224.

Östman Ö, Eklöf J, Eriksson BK, Olsson J, Moksnes P-O, Bergström U. 2016. Top-down control as important as eutrophication effects in North Atlantic coastal ecosystems. J Appl Ecol.

doi:10.1111/1365-2664.12654 


\section{Norsk sammendrag}

Folk er avhengige av havet og kysten og deres ressurser for å trives og overleve. Kystnære økosystemer i de nordiske landene leverer en rekke økosystemtjenester til lokalsamfunn og resten av befolkningen. Dette er økosystemer med høyt biologisk mangfold. De fungerer som viktige oppveksthabitater for flere arter av fisk, skalldyr og planter, inkludert kommersielle arter, samt er en viktig del av en rekke systemprosesser inkludert vannrensing, erosjonbeskyttelse og karbonbinding, for å nevne noen. Kystsonen er også viktig som rekreasjonsområder for bading og fiske, og det er et stort potensial for nye bruksområder innen biodrivstoffproduksjon og økt produksjon av alginat. Følgelig er det mange interesser og stor nytteverdi knyttet til disse områdene.

Fire naturtyper har blitt valgt som nøkkelhabitater som skal undersøkes i denne rapporten. Disse er tareskoger, blåskjellbanker, ålegrasenger og grunne bukter og viker. For tareskog og blåskjell, er det økonomiske potensialet for dyrking også vurdert.

Studien har fokusert på å undersøke verdier knyttet til disse kysthabitatene gjennom utvalgte eksempler og anbefaler anvendelsesmuligheter og relevans for forvaltningen av de nordiske kystområder og deres ressurser. Prosjektet har også identifisert viktige kunnskapshull og foreslår prioritering av videre arbeid.

\section{Tareskog}

Tareskogens tredimensjonale struktur gir habitat, oppvekstområder og mat for en myriade av mobile pelagiske og bentiske bunndyr. Tareplanter er fotosyntetiske organismer og derfor enormt viktige som primærprodusenter og regnes blant de mest produktive systemene på jorden. Produksjonen av partikulært organisk materiale gjennom hele året støtter sekundærproduksjon også i andre omkringliggende samfunn. Skogens struktur innebærer høy resiliens mot forstyrrelser og biologisk kontroll mot potensielle skadedyr og invaderende arter.

Tare har en lang tradisjon som gjødsel, og det er en økende interesse for mat basert på alger og tang og for hundrevis av forskjellige produkter laget av alginat. Det er også et økende behov for ikke-fossil energi som har gjort tare interessant som biobrensel. Norge sies å være i stand til å dyrke 20 million tonn tare med årlig verdiskaping på 40 
mrd NOK. Siden tareskogene er antatt å være viktige leveområder for mange økonomisk viktige fiskearter, er verdiskapingen fra fiskeri og annen sjømat stor. Fisk antas å avhenge av denne habitattypen for gyting, klekking, yngelpleie og beiting.

Tareskogene er bemerkelsesverdig motstandsdyktige mot naturlige forstyrrelser som bølger, storm og andre ekstreme oseanografiske begivenheter og denne tjenesten er avgjørende for ivaretakelse av viktige økosystemfunksjoner. Siden tareplantene er primærprodusenter, bruker de solenergi til å konvertere vorganisk materiale til organisk gjennom fotosyntese og påvirker dermed de biokjemiske sykluser og regulerer det globale klimaet ved bruk av $\mathrm{CO}_{2}$. Tareplantene fungerer som reservoarer for $\mathrm{CO}_{2}$ så lenge de er i live og ved avhending av dødt organisk plantemateriale i sedimentene, men andelen av det døde tarematerialet som er lagret for fremtiden er fortsatt et ubesvart spørsmål. Tareskogen bidrar til å redusere eutrofiering, bekjempe algeoppblomstring og hypoksi og bidrar dermed til forbedring av vannkvaliteten, som antas å gi enorme fordeler for produksjon av mat og alle andre aspekter ved økosystemets mangfold og funksjon. Mange studier undersøker også bioremediering og integrert havbruk der makroalger brukes som biofilter innen multitrophic oppdrettsvirksomhet. Kystforsvar, for eksempel erosjonssikring, representerer en viktig økosystemtjeneste som tareskog tilbyr og som vil bli stadig viktigere langs kysten, etter som de menneskeskapte klimaendringene forsterkes.

Visse økosystemtjenester knyttet til turisme, som dykking, kan være direkte forbundet med tareskog, ved at folk faktisk gleder seg over å se en sunn tareskog med tilhørende biologisk mangfold. Men det er også en sterk indirekte tilknytning via for eksempel tarens eutrofidempende rolle, ettersom bading og andre aktiviteter vil oppleves mer positivt i rent vann. Også fritidsfiske i marine farvann er en stor industri og er relatert til tare gjennom dens betydning som fiskehabitat.

\section{Ålegrasenger}

Ålegrasenger gir habitat for en lang rekke arter på grunn av sin tredimensjonale struktur som støtter en rik epifauna og flora som igjen gir husly og mat for ulike fiskesamfunn. Denne habitattypen regnes som den mest produktive blant grunne, sedimentære miljøer og produserer mye biomasse både over og under bakken i løpet av vekstsesongen. Ved sin høye primærproduksjon, næringssyklus og i form av sin tredimensjonale struktur, utøver ålegras på mange måter biologisk kontroll. Vekst av mange marine bakterier er hemmet av vannløselige ekstrakter av ålegrasblader, og på den måten endres aktiviteten til mikroorganismer direkte og indirekte ved å påvirke beitende amfipoder. 
I dag har høsting av ålegras liten verdi, men har i århundrer vært brukt som byggemateriale for hus, som fôr for storfe og i jordforbedring. Ingen legemidler er kjent ekstrahert fra ålegras, men det kan likevel være en idé å undersøke ålegras som mulig naturlig antibiotika på grunn av sin langsomme nedbrytningsrate. Verken kommersielt fiske eller høsting for eget hushold foregår i ålegrasenger idag, men ålegras kan likevel være avgjørende for kommersielle fiskerier gjennom sin rolle som viktige leveområder for torskeyngel og andre kommersielle arter.

Sjøgressenger er naturlige hot spots for karbonbinding og har en stor evne til å produsere, fange og lagre organiske forbindelser, noe som gjør dem viktige i karbonlagring. På grunn av sin rolle i næringskretsløpet kan ålegras redusere tilførselen av ammoniakk og fosfat i vannsøylen, bidra til rent vann, redusere overgjødsling og muligens redusere veksten av opportunistiske makroalger og planteplankton. Gjennom vekst og reproduksjon absorberer ålegraset næringssalter fra vannsøylen og kan spille en viktig rolle i biogeokjemisk kretsløp av tungmetaller. Ålegrasets opptak av næringssalter kan bidra til å forebygge algeoppblomstringer og forbedre vannets klarhet. Ålegrasets blader og nettverket av jordstengler og røtter bidrar til å feste og stabilisere sedimentet og reduserer resuspensjon.

Økosystemtjenestene som tilbys av ålegras, som høy biodiversitet, oppvekst- og næringsområde for mange arter, innebærer at ålegrasenger er populære fiskeplasser for fritidsfiske. Ålegrasenger tjener turismen ved å rense vannet, gjennom eutrofidemping og kystforsvar, samt å øke det biologiske mangfoldet på sandstrender og skape gode steder for bading og fritidsfiske.

\section{Blåskjellbanker}

Blåskjell er en av våre aller vanligste marine arter og en viktig habitatbygger. Dog ikke i samme størrelsesorden som tareskog og f.eks. kransalger, øker blåskjell biomangfoldet som substrat for alger og skjulested for små dyr. Blåskjell står for hele 70 \% of biomassen langs kysten i Østersjøen, og bidrar derfor significant til økosystemets struktur og funksjon. Som filtrerende organismer, kan blåskjell filtrere giftige alger og dermed forhindre farlige algeoppblomstringer og utøve biologisk kontroll.

Tradisjonelt har blåskjell vært mer brukt som beite enn som menneskeføde. Men muslinger er faktisk en god kiilde til både jern, selen og vitamin B12. De har små men sunne mengder fett, med en stor andel omega-3 fettsyrer. Pågående studier unders $\varnothing$ ker hvorvidt blåskjell kan brukes i kloakkrensing. Videre har blåskjell blitt studert for annen mulig utnyttelse og forskere har blant annet utviklet et slags lim som kan stoppe blødende sår i løpet av 60 sekunder. Kommersielt fiske av blåskjell er ikke av samme 
størrelse som fiskeoppdrett, men fiskere i Limfjorden i Danmark har i flere tiår høstet blåskjell for matproduksjon og her skrapes opp mot 100 ooo tonn skjell opp fra havbunnen hvert år.

Gjennom sin rolle som habitatbyggende art, har blåskjellbankene relativt høyt biomangfold, og er derfor også noenlunde resilient med evne til gjennopprettelse etter en eller annen form for forstyrrelse. Blåskjellets rolle i karbonlagring er antatt å være knyttet til mengden karbon som er lagret i skjellene til en hver tid. Hvor mye av karbonet fra nedbrutt musling som faktisk lagres for fremtiden er imidlertid antatt å være minimal. Ettersom blåskjell filtrerer planteplankton har de en nøkkelrolle i økosystemet, spesielt i lys av problemet med overgjødsling i Østersjøen og Skagerrak. Når muslinger høstes og brukes som mat, dyrefôr eller gjødsel, tas næringssalter ut av havet. Blåskjellets kanskje viktigste tjeneste, i tillegg til eutrofidemping, er dets evne til å ta opp og fjerne organiske miljøgifter. Blåskjell kan redusere mengden planteplankton i havet og bidra til vannrensing og å fjerne farlige stoffer. Muslinger kan lagre relativt store mengder giftstoffer uten selv å bli særlig påvirket og gjennom sitt lange livsløp hindre at at disse stoffene ender opp i langt mer sensitive organismer. Blåskjellbanker kan påvirke både effekten av tidevann og bølger, modifisere og stabilisere sedimentavsetninger og dermed redusere kysterosjon.

Om ikke veldig viktig i økonomisk sammenheng, er det stor glede assosiert med blåskjellplukking og i det å høste sin egen mat. Blåskjell kan brukes i en lang rekke spennende matretter. Blåskjellbanker kan også være et vakkert skue til glede for blant annet dykkere og hjelper til med å holde vannet klart og rent for badegjester.

\section{Grunne bukter og viker}

Svært mange økosystemtjenester er knyttet til grunne bukter og viker i nordre Østersjøen. De viktigste tjenestene er knyttet til deres tredimensjonale struktur som tjener som mat og habitat for mange ulike organismer. Disse habitatene er essensielle for en rekke store predatorfisk, som utøver «top-down» kontroll som, gjennom trofiske kaskader, hindrer overgjødslingssymptomer av systemet. Nyere forskning viser at primærproduksjonen hos bentiske mikro- og makroalger og rotfestede planter i grunne bukter og viker er betraktelig høyere enn tidligere antatt.

Kransalger har evnen til å effektivt fjerne organiske kjemikalier og metaller fra vannet. Disse plantene kan forhindre oppblomstring av cyanobakterier i overflatevannet, hemme visse giftige mikroalger og redusere utviklingen av bentisk biofilm. Både kom- 
mersielt fiske og fiske til egen husholdning avhenger av rekruttering av de høstbare artene, og abbor, gjedde, mort, sørv, suter, brasme og andre karpefisker har gode leveforhold i de relativt høye temperaturene i grunne bukter og viker.

Mange studier har målt karbonopptak og -lagring for enkelte arter og områder $\mathrm{i}$ beskyttede områder i Østersjøen og sett under ett er disse habitatene viktige for karbonsekvestrering. Vannplanter kan fjerne fosfor via assimilering og en rekke andre mekanismer. Sedimentering i bevokste områder kan redusere risikoen for resuspensjon, øke vannets klarhet og binde næringssalter i sedimentene, og på den måten redusere eutrofiering. Det er grunn til å tro at mange vannplanter i bukter og viker har sedimentstabiliserinde effekter, siden alle strukturer som demper bølger og strømmer bidrar til beskyttelse av kysten.

Fisk som lever i grunne beskyttede bukter og viker er uvurderlige i de Baltiske landene, og andelen av utgiftene brukt for fritidsfiske i disse landene som kan tilegnes disse habitattypene er potensielt veldig høy. På grunn av sin beskyttende karakter, er grunne bukter og viker populære habitattyper for båtliv, bading, padling og andre aktiviteter. 
Nordic Council of Ministers

Ved Stranden 18

DK-1061 Copenhagen K

www.norden.org

\section{Ecosystem Services}

People are dependent on the ocean and coasts and their resources for their survival and well-being. Coastal ecosystems of the Nordic countries, such as kelp forests, blue mussel beds, eelgrass meadows and shallow bays and inlets, provide a number of supporting, provisioning, regulating, and cultural ecosystem services to both the local communities as well as the wider population who benefit from them. The study has focused on examining these coastal values through selected examples, and recommend possible applications and relevance for the management of the Nordic coastal areas and their resources. The project has also identified key gaps in the knowledge and suggests where further work should be emphasized. 